\title{
Temozolomide for high grade glioma (Review)
}

\author{
Hart MG, Garside R, Rogers G, Stein K, Grant R
}

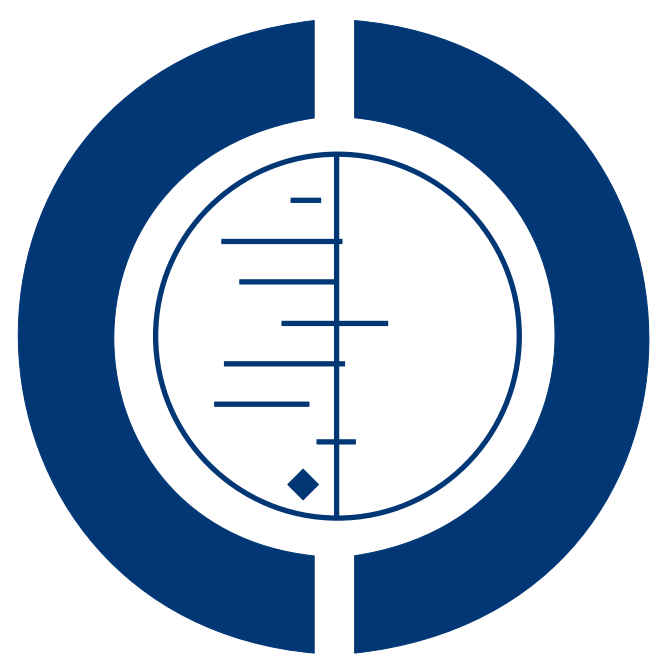

\section{THE COCHRANE COLLABORATION $^{\circledR}$}

This is a reprint of a Cochrane review, prepared and maintained by The Cochrane Collaboration and published in The Cochrane Library 2013, Issue 4

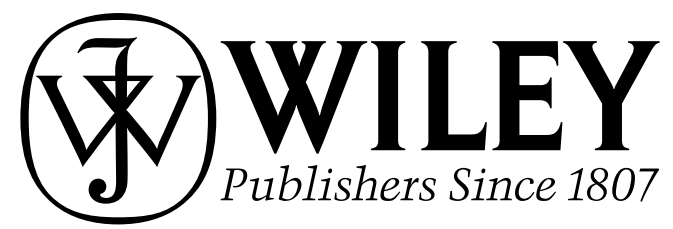

Temozolomide for high grade glioma (Review)

Copyright $\odot 2013$ The Cochrane Collaboration. Published by John Wiley \& Sons, Ltd. 
TABLE OF CONTENTS

HEADER . . . . . . . . . . . . . . . . . . . . . . . . . . . . . . . . . . . . . . . 1

ABSTRACT . . . . . . . . . . . . . . . . . . . . . . . . . . . . . . . . . . . . . . .

PLAIN LANGUAGE SUMMARY . . . . . . . . . . . . . . . . . . . . . . . . . . . . . . . . . . 2

BACKGROUND . . . . . . . . . . . . . . . . . . . . . . . . . . . . . . . . . . . . . .

OBJECTIVES . . . . . . . . . . . . . . . . . . . . . . . . . . . . . . . . . . . . . . .

METHODS . . . . . . . . . . . . . . . . . . . . . . . . . . . . . . . . . . . . . .

Figure 1. . . . . . . . . . . . . . . . . . . . . . . . . . . . . . . . . . . . . . 5

RESULTS . . . . . . . . . . . . . . . . . . . . . . . . . . . . . . . . . . . . . 7

Figure 2. . . . . . . . . . . . . . . . . . . . . . . . . . . . . . . . . . . . . . 11

Figure 3. . . . . . . . . . . . . . . . . . . . . . . . . . . . . . . . . . . . . . . . .

Figure $4 . \quad$. . . . . . . . . . . . . . . . . . . . . . . . . . . . . . . . . . . . . 415

DISCUSSION . . . . . . . . . . . . . . . . . . . . . . . . . . . . . . . . . . . . . . . .

AUTHORS' CONCLUSIONS . . . . . . . . . . . . . . . . . . . . . . . . . . . . . . . . . . . . . . .

ACKNOWLEDGEMENTS . . . . . . . . . . . . . . . . . . . . . . . . . . . . . . . . . . . . . . . . 18

REFERENCES . . . . . . . . . . . . . . . . . . . . . . . . . . . . . . . . . . . . . . 18

CHARACTERISTICS OF STUDIES . . . . . . . . . . . . . . . . . . . . . . . . . . . . . . . . . . . . . 21

DATA AND ANALYSES . . . . . . . . . . . . . . . . . . . . . . . . . . . . . . . . . . . . . . . . . . . . . . . . . .

Analysis 1.1. Comparison 1 Primary Concomitant/Adjuvant Therapy, Outcome 1 Overall survival. . . . . . . . 37

Analysis 1.2. Comparison 1 Primary Concomitant/Adjuvant Therapy, Outcome 2 Progression-free survival. $\quad$. . . 38

Analysis 1.3. Comparison 1 Primary Concomitant/Adjuvant Therapy, Outcome 3 Adverse events. . . . . . . . 39

Analysis 2.1. Comparison 2 Temozolomide versus radiotherapy in the elderly, Outcome 1 Survival (temozolomide alone versus hypofractionated radiotherapy) alone.

Analysis 2.2. Comparison 2 Temozolomide versus radiotherapy in the elderly, Outcome 2 Survival (temozolomide alone versus standard radiotherapy alone).

Analysis 2.3. Comparison 2 Temozolomide versus radiotherapy in the elderly, Outcome 3 Progression free survival (temozolomide alone versus standard radiotherapy alone).

Analysis 2.4. Comparison 2 Temozolomide versus radiotherapy in the elderly, Outcome 4 Adverse Events. . . . . Analysis 3.1. Comparison 3 Different temozolomide dosing schedules, Outcome 1 Survival. . . . . . . . . . . . 44

Analysis 3.2. Comparison 3 Different temozolomide dosing schedules, Outcome 2 Adverse events. . . . . . . . . 45

Analysis 4.1. Comparison 4 Therapy for recurrent disease, Outcome 1 Survival. . . . . . . . . . . . . . . . . . 46

Analysis 4.2. Comparison 4 Therapy for recurrent disease, Outcome 2 Progression-Free Survival. . . . . . . . . . 47

Analysis 4.3. Comparison 4 Therapy for recurrent disease, Outcome 3 Adverse events. . . . . . . . . . . . . . . . 48

ADDITIONAL TABLES . . . . . . . . . . . . . . . . . . . . . . . . . . . . . . . . . . . . . . . . . . . . . . 48

APPENDICES . . . . . . . . . . . . . . . . . . . . . . . . . . . . . . . . . . . . . . . . . . . 52

WHAT'S NEW . . . . . . . . . . . . . . . . . . . . . . . . . . . . . . . . . . . . . 56

HISTORY . . . . . . . . . . . . . . . . . . . . . . . . . . . . . . . . . . . . . . 57

CONTRIBUTIONS OF AUTHORS . . . . . . . . . . . . . . . . . . . . . . . . . . . . . . . . . . . . . . . 57

DECLARATIONS OF INTEREST . . . . . . . . . . . . . . . . . . . . . . . . . . . . . . . . . . . . . . . . . $\quad . \quad 57$

SOURCES OF SUPPORT . . . . . . . . . . . . . . . . . . . . . . . . . . . . . . . . . . . . . . . . . . . 57

INDEX TERMS . . . . . . . . . . . . . . . . . . . . . . . . . . . . . . . . . . . . . . . . . . . . . 58

Temozolomide for high grade glioma (Review)

Copyright $\odot 2013$ The Cochrane Collaboration. Published by John Wiley \& Sons, Ltd. 


\title{
[Intervention Review]
}

\section{Temozolomide for high grade glioma}

\author{
Michael G Hart ${ }^{1}$, Ruth Garside ${ }^{2}$, Gabriel Rogers ${ }^{3}$, Ken Stein ${ }^{4}$, Robin Grant ${ }^{5}$ \\ ${ }^{1}$ Academic Division of Neurosurgery, Department of Clinical Neurosciences, Department of Neurosurgery, Cambridge, UK. ${ }^{2}$ European \\ Centre for Environment and Human Health, University of Exeter Medical School, University of Exeter, Truro, UK. ${ }^{3}$ Centre for Clinical \\ Practice, National Institute for Health and Clinical Excellence, Manchester, UK. ${ }^{4}$ PenTAG, Peninsular Medical School, Exeter, UK. \\ ${ }^{5}$ Edinburgh Centre for Neuro-Oncology (ECNO), Western General Hospital, Edinburgh, UK
}

Contact address: Michael G Hart, Academic Division of Neurosurgery, Department of Clinical Neurosciences, Department of Neurosurgery, Box 167, Addenbrookes Hospital, Cambridge, CB2 0QQ, UK. mikehart82@me.com.

Editorial group: Cochrane Gynaecological Cancer Group.

Publication status and date: New search for studies and content updated (no change to conclusions), published in Issue 4, 2013.

Review content assessed as up-to-date: 6 March 2013.

Citation: Hart MG, Garside R, Rogers G, Stein K, Grant R. Temozolomide for high grade glioma. Cochrane Database of Systematic Reviews 2013, Issue 4. Art. No.: CD007415. DOI: 10.1002/14651858.CD007415.pub2.

Copyright (C) 2013 The Cochrane Collaboration. Published by John Wiley \& Sons, Ltd.

\section{A B S T R A C T}

\section{Background}

High grade glioma (HGG) is an aggressive form of brain cancer. Treatment of HGG usually entails biopsy, or resection if safe, followed by radiotherapy. Temozolomide is a novel oral chemotherapy drug that penetrates into the brain and purportedly has a low incidence of adverse events.

\section{Objectives}

To assess whether temozolomide has any advantage for treating HGG in either primary or recurrent disease settings.

\section{Search methods}

The following databases were searched: CENTRAL (Issue 10, 2012), MEDLINE, EMBASE, Science Citation Index, Physician Data Query and the Meta-Register of Controlled Trials in October, 2012. Reference lists of identified studies were searched. The Journal of Neuro-Oncology and Neuro-oncology were handsearched from 1999 to 2012 including conference abstracts. We contacted neurooncologists regarding ongoing and unpublished trials.

\section{Selection criteria}

Randomised controlled trials (RCTs) where the interventions were the use of temozolomide during primary therapy or for recurrent disease. Comparisons included no chemotherapy, non-temozolomide chemotherapy or different dosing schedules of temozolomide. Patients included those of all ages with histologically proven HGG.

\section{Data collection and analysis}

Two review authors undertook the quality assessment and data extraction. Outcome measures included: overall survival (OS); progression-free survival (PFS); quality of life (QoL); and adverse events. 


\section{Main results}

For primary therapy three RCTs were identified, enrolling a total of 745 patients, that investigated temozolomide in combination with radiotherapy versus radiotherapy alone for glioblastoma multiforme (GBM). Temozolomide increased OS (hazard ratio (HR) 0.60, 95\% confidence interval (CI) 0.46 to 0.79 , P value 0.0003 ) and increased PFS (HR 0.63, 95\% CI 0.43 to 0.92, P value 0.02 ), when compared with radiotherapy alone, although these benefits only appear to emerge when therapy is given in both concomitant and adjuvant phases of treatment. A single RCT found that temozolomide did not have a statistically significant effect on QoL. Risk of haematological complications, fatigue and infections were increased with temozolomide.

In recurrent HGG, two RCTs enrolling 672 patients in total found that temozolomide did not increase OS compared to standard chemotherapy (HR 0.9, 95\% CI 0.76 to 1.06 , P value 0.2 ) but it did increase PFS in a subgroup analysis of grade IV GBM tumours (HR 0.68, 95\% CI 0.51 to 0.90 , P value 0.008 ). Adverse events were similar between arms.

In the elderly, 2 RCTs of 664 patients found OS and PFS was similar with temozolomide alone versus radiotherapy alone. QoL did not appear to differ between arms in a single trial but certain adverse events were significantly more common with temozolomide.

\section{Authors' conclusions}

Temozolomide when given in both concomitant and adjuvant phases is an effective primary therapy in GBM compared to radiotherapy alone. It prolongs survival and delays progression without impacting on QoL but it does increase early adverse events. In recurrent GBM, temozolomide compared with standard chemotherapy improves time-to-progression (TTP) and may have benefits on QoL without increasing adverse events but it does not improve overall. In the elderly, temozolomide alone appears comparable to radiotherapy in terms of OS and PFS but with a higher instance of adverse events.

\section{PLAIN LANGUAGE SUMMARY}

\section{Temozolomide for brain cancer}

High grade glioma (HGG) is a rapidly progressive form of brain cancer with a poor survival rate even after standard treatment with surgery and radiotherapy. Temozolomide is an oral anti-cancer drug.

Three randomised controlled trials (RCTs) enrolling patients with newly diagnosed glioblastoma multiforme (GBM - a form of HGG) have studied chemotherapy with temozolomide during and after radiotherapy. This was compared with radiotherapy only.

Those who received temozolomide had an improved survival and delayed progression of the disease. The short-term adverse events associated with temozolomide are low but can be severe, while the long-term effects are unknown. No RCTs investigated the use of temozolomide in HGGs other than GBM. In recurrent GBM, temozolomide delayed progression but did not improve overall survival. In the elderly population (age over 60 years), temozolomide alone appears to be a suitable alternative to radiotherapy alone for primary therapy of GBM. Either treatment has similar overall survival, progression-free survival and quality of life, but there are possibly more adverse events with temozolomide.

All these trials enrolled highly selected patients with good prognostic features that are not entirely representative of all patients with HGG limiting the general applicability of these results.

\section{B A C K G RO U N D}

\section{Description of the condition}

Gliomas are tumours of the brain and spinal cord, so called because they develop from the glial cells which form structures that surround and support neurons. Gliomas are graded by the World Health Organization classification on a scale of I to IV based on the histological appearance of the tumour (Louis 2007, Kleihues 1993). Grades III and IV are classified as high grade gliomas (HGG) and have in common an aggressive and infiltrating na- 
ture. The majority of HGG are glioblastoma multiforme (GBM), anaplastic astrocytoma (AA) and anaplastic oligodendrocytoma (AO). The incidence of HGG is less than 8 per 100,000 per year, resulting in around 4800 new cases in the UK each year (Counsell 1996). Overall, HGG make up about one per cent of all new cancers diagnosed each year (SHS 2006).

\section{Description of the intervention}

In general HGGs have a poor prognosis, are rapidly progressive, and resistant to therapy. Their infiltrating nature means they cannot be completely excised and the majority will recur locally (Giese 2004). Management is based on symptomatic relief, optimising quality of life, and increasing survival. Securing a histological diagnosis entails either biopsy or resection. Currently, there is only a single small RCT of biopsy versus resection that is of too poor methodological quality to reach definitive conclusions, although non-randomised studies (NRS) have suggested that resection is desirable when it can be achieved safely (Hart 2011a). Radiotherapy forms the mainstay of treatment, resulting in an increase in median survival from three to four months to around nine to ten months (Walker 1978). Medical therapy primarily involves glucocorticosteroids which often produce a marked improvement in neurological symptoms and survival by themselves (Kaal 2004). Chemotherapy has been used for primary therapy as either single agent or multi-agent regimens. Results have generally been conflicting and significant systemic toxicity is possible (Rampling 2005). A meta-analysis of chemotherapy in HGG has demonstrated an improvement in survival with PCV (procarbazine, lomustine and vincristine) chemotherapy (HR 0.85, CI 0.78 to 0.92 $\mathrm{P}<0.0001)$ with an overall improvement of two months in median survival to around 12 months (GMT Group 2002). It is not clear whether the gain in survival reflects a useful period of good quality of life (QoL). In grade III tumours, two RCTs did not demonstrate an increase in overall survival (OS) with systemic chemotherapy (Cairncross 2006; van den Bent 2006).

\section{How the intervention might work}

Temozolomide is a chemotherapy drug that methylates DNA in a way which prevents tumour cell proliferation. It is easily administered in an out-patient setting as an oral agent. Penetration into brain tumours and through the blood brain barrier is good which should potentially maximise effectiveness and limit systemic toxicity.

\section{Why it is important to do this review}

Early case series have suggested temozolomide to be a safe therapy, with haematological toxicity of 5 to $10 \%$, and is associated with a good median survival of around 16 months (Lanzetta 2003; Stupp
2002). These survival figures compared favourably with expected prognosis in GBM, while toxicity was lower than with traditional PCV based chemotherapy regimens. Adjuvant temozolomide after GBM resection is rapidly becoming the standard of care in the primary disease setting, but this practice has largely been based on a single high profile RCT, with no systematic review and metaanalysis in the field to fully assess the evidence basis for this trend in clinical practice.

\section{O B J E C T I VES}

The aim of this review is to assess the effectiveness of temozolomide in HGG.

\section{METHOD S}

\section{Criteria for considering studies for this review}

\section{Types of studies}

Randomised controlled trials (RCTs).

\section{Types of participants}

- Primary therapy i.e. in newly diagnosed disease not previously treated. Participants were patients of any age with a histologically confirmed HGG. They may have undergone any form of surgery to reach a histological diagnosis (biopsy or resection).

- Recurrent disease i.e. previously treated disease. Participants were patients of all ages with a previous histologically confirmed HGG and presumed recurrent disease. Recurrent disease must have been confirmed by both clinical and radiological criteria (Wen 2010). Prior treatment with temozolomide was not a contra-indication to inclusion.

- Specific HGG include glioblastoma multiforme (GBM), anaplastic astrocytoma (AA), anaplastic oligodendrocytoma (AO) and mixed anaplastic oligoastrocytoma (AOA).

- Patients should be stratified for age, performance status and histology (the main prognostic factors) in order to provide comparable treatment arms. Performance status was recorded using the Karnofsky Performance Score (KPS) (Karnofsky 1948) or World Health Organization (WHO) score. 


\section{Types of interventions}

- Treatment arms: the intervention under investigation was the use of oral temozolomide.

- Control arms: different dosing regimens of temozolomide were eligible for inclusion but were subject to subgroup analysis. Inclusion of systemic chemotherapy in the control arm was not stipulated as this is not necessarily part of standard practice in all countries, however, in light of good evidence for the effectiveness of PCV chemotherapy in primary disease (GMT Group 2002), a subgroup analysis was performed. The use of chemotherapeutic wafers was also eligible for inclusion as part of the comparison arm but subjected to subgroup analysis.

- Differerent doses of radiotherapy were eligible: e.g.,standard dose (e.g. 60 Gy in 30 fractions of 2 Gy over 6 weeks), limited dose, or part of the intervention.

- Post-operative management: this includes medical management of seizures, symptom control, and glucocorticosteroids for brain oedema, symptoms of raised intracranial pressure or focal deficits. Similar care should have been given to both arms, ideally conforming to established practice (Grant 2004; Rampling 2005)

\section{Types of outcome measures}

Ideally all outcome measures should have been assessed by at least two independent assessors at frequent intervals.

\section{Primary outcomes}

- Overall survival (OS): from time of randomisation to time of death.

\section{Secondary outcomes}

- Time-to-progression (TTP)/progression-free survival (PFS): open and thorough criteria should be used to define recurrence according to clinical symptoms, imaging or increasing steroid therapy (Wen 2010).

- Quality of life (QoL): a reliable and objective grading measure should be used, for example the EORTC QLQC30/ BN-20 and FACT-BrS (Mauer 2008).

- Adverse events: nature (as defined using MedDRA (Medical Dictionary for Regulatory Authorities) criteria), timing and grade (only severe grade 3 to 4 included). Specific relevant examples include: haematological, fatigue, thromboembolic and infection. Further procedures required for complications should be noted. Both the total number of complications and complications per patient should be stated.

\section{Search methods for identification of studies}

\section{Electronic searches}

The full search strategies for both the original review and the update are described in Appendix 1; Appendix 2; Appendix 3; Appendix 4; Appendix 5; Appendix 6; Appendix 7; Appendix 8; Appendix 9. Foreign language journals were eligible for inclusion. The dates for the updated searches were:

MEDLINE: 2007 to October week 22012

EMBASE: 2007 to 2012 week 42

CENTRAL Issue 102012

\section{Searching other resources}

The references of all identified studies were searched to identify more RCTs.

\section{Handsearch}

A handsearch of the Journal of Neuro-Oncology from 1991 to December 2012 was undertaken in order to identify trials that may not have been present in the electronic databases. This included searching all conference abstracts published in the journal.

\section{Personal communication}

We contacted the manufacturer of the temozolomide brand Temodar/Temodal ${ }^{\circledR}$ (Merck \& Co formerly Schering-Plough) for information regarding any further RCT(s) using their product. We contacted the following researchers by e-mail for information on any current or pending RCTs for the 2013 update: Prof Susan Short; Prof Dr Roger Stupp; Prof Dr (med) Michael Weller; Prof Dr Wolfgang Wick.

\section{Data collection and analysis}

\section{Selection of studies}

Identification of studies was made in two stages (Figure 1). In this update two review authors (MGH \& RG) independently examined the abstracts returned by the search. Those studies that clearly did not meet the inclusion criteria were excluded and copies of the full text of potentially relevant references were obtained. The same two authors independently examined the full texts of the selected references for inclusion or exclusion criteria. At all times any disagreements were resolved through discussion. If sufficient data were not available for assessment then we contacted the relevant authors of the trials. 
Figure I. Study flow diagram: search strategy update $2007-2012$

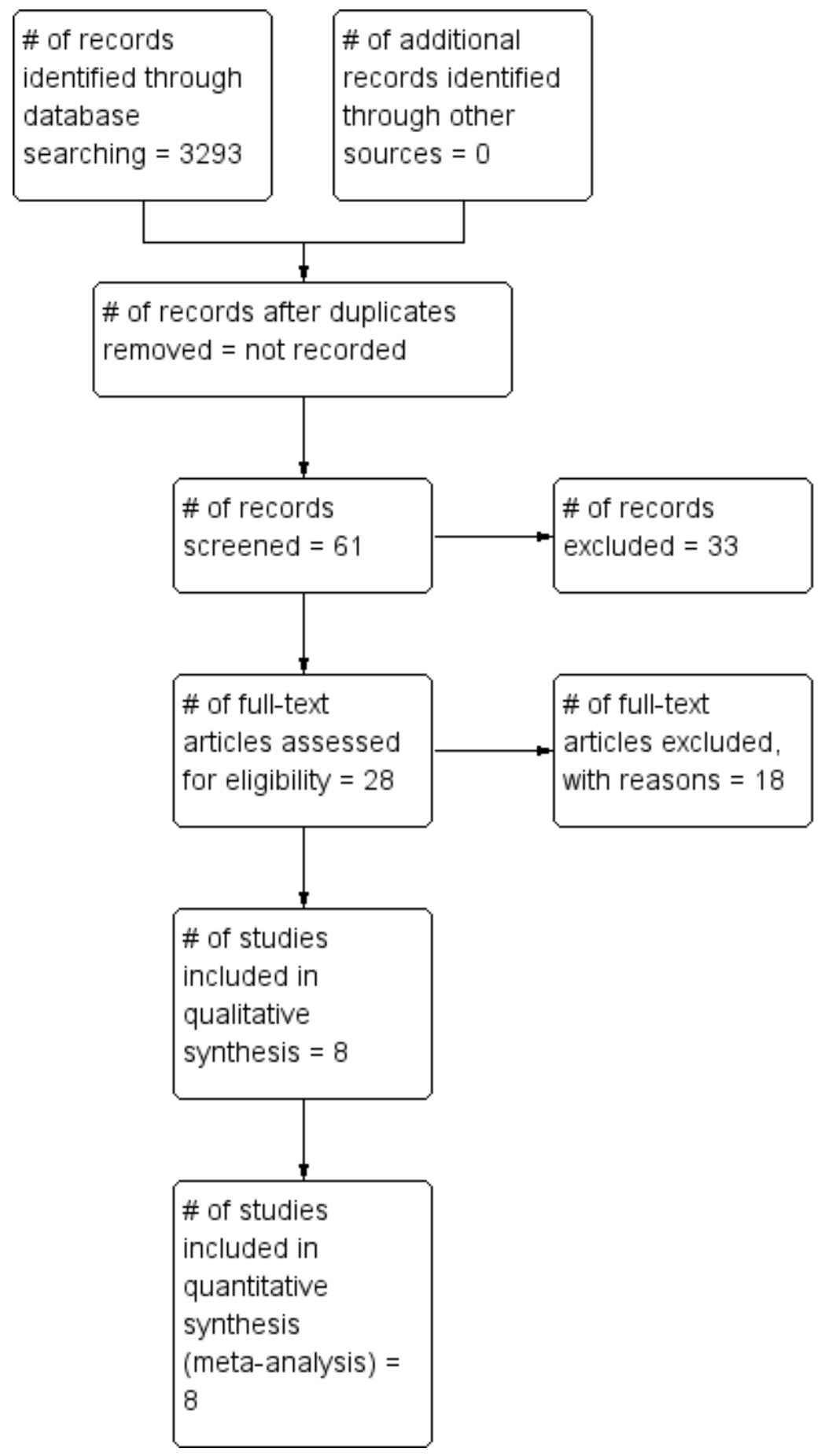




\section{Data extraction and management}

For the included studies, a single review author (MGH) independently abstracted data on characteristics of patients and interventions, study quality, endpoints and deviations from protocol using a pre-specified form designed to complete the information required for the table of Characteristics of included studies, Table 1 and Table 2. Differences were reconciled by discussion or by consultation with a third review author.

Data integration to RevMan 5.1 was performed by a single review author (MGH).

\section{Assessment of risk of bias in included studies}

Trials deemed relevant were critically appraised according to checklist (Fowkes 1991) and the criteria reported in the NHS CRD Report No. 4. We constructed tables to summarise internal and external validity (Juni 2001). Risk of bias was ascertained as described in the Cochrane Handbook of Systematic Reviews of Interventions (Higgins 2009). Two review authors (MGH \& RG) performed the critical appraisal. Any disputes were resolved through discussion.

\section{Measures of treatment effect}

- For time to event data (OS and TTP/PFS), we abstracted the hazard ratio (HR) and its variance from trial reports; if these were not presented, we attempted to abstract the data required to estimate them (Parmar 1998).

- For dichotomous outcomes (e.g. adverse events), we abstracted the number of patients in each treatment arm who experienced the outcome of interest, in order to estimate a odds ratio (OR). For continuous outcomes (e.g. QoL) the final value and standard deviation of the outcome of interest in each treatment arm at the end of follow-up was abstracted for each study.

- For continuous outcomes (e.g. QoL), the final value and standard deviation of the outcome of interest in each treatment arm at the end of the follow-up was abstracted for each study.

- For dichotomous and continuous data, we abstracted the number of patients assessed at endpoint.

\section{Unit of analysis issues}

For time to event data (OS and TTP/PFS), if the HR and its variance was not presented, we attempted to abstract the data required to estimate them (Parmar 1998).

\section{Dealing with missing data}

Loss to follow-up: the number of participants lost to follow-up in each intervention arms whose outcomes were not reported at the end of the study was recorded; we also noted if loss to follow-up was not reported.

In the case of missing data required for the review outcomes, we contacted the study authors.

\section{Assessment of heterogeneity}

Visual inspection of forest plots in combination with the Chi ${ }^{2}$ test were used to gauge whether trials were of sufficient homogeneity to be combined in a meta-analysis.

\section{Assessment of reporting biases}

Where possible, all data abstracted were those relevant to an intention-to-treat analysis. A funnel plot of treatment effect versus precision with the data from all studies was performed in order to investigate the likelihood of publication bias.

\section{Data synthesis}

We pooled the results of trials of primary therapy and recurrent disease into separate meta-analyses.

- For time to event data, HR and its variance were pooled using the generic inverse variance facility of RevMan 5.1.

- For continuous outcomes, we pooled the mean differences between the treatment arms at the end of follow-up using the mean difference (MD) method if all trials have measured the outcome on the same scale, or using the standardised mean difference (SMD) method otherwise.

- For dichotomous outcomes, we calculated the OR for each study and then all studies were pooled.

We performed both fixed-effect and random-effects models for all meta-analyses (Der Simonian 1986).

\section{Subgroup analysis and investigation of heterogeneity}

Subgroup analyses included: various temozolomide dosing regimens (e.g. standard 'Stupp regime', 'dose dense', 'metronomic', 'prolonged course'), systemic chemotherapy, chemotherapy wafers, studies with a minimum age criteria, and different radiotherapy dosing schedules.

\section{Sensitivity analysis}

Assessment were performed without trials at significant risk of bias or if the methodology was significantly different from other studies to determine the effects on the overall conclusions. 


\section{RE S U L T S}

\section{Description of studies}

See: Characteristics of included studies; Characteristics of excluded studies.

\section{Results of the search}

For the update in 2013, the total additional number of studies identified by the literature searches since the original 2008 review were:

- MEDLINE: 1026

- EMBASE: 2006

- CENTRAL: 261

From these, a total of 61 abstracts were reviewed and 28 articles were chosen for retrieval because they either met the inclusion criteria or insufficient data were available. Subsequently, 10 new articles, 7 included and 3 excluded, were added to the current version of the review and 18 were excluded.

\section{Included studies}

\section{Primary therapy}

In total eight RCTs (presented in eleven articles) met the inclusion criteria (Description of studies).

\section{- Temozolomide and radiotherapy versus radiotherapy} alone

EORTC/NCIC 26981-22981

This RCT (EORTC 26982-22981/NCIC CE3) involved 85 centres in 15 Europe and Canada enrolling 573 patients between 2000 to 2002 . The primary hypothesis was to assess concomitant and adjuvant temozolomide with radiotherapy versus radiotherapy alone in primary therapy for histologically confirmed GBM only in patients who had undergone biopsy or resection but excluding patients over 70 years old. Inclusion criteria were: age between 18 to 70 , stable steroid requirements, adequate baseline blood tests, and a WHO performance score of two or less (Table 3). Exclusion criteria were not specified. Histology was centrally verified. Standard radiotherapy schedules of $60 \mathrm{~Gy}$ for six weeks was given to both arms. The treatment arm comprised of temozolomide $75 \mathrm{mg} /$ $\mathrm{m}^{2}$ daily during radiotherapy then up to six adjuvant cycles of 150 to $200 \mathrm{mg} / \mathrm{m}^{2}$ for one to five out of every 28 days for a total of six further cycles. No routine chemotherapy was given to the control arm. Subsequent management was given according to need with no pre-specified protocol mentioned. The primary end point was OS; secondary endpoints included PFS, safety and QoL (reported separately). Definitions were given for progression (radiological or increasing steroids), extent of surgery (surgeon's opinion) and adverse events (National Cancer Institute Cancer Treatment Criteria
(NCICTC)). Follow-up was at baseline, 28 days after completing radiotherapy, and thereafter, at three-monthly intervals.

A follow-up report had increased median follow-up and a further multivariate analysis on putative prognostic factors. Data from this report were chosen for inclusion in the meta-analysis over the earlier reported findings due to the improved follow-up.

Quality of life data (QoL) was reported in a separate article. Additional outcome measures included the EORTC QLQ-C30 and QLQ-BCM20 as combined outcome measures which were then converted to a score of 0 to 100 (with a higher score translating to a higher level of functioning or symptoms). The difference between groups and from baseline was recorded for seven groups (overall, fatigue, social function, emotional function, future uncertainty, insomnia and communication deficit), based on previous experience with temozolomide, to reduce multiple testing errors. Differences of at least 10 points were classified as clinically meaningful. Compliance with questionnaires was also recorded. Follow-up was: prior to treatment; week four of radiotherapy; four weeks after completing radiotherapy; at the end of the third and six month of adjuvant temozolomide; and three-monthly afterwards until disease progression. Standard EORTC procedures were used for completing, handling and analysing the data from the forms. Athanassiou 2005

This was a randomised phase II study set in a single centre in Greece enrolling 130 patients from 2000 to 2002 . The primary hypothesis was to test the concomitant and adjuvant temozolomide (using a novel dose intensification schedule) with radiotherapy versus radiotherapy alone in primary therapy for newly diagnosed patients with GBM. Patients were randomised to either radiotherapy and temozolomide (concomitant and adjuvant) or radiotherapy alone. It used a dose intensification schedule of temozolomide in the adjuvant phase involving $150 \mathrm{mg} / \mathrm{m}^{2}$ temozolomide on days 1 to 5 and days 15 to 19 . In the concomitant phase temozolomide was administered using a standard $75 \mathrm{mg} / \mathrm{m}^{2}$ daily dose throughout. Radiotherapy was administered to both arms in a dose of $60 \mathrm{~Gy}$ over 6 weeks. Inclusion criteria were: GBM on histology, KPS of 60 or more (Table 4), and age over 18 (but with no upper age limit specified). Exclusion criteria were: poor medical condition. Primary outcome measures were OS and TTP; secondary outcome measures included toxicity. Follow-up was weekly clinical assessment during radiotherapy, weekly blood tests during therapy, and MRI scans every two to three months. Definitions were specified for progression (multifactorial including imaging, neurological and clinical factors) and adverse events (NCICTC).

Kocher 2008

This was a multi-institutional study on primary treatment for GBM based on a German neuro-oncology network recruiting 65 patients between 2002 and 2004. Recruitment was stopped short of the power calculation target of 500 due to the publication of results from a similar RCT (EORTC/NCIC 26981-22981). It focused on patients at primary therapy with a confirmed GBM with complete tumour resection treated with concomitant radiotherapy 
and temozolomide (but not adjuvant temozolomide) compared with radiotherapy only. Inclusion criteria were: age 18 to 70 , unifocal GBM, macroscopic tumour resection (based on early CT and MRI), PS 0 to 2 (Table 3), and stable labs. Exclusion criteria were: recurrent disease, prior therapy, other major medical illness or infection, previous malignancy, and pregnancy. Radiotherapy involved 60 Gy in 2.0 Gy daily fractions 5 days per week. The treatment arm was: temozolomide $75 \mathrm{mg} / \mathrm{m}^{2}$ on days 1 to 28 . The control arms: radiotherapy alone (no further therapy). Follow-up was based on clinical assessment, WHO assessment, and MRI at least three-monthly. Outcomes were: OS, PFS, and adverse events. Definitions were given for progression (multifactorial) and extent of resection. Further outcome data were supplied by the authors.

- Temozolomide versus radiotherapy in the elderly

Nordic 2012

The was a randomised, controlled phase III study involving 28 predominantly European oncology centres enrolling 342 patients between 2000 and 2009. It focused on patients over 60 years old with a histologically confirmed WHO grade IV astrocytoma. The primary hypothesis was to test if chemotherapy with temozolomide was similar to or better than hypofractionated radiotherapy (deemed the current standard of care for elderly patients) or standard radiotherapy in terms of survival but with an improved QoL and adverse events profile. Additional inclusion criteria were: WHO performance score 0 to 2 (or 3 if a neurological deficit); adequate haematological, renal and liver function; and were expected by the doctor to tolerate all treatment options. After 2004 patients deemed fit to receive combination treatment were excluded based on the results of another trial (EORTC/NCIC 26981-22981). Exclusion criteria were: another primary cancer; WHO performance score 3 to 4; any disorder likely to interfere with study treatment; previous therapy for a brain tumour; and previous radiotherapy to the head that would prevent further irradiation. Patients were randomised depending on the institution to either 1:1:1 in blocks of 9 to temozolomide, hypofractionated radiotherapy, or standard radiotherapy; or in blocks of 8 to either temozolomide or hypofractionated radiotherapy. Blinding was not used. Temozolomide was administered orally in $200 \mathrm{mg} / \mathrm{m}^{2}$ doses on days 1 to 5 of every 28 days for up to six cycles or until radiological progression, clinical progression, or both, unacceptable adverse effects were seen, or until a physician or patient chose to discontinue treatment. Hypofractionated radiotherapy was administered in 6 fractions of 5.0 Gy for 3 days a week over 2 weeks of 34.0 Gy delivered in 10 fractions of $3.4 \mathrm{~Gy}$ on 5 days a week over 2 weeks. Standard radiotherapy was $60.0 \mathrm{~Gy}$ in 30 fractions of $2.0 \mathrm{~Gy}$ over 6 weeks. Outcome measures were: EORTC QLQ C-30 and BN-20. Assessments were at 6 weeks, 3 months and 6 months. Adverse events were assessed by the WHO grading system except nausea and vomiting which were assessed by the NCIC version 2.0. Further therapy was at the discretion of the treating physician. The power calculation was that 480 patients with 160 per treatment group was need to detect a $10 \%$ survival difference (i.e. 10 to $20 \%$ at 1 year) with a $90 \%$ power at the $5 \%$ significance level. Spoonsors had no role in the study design, data collection, data analysis, data interpretation, or writing of the report.

NOA-08 2012

This is a randomised, phase III trial recruiting 412 patients from 23 university centres across Germany and one in Switzerland from 2005 to 2009 . The primary hypothesis was to assess whether temozolomide (dose-dense schedule) alone is inferior to radiotherapy alone (i.e. a non-inferiority study) in the primary therapy of HGG (either GBM or AA). A further aim was to investigate the role of $\mathrm{O}^{6}$-methylguanine-DNA methyltransferase (MGMT) promotor methylation. Inclusion criteria were: de-novo anaplastic astrocytoma or glioblastoma; age older than 65; and a Karnofsky performance score (KPS) of 60 or more. Exclusion criteria were: previous chemotherapy or radiotherapy to the brain; inadequate bone-marrow reserve, liver function or renal function. Temozolomide was administered according to a 1 week on, 1 week off schedule, with $100 \mathrm{mg} / \mathrm{m}^{2}$ on days 1 to 7 with increases or decreases in $25 \mathrm{mg} /$ $\mathrm{m}^{2}$ depending on blood-cell counts and general tolerability. Radiotherapy was administered to the gross tumour volume plus a $2 \mathrm{~cm}$ margin over 6 to 7 weeks in fractions of 1.8-2.0 Gy to a total of 60 Gy. Tumour response or progression was defined according to the Macdonald criteria. Methylation of the MGMT promotor was assessed with two distinct methylation-specific PCR assays. The primary endpoint was overall survival. Secondary endpoints included event-free survival (EFS), best response, health-related (HR) QoL, and safety. The sponsor had no role in the study design, data collection, data analysis, data interpretation or writing of the report.

\section{- Different Temozolomide dose schedules}

\section{Clarke 2009}

This was a single institution study based in the USA recruiting 85 patients with newly diagnosed GBM at pathology between 2005 to 2007 . The primary hypothesis was to test the efficacy of dose dense versus metronomic temozolomide in the adjuvant phase of treatment after both arms had received standard radiotherapy and concomitant temozolomide. Inclusion criteria were: age 18 to 70 and KPS (Table 4) greater than or equal to 60. Exclusion criteria were: other cancer, abnormal baseline blood tests, pregnancy, and nursing. The treatment arm comprised of 'dose dense' temozolomide $150 \mathrm{mg} \mathrm{m}^{2}$ on days 1 to 7 and 15 to 21 of every 28 days cycle. The control arm consisted of 'metronomic' temozolomide at $50 \mathrm{mg} / \mathrm{m}^{2}$ on days 1 to 28 of adjuvant therapy. Both arms received standard radiotherapy (60 Gy in 30 doses over 6 weeks including intensity modulated therapy) and concomitant temozolomide $75 \mathrm{mg} / \mathrm{m}^{2}$ daily as well as 13 -cis-retinoic acid after treatment was completed. Outcome criteria were: MacDonald criteria \& MRI $2 / 12$. Definitions were specified for progression (MacDonald criteria), pseudo-progression, and adverse events (NCI CTC). Data for survival and PFS were estimated from the Kaplan-Meier plots. 


\section{Recurrent disease}

In total two RCTs presented in three articles were retrieved.

- Temozolomide versus nitrosourea based chemotherapy

Yung 2000a

This was a multicentre, multinational randomised phase II study enrolling 225 patients between 1995 and 1997. The primary hypothesis was to compare temozolomide with procarbazine (deemed best standard therapy at recurrence) for recurrent GBM previously confirmed on histology. Inclusion criteria were: age 18 or over, confirmed GBM or gliosarcoma, a KPS of 70 or more (Table 4), a life expectancy of 12 weeks or more, and unequivocal evidence of tumour progression at first relapse on MRI or enhanced CT after radiation therapy. Exclusion criteria were abnormal baseline blood tests, multiple previous chemotherapy regimens and other systemic illnesses (detailed within article). The treatment arm consisted of temozolomide 150 to $200 \mathrm{mg} / \mathrm{m}^{2}$ on days 1 to 5 of 28 depending on previous exposure to temozolomide. The control arm consisted of procarbazine 125 to $150 \mathrm{mg} / \mathrm{m}$ 2 administered for 28 days out of every 56 depending on previous exposure. No radiotherapy was administered to either arm at recurrence (both had previously received radiotherapy as stipulated in the inclusion criteria). Outcome measures were OS, PFS, QoL, treatment response and adverse events. Definitions were given for QoL (measured by EORTC QLQ-C30 and QLQ-BCM20), objective responsiveness and adverse events (NCICTC).

A separate article documented the QoL data. Please note that for the original review in 2008 this study was excluded due to difficulties in assessing the QoLpresented, but subsequently for the 2013 update there was greater experience in assessing the reliability of this data and it was possible to included the study. Consequently, the trial methodology, intervention and follow-up were identical to that previously described. Additional outcome measures were the EORTC-QLC30 and BCM20 questionnaires focusing on QoL. Follow-up was prior to each cycle of chemotherapy. Scoring was according to standard procedures with conversion to a range of 0 to 100 and higher scores indicating better functioning or more symptoms. To reduce error due to repeat statistical testing seven criteria were chosen pre-hoc for testing based on prior knowledge. Changes were assessed at six months as well as prior to, and at the time of, disease progression. The significance of changes was determined by statistics, effect sizes, and the proportions of patients with an improvement of ten points or more (the minimum considered clinically significant: smaller changes were disregarded).

BR12 2010

This is a multicentre RCT based in the UK recruiting 447 patients between 2003 to 2007 . The primary hypothesis was to test whether temozolomide (in either of two different dosing regimens) versus PCV chemotherapy in a variety of HGG (grades 3 and 4) at recurrence after initial therapy. Inclusion criteria were an interval of over two months since completing primary therapy, a life expectancy of over one month, adequate baseline laboratory function and general fitness to commence further therapy. Exclu- sion criteria were pregnancy, oligodendroglial histology, a WHO score of four (Table 3), and previous chemotherapy, radiosurgery or brachytherapy. The treatment arm consisted of either temozolomide $200 \mathrm{mg} / \mathrm{m}^{2}$ for days 1 to 5 of 28 (TMZ-5) or temozolomide $100 \mathrm{mg} / \mathrm{m}^{2}$ for days 1 to 21 of 28 (TMZ-21 or 'dose dense'). The control arm consisted of standard PCV chemotherapy (at standard doses) every six weeks until progression or six cycles in total. Outcomes were OS, PFS, and QoL. Definitions were given for recurrence (multifactorial) and QoL.

\section{Excluded studies}

For the 2008 publication we excluded 339 references and retrieved 12 for detailed evaluation. Of these we excluded 7 for the following reasons (see table of excluded studies):

- Two phase II studies of temozolomide for primary therapy in GBM (Stupp 2002; Lanzetta 2003)

- Two phase II studies of temozolomide in therapy for recurrence of GBM (Bower 1997; Yung 2000b)

- One phase II study of temozolomide for anaplastic astrocytoma or oligoastrocytoma at first relapse (Yung 1999)

- One QoL review of an included RCT (Osoba 2000b)

- One single centre retrospective series of temozolomide for both primary and recurrent therapy (Newlands 1996)

- One study that was excluded for the 2008 publication was subsequently included in the 2012 update due to improvements in data analysis (Osoba 2000a).

For the 2013 update we excluded an additional 18 studies.

- Nine abstracts of conference proceedings were excluded due to a lack of complete presentation of the final results (Gilbert 2010; Kim 2010; Naboors 2009; Najak 2010; Malmstrom 2010; Malmstrom 2010b; Renard 2010; Weller 2010; Wick 2010; )

- One RCT because of insufficient data presentation (Qian 2009)

- Three because they were a review, commentary or presentation of an included RCT (Hamilton 2006; Lee 2008; Linz 2009).

- Two meta-analysis of RCTs Spiegel 2007; Wang 2010.

- Two because the study question was based on the benefit of an additional therapy with temozolomide as the control arm. One study considered the benefit of erlotinib (a tyrosine kinase inhibitor) versus temozolomide or carmustine in patients with recurrent GBM (van den Bent 2009). Another compared trabedersen (a TGF B2 antisense oligodeoxynucleotide) in one of two doses delivered through an intra-tumoural convection enhanced delivery system with best medical care (involving either standard dose temozolomide or PCV) for recurrent/ refractory HGG (Bogdahn 2011).

- One RCT tested if initial upfront chemotherapy alone (with either PCV or temozolomide) was as efficacious as initial radiotherapy alone regarding time to treatment failure with a randomisation schedule of 1:1:2.compared (Wick 2009). 
However, individual results for the temozolomide arm were not reported prohibiting inclusion in the review.

\section{Risk of bias in included studies}

A full analysis of the internal validity of the included studies is described in Table 1 . The salient points are outlined below and in Figure 2 and Figure 3. 
Figure 2. Risk of bias summary: review authors' judgements about each risk of bias item for each included study.

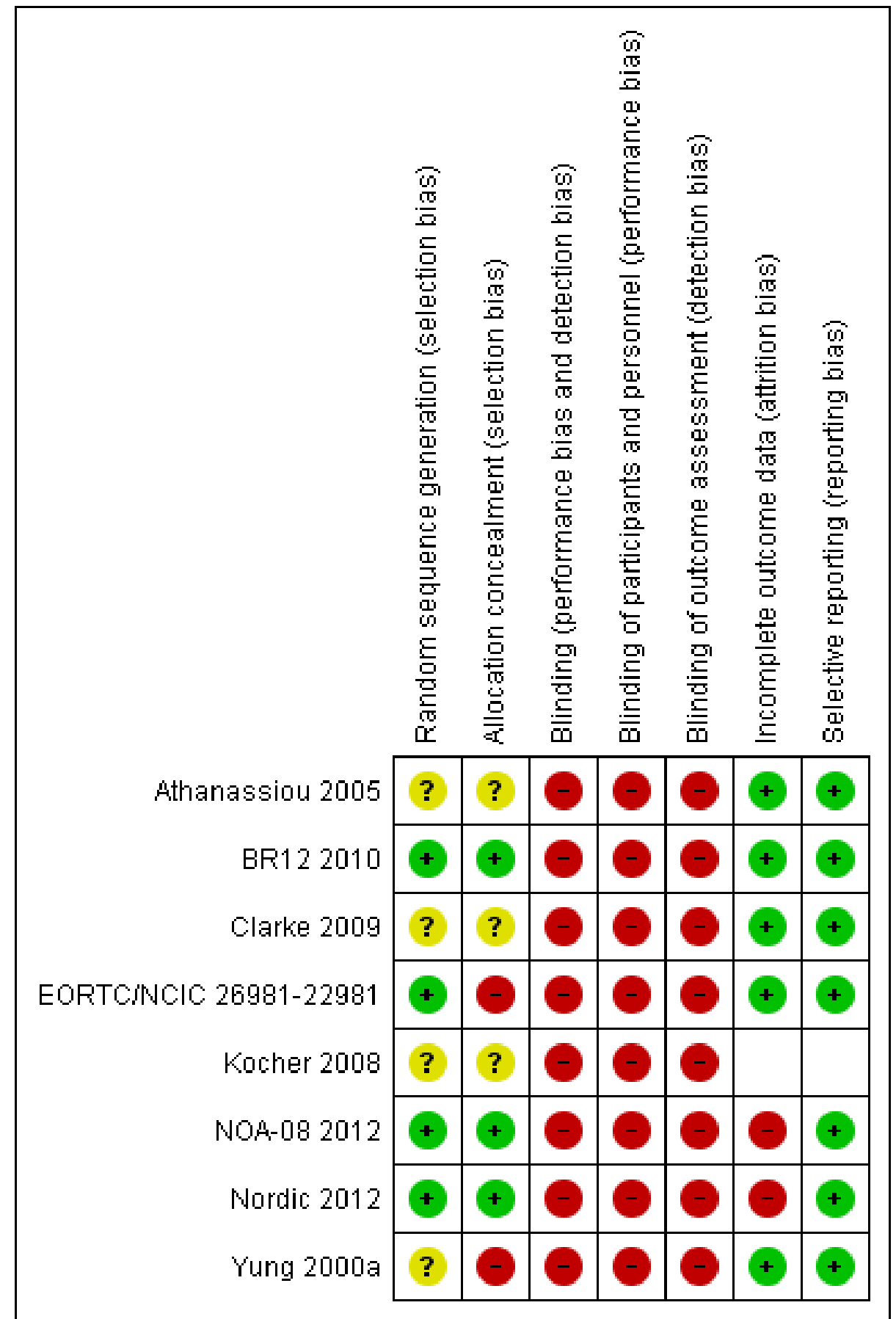


Figure 3. Risk of bias graph: review authors' judgements about each risk of bias item presented as percentages across all included studies.

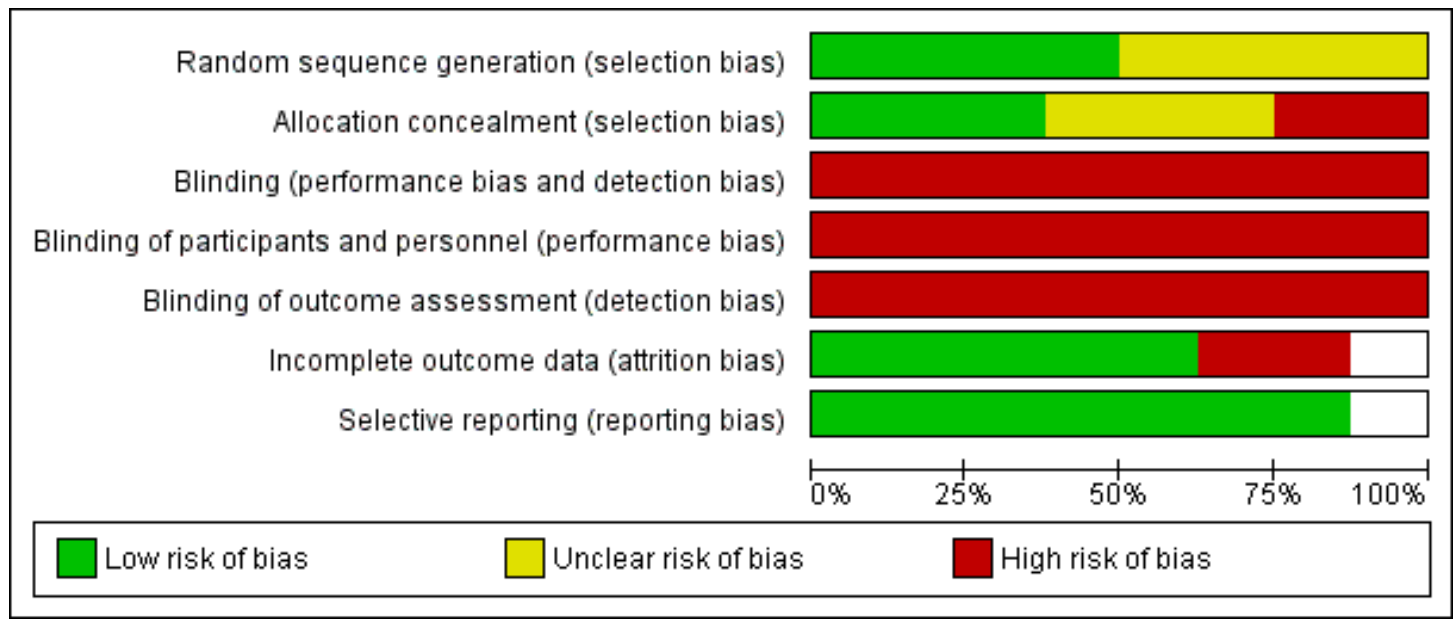

\section{Primary therapy}

The differences in trial methodology, participants and interventions were not of sufficient clinical significance to preclude metaanalysis. The three RCTs of temozolomide and radiotherapy versus radiotherapy alone in HGG were suitable for meta-analysis (Athanassiou 2005; EORTC/NCIC 26981-22981; Kocher 2008). Subgroup analysis was indicated for: concomitant and adjuvant temozolomide (Athanassiou 2005; EORTC/NCIC 2698122981) or versus concomitant but not adjuvant temozolomide (Kocher 2008). Separate meta-analyses were required for different: dosing schedules of temozolomide (Clarke 2009); and temozolomide versus radiotherapy in the elderly (Nordic 2012; NOA-08 2012)

\section{Therapy for recurrent disease}

The differences in trial methodology, participants and interventions were not of sufficient clinical significance to preclude metaanalysis.

\section{Allocation}

Studies at low risk of allocation (selection) bias included BR12 2010; Clarke 2009; EORTC/NCIC 26981-22981. These all had excellent methods of randomisation, appropriate use of stratification, and clear power calculations that were achieved. Se- lected studies did not clearly report their methods of randomisation, if stratification was used, and on allocation concealment (Athanassiou 2005; Yung 2000a). In certain instances the study groups were not similar at baseline which could be indicative of selection bias. For example in the trial by Yung 2000a there was a greater time to relapse from initial diagnosis or radiotherapy for the procarbazine arm. It is not clear however if this is a marker for prognosis or different disease characteristics. In the trial by Kocher 2008 baseline characteristics appeared to suggest more males and more patients with seizures were present in the radiotherapy alone arm. A lack of statistical tests for baseline characteristics was apparent in a single trial (EORTC/NCIC 26981-22981).

\section{Blinding}

The most serious concern relating to all the included trials related to the lack of blinding or use of placebo, which raises concerns of bias in outcome assessment and in post-treatment therapy. Unblinded studies are known to over-estimate treatment effects such as disease progression (Juni 2001).

This may lead to bias in reporting all non-objective outcome measures (essentially everything apart from OS) including PFS, TTP, QoL and adverse events. It is recognised that one of the reasons given for not using a placebo (and therefore allowing blinding) is obvious changes in blood parameters that can occur during chemotherapy. 


\section{Incomplete outcome data}

All studies analysed there data on an intention-to-treat basis except one (Athanassiou 2005): in this trial 20 out of 130 patients were withdrawn from the analysis after randomisation. Two used a modified intention-to-treat analysis only analysing those that actually received treatment (NOA-08 2012; Nordic 2012). All studies recording QoL data had as expected significant difficulties with attrition bias (EORTC/NCIC 26981-22981; Osoba 2000b; NOA-08 2012; Nordic 2012). Recognition of these limitations and methodology to minimise these effects were commendable.

\section{Selective reporting}

In the trial by Yung 2000a measures used for analysing QoL were ideal but methods of analysis less than optimal: changes were only evaluated at six months or at disease progression limiting sensitivity. The issue of blinding and recording of QoL outcomes is of particular concern given the subjective nature of recording such data. The intervals between recordings of data (three-monthly) were long enough to introduce some lag time bias i.e. a lack of sensitivity in detecting actual timing of events.

\section{Other potential sources of bias}

Quality of life data proved troublesome to integrate directly into RevMan. Outcome data for QoL were included in a descriptive manner because of this and because there were relatively few trials. Alternative methods of presenting the results that could have lent themselves better to meta-analysis would be to have a hazard ratio for risk to decline in QoL, although this would require setting an arbitrary cut-off value.

Central pathology review was only used in selected studies (BR12 2010; EORTC/NCIC 26981-22981; NOA-08 2012; Nordic 2012). Variation in pathological diagnoses between treatment arms at baseline could be a significant confounding variable i.e. a disproportionate number of lower grade tumours would be expected to improve survival in that arm independently of treatment. Inter-observer variations in the interpretation of the histology is known to exist with concordance rates between experienced neuro-pathologists of between $81 \%$ to $90 \%$ when histological typing and grading of neuro-epithelial tumours is concerned and higher when diagnosing other types of brain tumours (Castillo 2004; Velasquez-Perez 2002).

Strict definitions for recurrence are important for determining PFS and in recruiting patients for trials of therapy in recurrent disease. When only radiological criteria are used for diagnosis of recurrence this is known to be inadequate and will include some who do not have recurrence but changes due to treatment (Wen 2010). Open and thorough criteria should be used to define recurrence according to clinical symptoms, imaging or increasing steroid therapy: the 'Macdonald criteria' (with subsequent update) can be considered as the accepted standard (Wen 2010). Only four trials included included adequate definitions of recurrence (BR12 2010; Clarke 2009; Nordic 2012; NOA-08 2012).

Pharmaceutical companies were essentially involved with all the trials to some degree (specifically: Schering-Plough; Merck; Merck Sharp \& Dohme; and ESSEX Pharma®). This was through either links to certain authors or direct sponsorship of the trial. In most cases it was emphasised that the pharmaceutical companies had no other role in trial design or data analysis.

\section{Effects of interventions}

\section{Primary concomitant/adjuvant therapy}

Three studies were included with 745 patients in total ( Athanassiou 2005; EORTC/NCIC 26981-22981; Kocher 2008). Temozolomide resulted in an increase in survival (HR 0.60, 95\% CI 0.46 to 0.79 , P value 0.0003 (Analysis 1.1)) compared with radiation only. Random-effects models were used but the overall effect size was similar using fixed-effect models. Significant intertrial heterogeneity was suggested (P value 0.11 ; $\mathrm{I}^{2}=55 \%$ ). This may partially be explained by study design: the two trials investigating temozolomide therapy in both concomitant and adjuvant phases (Athanassiou 2005; EORTC/NCIC 26981-22981) gave results that were strongly in favour of temozolomide (pooled HR $=0.56,95 \%$ CI 0.42 to 0.74 ), whereas results from the single trial using temozolomide in the concomitant phase only (Kocher 2008) were equivocal ( $\mathrm{HR}=0.89,95 \%$ CI 0.49 to 1.61$)$. Nevertheless, when the trials were stratified according to this characteristic, there was insufficient evidence to reject a null hypothesis of homogeneous strata (P value 0.17; $\mathrm{I}^{2}=47.8 \%$ ).

Similar results were seen for PFS (Analysis 1.2). Across all three trials, a significant benefit in favour of temozolomide was observed $(\mathrm{HR}=0.63$, 95\% CI 0.43 to 0.92). Again, there was clear evidence of inter-trial heterogeneity ( $\mathrm{P}$ value 0.03 ; $\mathrm{I}^{2}=71 \%$ ) but, in this analysis, experimental design was an even more convincing explanation of statistical heterogeneity. The two concomitant and adjuvant trials gave strong and congruent estimates of PFS extension with temozolomide (pooled HR $=0.54,95 \%$ CI 0.46 to 0.64 ; heterogeneity: $P$ value $0.47 ; \mathrm{I}^{2}=0 \%$ ). In contrast, the trial using temozolomide in the concomitant phase only found no such benefit $(\mathrm{HR}=1.06,95 \%$ CI $0.65,1.75)$, and a stratified metaanalysis was strongly suggestive of a statistical difference between the two approaches (P value 0.01; $\mathrm{I}^{2}=84.2 \%$ ).

Taken together, evidence for OS and PFS suggest that the use of temozolomide concomitantly and adjuvantly to radiotherapy results in extended survival, when compared with radiotherapy alone. However, a similar benefit has not been demonstrated when temozolomide therapy is confined to the concomitant phase only. For QoL the results from the single included RCT are presented descriptively (EORTC/NCIC 26981-22981). A total of 490 of 573 patients were suitable after baseline analysis. At first followup, groups differed only in social functioning, favouring the ra- 
diotherapy-only group. There was no difference between the two arms for any of the seven outcome measures (overall, fatigue, social function, emotional function, future uncertainty, insomnia and communication deficit). Overall baseline health-related quality of life (HRQoL) was substantially impaired compared with controls but not between arms.

Data for adverse events (Analysis 1.3) were complete but for only grade 3 or 4 toxicity in one trial (EORTC/NCIC 26981-22981) and only incomplete outcomes were reported in another (Kocher 2008). Only selected grade 3 to 4 toxicity was analysed: detailed results are presented in Characteristics of included studies. A statistically significant increase in risk was found in the temozolomide arm for haematological (odds ratio (OR) 8.09, 95\% CI 4.69 to 13.97), fatigue (OR $1.98,95 \%$ CI 1.15 to 3.41 ), and infections (OR 2.45, 95\% CI 1.15 to 5.23) but not for thromboembolic events (OR $0.74,95 \%$ CI 0.35 to 1.58 ).

\section{Temozolomide versus radiotherapy in the elderly}

Two studies were included with 664 patients randomised (Nordic 2012; NOA-08 2012). For OS, temozolomide alone did not result in a significant difference versus hypofractionated radiotherapy alone based on a single trial (Nordic 2012) of 242 patients (HR $0.82,95 \%$ CI 0.63 to $1.07, \mathrm{P}$ value 0.14 , Analysis 2.1 ) or versus standard radiotherapy based on two trials of 566 patients (HR 0.88, 95\% CI 0.57 to 1.36 , P value 0.56 , Analysis 2.2 ). In the latter analysis significant heterogeneity was demonstrated between the trials $\left(\mathrm{I}^{2}=0.84 \%, \mathrm{P}\right.$ value 0.01$)$ which may be due to one trial being designed as a non-inferiority study. Data on PFS was only available for a single trial of 373 participants comparing temozolomide alone with standard radiotherapy (NOA-08 2012) and did not demonstrate a difference between arms (HR 1.15, 95\% CI 0.92 to 1.44 , P value 0.22 , Analysis 2.3). Adverse events data (greater than grade 2) demonstrated significantly higher risk with temozolomide of neutropaenia, thrombocytopaenia, lymphocytopaenia, infections, thromboembolic events, nausea/vomiting and overall adverse events (OR 3.18, 95\% CI 1.81 to 5.58, P $<0.0001$, Analysis 2.4). There was no difference for pancytopaenia, fatigue, seizures or cutaneous effects. In general the rates of adverse events were more frequent in one of the trials than the other introducing significant heterogeneity $\left(\mathrm{I}^{2} 87 \%, \mathrm{P}<0.0001\right)$. For QoL the data is presented in a descriptive fashion. In one trial health-related quality of life was similar in both groups for the $82 \%$ of patients that data was available (NOA-08 2012). In the second trial again the ratings for global health status were similar between arms it was reported that patients in the temozolomide arm generally reported better QoL (Nordic 2012). However, there was significant attrition with data available for only $83 \%$ at baseline, $59 \%$ at 6 weeks, $44 \%$ at 3 months, and a low enough return at 6 months to effectively preclude meaningful analysis.

\section{Different temozolomide dosing schedules}

A single RCT of 85 patients compared dose-dense temozolomide versus metronomic temozolomide as primary therapy for GBM (Clarke 2009). Overall survival was not statistically different between arms (HR 0.84, 95\% CI 0.50 to 1.41 , P value 0.51 ) (Analysis 3.1). No data on PFS or QoL were reported in this trial. Adverse events were incompletely recorded with regard to total haematological events, infections and thromboembolism. Individual adverse events were limited by low numbers but lymphopaenia (OR 5.09, 95\% CI 2.12 to 12.18 , P value 0.0003 ) and overall adverse events (OR 2.12, 95\% CI 1.15 to 3.91, P value 0.02] were more common with metronomic than dose dense therapy (Analysis 3.2).

\section{Therapy for recurrent disease}

Two studies were included with 672 patients in total (BR12 2010; Yung 2000a). Temozolomide did not improve OS for grade III and IV tumours (HR $0.90,95 \%$ CI 0.76 to 1.06 , P value 0.2 ) including the grade IV tumour only subgroup (HR $0.8795 \%$ CI 0.65 to 1.16 ) (Analysis 4.1 ). There was no heterogeneity between trials $\left(\mathrm{Chi}^{2}=0.06, \mathrm{df}=1(\mathrm{P}\right.$ value 0.80$\left.) ; \mathrm{I}^{2}=0 \%\right)$.

Temozolomide was associated with a significant extension of PFS in the trial conducted in participants with grade IV tumours only ( Yung 2000a; HR 0.68 (95\% CI 0.51 to 0.90)), whereas evidence in the trial that enrolled people with all high-grade gliomas i.e. grade III and IV tumours (BR12 2010) did not conclusively demonstrate a benefit $(\mathrm{HR}=0.89(95 \% \mathrm{CI} 0.73$ to 1.09$))$. When pooled into a single meta-analysis, this difference leads to expected statistical heterogeneity (P value $0.13 ; \mathrm{I}^{2}=56 \%$ ). The pooled effect estimate depends critically on the model used: a fixed-effects model suggests that temozolomide is associated with significant PFS benefit (HR $=0.81$ (95\% CI 0.69 to 0.96$) ; \mathrm{P}$ value 0.01$)$; however, when a random-effects synthesis is used, the confidence interval broadens, becoming consistent with a null effect ( $\mathrm{HR}=0.79$ (95\% CI 0.61 to 1.03$)$; P value 0.08 ).

Two studies were included with 553 of 609 participants providing data on QoL (BR12 2010; Yung 2000a). The results are presented descriptively in light of the difficulties in integrating QoL data into a meta-analysis.

- Yung 2000a: At six months of treatment, patients who were free of progression reported either an improvement of maintenance of all the preselected health related QoL domain scores. Patients with disease progression by six months usually experienced improvement prior to progression, but there was a sharp decline in most of the preselected domains at progression.

- BR12 2010: At 24 weeks, the mean QoL scores were 51.9 for PCV versus 59.8 for temozolomide (P value 0.038 ). The percentage of patients with a 10-point improvement from baseline to 24 weeks was more marked in the TMZ-5 group (TMZ-5 (49\%) versus TMZ-21 (19\%), P value $=0.005$; TMZ$5(49 \%)$ versus PCV (23\%), P value $=0.007)$. 
Adverse events were reported in two trials but only incompletely (BR12 2010; Yung 2000a). No statistically significant increase in the risk of adverse events with temozolomide was documented for any adverse events (OR 1.53, 95\% CI 0.81 to 2.89 ), haematological (OR 1.01, 95\% CI 0.61 to 1.65 ) or fatigue (OR 1.5, 95\% CI 0.26 to 8.82 ) (Analysis 4.3).

Funnel plots do not support evidence of publication bias although the total number of included studies is low (Figure 4).

Figure 4. Funnel plot of comparison: 2 Recurrence Therapy, outcome: 2.I Survival.

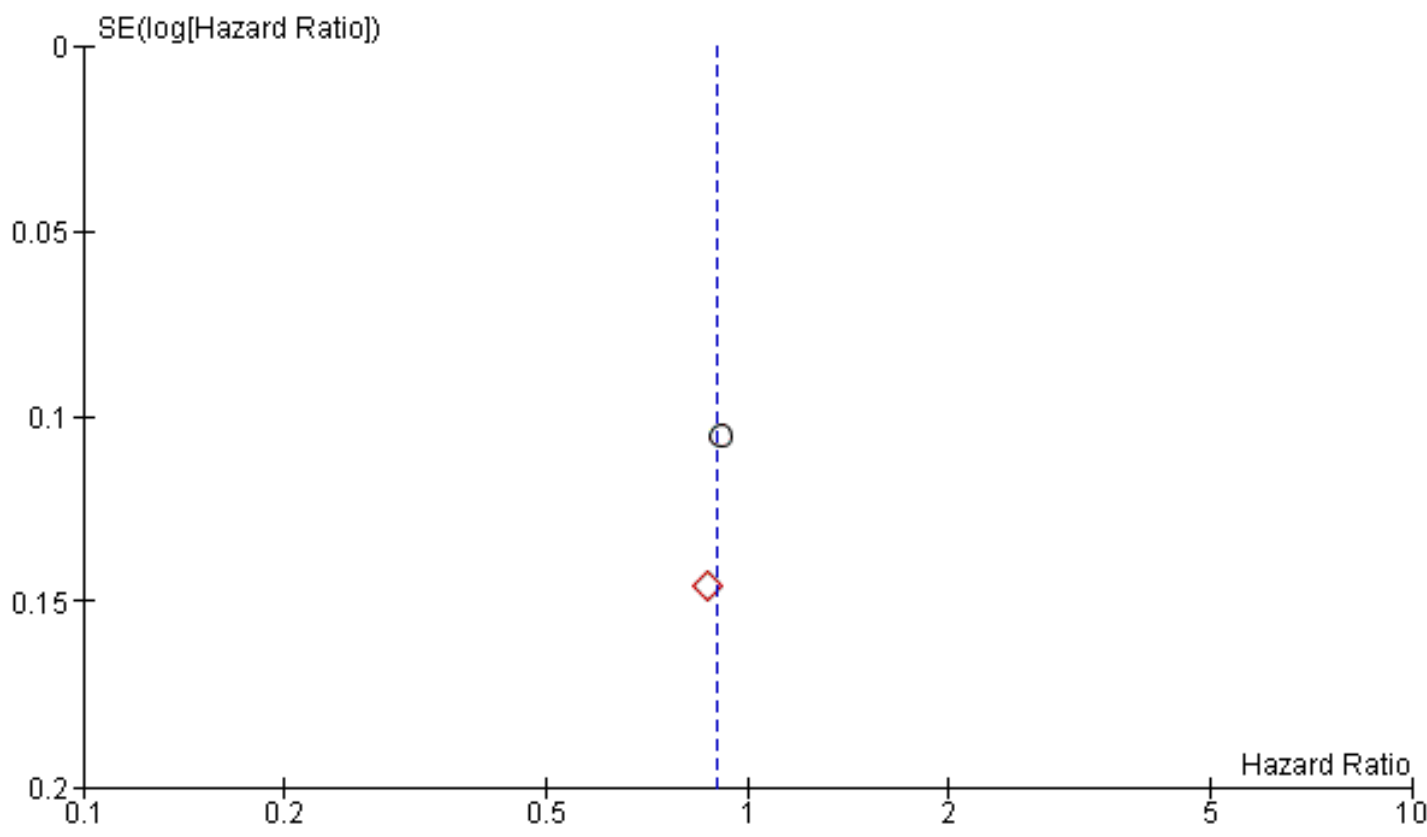

Subgroups

Grade $3 \& 4$ tumours $\diamond$ Grade 4 tumours only

\section{DISCUSSION}

\section{Summary of main results}

This review found that temozolomide increased overall survival (OS) and progression free survival (PFS) when used as part of concomitant and adjuvant primary therapy for GBM: insufficient data are available for other forms of HGG (e.g. grade III glioma) as primary therapy. From the individual trial data, median survival is estimated to be around 14 months with temozolomide with a two-month increase over radiotherapy alone. Analysis of the individual Kaplan-Meier plots suggests this benefit is mostly after six months. Adverse events were more common with temozolomide but drop outs were low suggesting that the clinical management of adverse events was sufficient to control the symptoms. Longterm data are minimal and there is the concern that combination treatment of chemo-radiotherapy may result in significant longterm toxicity although this has to be balanced with the poor OS in HGG. It is important to remember that patients were randomised after surgery and only included if their disease was stable and per- 
formance status (WHO/KPS) of an appropriate level to consider further therapy. The median survival times seen are likely to be higher than in series randomising patients prior to surgery due to the exclusion of aggressive disease and post-operative deaths.

In the elderly, temozolomide alone results in similar survival times when compared to standard or hypofractionated radiotherapy. There was significant heterogeneity between the studies with one trial being of non-inferiority design (NOA-08 2012): when the survival figures were analysed without including this study temozolomide alone resulted in improved survival compared to standard dose radiotherapy. Progression-free survival appeared similar between temozolomide alone versus standard dose radiotherapy alone but this was only based on the single study of non-inferiority design. Quality of life data suffered from significant attrition but in general it did not appear to be significantly different between arms. Adverse events were more common with temozolomide alone than either radiotherapy regimen.

In recurrent disease, temozolomide was not effective in terms of OS but improved PFS in GBM compared to nitrosourea based chemotherapy. Data on QoL, however, suggested that temozolomide resulted in maintenance or improvement in scores prior to recurrence, improved overall scores and a greater percentage of patients improving, particularly with the less intensive temozolomide regimens. Adverse events again were not more common between arms although they were incompletely reported. Despite the broad entry criteria fewer patients will be suitable for chemotherapy in the recurrent disease setting due to poor performance status.

\section{Overall completeness and applicability of evidence}

When considering the applicability of these findings to patients in clinical practice, it is important to remember that the patients enrolled were highly selected, enrolling mainly young and fit patients. A proportion or patients will also be excluded after surgery due to post-operative complications or aggressive disease. Subgroup analysis from the individual trials suggests that young and fit patients undergoing resection rather than biopsy benefit the most (EORTC/NCIC 26981-22981). Therapy after recurrence was also aggressive, with a high proportion undergoing further surgery or chemotherapy, and this needs to be bourne in mind when considering the applicability of these results in day-to-day clinical practice (see table of external validity Table 2 ).

Molecular markers, specifically MGMT promotor methylation, have been proposed as a means of predicting those who respond best to temozolomide. Studies that have analysed MGMT promotor methylation status (EORTC/NCIC 26981-22981; NOA-08 2012; Nordic 2012) have in general found improved response and survival with temozolomide in those with methylation of the MGMT promotor compared to those without. Additionally, in the elderly it has been suggested that MGMT promotor methylation can be used to stratify treatment, whereby in patients that have MGMT promotor methylation temozolomide alone should be used, while in patients that are unmethylated radiotherapy alone is more appropriate. Applicability of such data is limited, however, by several factors including: data on MGMT promotor methylation status is usually only available for an incomplete and non-randomised subgroup of the overall trial population; MGMT subgroup end-points are usually secondary rather than the primary outcome of the trial leading to issues with under-powering; and technical difficulties in assessing MGMT methylation status with possible heterogeneity between laboratories in the results and techniques used (although to some extent this can be minimised by central testing). Analysis of the relevance of MGMT promotor methylation testing should ideally be performed as part of a Cochrane diagnostic test accuracy review in order to determine sensitivity, specificity, optimal testing modality, influence on treatment decisions, effect on clinical outcomes, and cost-effectiveness.

\section{Quality of the evidence}

Although these findings are generally in favour of temozolomide there are some reservations with the quality of the data from the RCTs. The major concern is the lack of blinding or placebo control in all of the included trials which could lead to detection bias with QoL, PFS and adverse event reporting. There could also be a bias with post-intervention therapy between arms which in turn could in turn effect OS. All of the studies assessed included some form of industry sponsorship although it was emphasised that this did not interfere with the actual trial process itself and probably did not introduce a further source of bias. Optimal reporting methods for RCTs should focus on: clarifying methods of allocation concealment; clear reporting of hazard ratios and confidence intervals for all time-to-event data; clearly presenting QoL; objective definitions of recurrence; standardised care pathways for managing recurrent disease and post-intervention therapy.

Longitudinal data on QoL were only reported in one trial. Although the questionnaires and methodology used were excellent data, the expected difficulties in obtaining complete data sets (Walker 2003) puts this study at significant risk of attrition bias. Other limitations include selective reporting and only including data up until progression.

\section{Potential biases in the review process}

In the elderly, variability between the studies in terms of the patients included and interventions performed could lead to concerns over appropriate pooling of the studies into a meta-analysis. Specifically the age range cut-offs demonstrated some heterogeneity in whether they assessed elderly as being over 60 (Nordic 2012), 65 (NOA-08 2012), or 70 (EORTC/NCIC 26981-22981). Temozolomide schedules also varied depending on whether it was given as either standard therapy, dose-intensified therapy, concomitant and adjuvant or only concomitant therapy. Radiotherapy schedules could be either standard or hypofraction- 
ated. We deemed it appropriate to pool these studies in light of their being little proven difference with the variations in each of the interventions but also performed sub-group analyses which could have lead to issues with multiple comparisons and small treatment groups.

Incorporation of QoL into meta-analysis is hindered by multiple analyses, variable definitions, repeated testing and high numbers of drop outs. Although the study reported that QoL was much the same between groups, this did not reflect the significant impairment that both arms had with controls at baseline and the marked deterioration at disease progression. Interpretation of this data is most valuable in confirming that therapy with temozolomide does not appear to be detrimental to QoL.

\section{Agreements and disagreements with other studies or reviews}

Previous studies have suggested that conventional standard radiotherapy is not well tolerated in the elderly and that hypofractionated radiotherapy is better in terms of overall survival (OS) compared to best standard care (ANOCEF 2007). Our finding that temozolomide alone is better than standard radiotherapy but not hypofractionated radiotherapy is in keeping with this belief. Additionally, sub-group analysis from the individual trials indicates a high proportion of patients allocated standard radiotherapy fail to complete the full treatment schedule (Nordic 2012). The main RCT for standard radiotherapy with concomitant and adjuvant temozolomide found that although in the complete treatment population of those aged 18-70 temozolomide was efficacious but that this advantage decreased with age particularly in those over 65 (EORTC/NCIC 26981-22981). In general, it appears that elderly patients do not tolerate standard dose radiotherapy, but do benefit from anti-tumour therapy with either hypofractionated radiotherapy or temozolomide. A new RCT is currently underway to assess hypofractionated radiotherapy with concomitant and temozolomide versus temozolomide alone in patients over 65 with GBM (NCT0048267).

Other means of delivering chemotherapy in HGG include implantation of wafers coated with carmustine (Gliadel ${ }^{\circledR}$ ) onto the resection cavity wall at the time of resection or systemic nitrosourea based chemotherapy (PCV). Compared with these treatments, the median survival with temozolomide is similar to that seen in a meta-analysis of Gliadel ${ }^{\circledR}$ (Hart 2011b) and in a meta-analysis of PCV chemotherapy (GMT Group 2002). Gliadel@ also has a low incidence of adverse effects but PCV therapy is potentially toxic. Data on TTP and QoL are more limited than that with temozolomide. Gliadel ${ }^{\circledR}$ is expensive and not all patients will be suitable due to anatomic and other surgical considerations. Decisions over which therapy is to be recommended in an individual patient are best taken in a multidisciplinary setting.

\section{AUTHORS' CONCLUSIONS}

\section{Implications for practice}

For primary therapy of glioblastoma multiforme (GBM), temozolomide is effective when used as primary therapy compared with radiotherapy alone when used in a concomitant and adjuvant manner. It prolongs survival and progression-free survival (PFS) but with an increased risk of early adverse events. These results are based on three randomised controlled trials (RCTs) of 745 patients in total. A single RCT did not find any difference in survival with either dose-dense or metronomic temozolomide schedules for primary disease. There are no data on other high grade gliomas (e.g. grade III glioma).

In the elderly population, temozolomide alone is comparable to hypofractionated radiotherapy in terms of overall survival (OS), although adverse events appeared to be more common. Temozolomide alone results in better OS and time to progression (TTP) compared with standard dose radiotherapy which appears to be poorly tolerated. Although quality of life $(\mathrm{QoL})$ data is limited there does not appear to be a significant difference between the two treatments. Either temozolomide alone or hypofractionated radiotherapy could be recommended as first line treatment options depending on patient preferences for follow-up, monitoring and adverse events.

In recurrent $\mathrm{HGG}$, temozolomide improves PFS (in the subgroup of grade IV tumours only) and may have beneficial effects on QoL but does not improve OS. There are still some reservations with these data as the trials were not blinded or placebo controlled while quality of life data could be further expanded upon. In a well selected subgroup of patients with GBM, temozolomide warrants consideration for use as initial therapy, but decisions need to be made on an individual patient basis as part of a multidisciplinary meeting discussion.

\section{Implications for research}

Further trials are needed with improved methodology, including placebo control, blinding, and the use of clear statistical reporting of outcome measures, particularly QoL. Dose intensification schedules or combination therapies present room for exploration as a means of decreasing resistance to therapy. A trial comparing Gliadel ${ }^{\circledR}$ either in comparison or combination with temozolomide is warranted in light of the similar survival benefits in a comparable patient populations. Application of molecular marker (e.g. MGMT promotor methylation) testing in order to predict response to temozolomide is an active area of research which could prioritise treatment to only those who are expected to benefit; ideally definitive assessment should be performed as part of a Cochrane diagnostics test accuracy review. Extrapolation of the findings from the highly selected patients enrolled in RCTs to 'real world' situations is urgently needed to confirm the external validity of these findings 


\section{ACKNOW LEDGEMEN TS}

Many thanks to the Peninsula Technology Assessment Group (PenTAG, Peninsula Medical School) for allowing use of their report into temozolomide for HGG, on which this review is based. The lead author $(\mathrm{MGH})$ acknowledges the receipt of funding from the Cochrane Gynaecological Cancer Review Group for completion of this review. We also thank Maragret Somervillefor her contribution to the original review.

\section{RE F E R E C E S}

\section{References to studies included in this review}

Athanassiou 2005 \{published data only\}

Athanassiou H, Synodinou M, Maragoudakis E, Paraskevaidis M, Verigos C, Misailidou D, et al.Randomised phase II study of temozolomide and radiotherapy compared with radiotherapy alone in newly diagnosed glioblastoma multiforme. Journal of Clinical Oncology 2005;23(10): 2372-77.

BR12 2010 \{published data only\} Brada M, Stenning S, Gabe R, Thompson LC, Levy $\mathrm{D}$, Rampling R, et al.Temozolomide versus procarbazine, lomustine, and vincristine in recurrent high-grade glioma. Journal of Clinical Oncology 2010;28(30):4601-10.

Clarke 2009 \{published data only\}

Clarke JL, Iwamoto FM, Sul J, Panageas K, Lassman $\mathrm{AB}$, DeAngelis LM, et al.Randomized phase II trial of chemoradiotherapy followed by either dose-dense or metronomic temozolomide for newly diagnosed glioblastoma. Journal of Clinical Oncology 2009;27(23): 3861-7.

EORTC/NCIC 26981-22981 \{published data only\}

Stupp R, Hegi ME, Mason WP, van den Bent MJ, Taphoorn MJ, Janzer RC, et al and European Organisation for Research and Treatment of Cancer Brain Tumour and Radiation Oncology Groups and National Cancer Institute of Canada Clinical Trials Group. Effects of radiotherapy with concomitant and adjuvant temozolomide versus radiotherapy alone on survival in glioblastoma in a randomised phase III study: 5-year analysis of the EORTCNCIC trial. Lancet Oncology 2009;10(5):459-66.

Stupp R, Mason WP, van den Bent MJ, Weller M, Fisher $\mathrm{B}$, Taphoorn MJ, et al.Radiotherapy plus concomitant and adjuvant temozolomide for glioblastoma. New England Journal of Medicine 2005;352(10):987-96.

Taphoorn MJ, Stupp R, Coens C, Osoba D, Kortmann $\mathrm{R}$, van den Bent MJ, et al.Health-related quality of life in patients with glioblastoma: A randomised controlled trial. Lancet Oncology 2005;6:937-44.

Kocher 2008 \{published data only\}

Kocher M, Frommolt P, Borberg SK, Ruhl U, Steingraber $\mathrm{M}$, Niewald $\mathrm{M}$, et al.Randomized study of postoperative radiotherapy and simultaneous temozolomide without adjuvant chemotherapy for glioblastoma. Strablentherapie und Onkologie 2008;184(11):572-9.

NOA-08 2012 \{published data only\} Wick W, Platten M, Meisner C, Felsberg J, Tabatabai G, Simon M, Nikkhah G, Papsdorf K, Steinback JP, Sabel M, Combs SE, Vesper J, Brain C, Meixensberger J, Ketter R, Mayer-Steinacker R, Reifenberger G, Weller $M$, for the NOA-08 Study Group of the Neuro-oncology Working Group (NOA) of the German Cancer Society. Temozolomide chemotherapy alone versus radiotherapy alone for malignant astrocytoma in the elderly: the NOA08 Randomised ,phase 3 trial. Lancet Oncology 2012;13(7): 707-715.

Nordic 2012 \{published data only\}

Malmstrom A, Gronberg BH, Marosi C, Stupp R, Frappaz D, Schultz H, Abacioglu U, Tavelin B, Lhermitte B, Hegi ME, Rosell J, Henriksson R, for the Nortic Clinical Brain Tumour Study Group (NCBTSG). Temozolomide versus standard 6-week radiotehrapy versus hypofractionated radiotherapy in patients older than 60 years with gliobalastoma: the Nordic randomised, phase 3 trial. Lancet Oncology 2012;13:916-926.

Yung 2000a \{published data only\}

Osoba D, Brada M, Yung WKA, Prados MD. Health related quality of life in patients treated with temozolomide versus procarbazine for recurrent glioblastoma multiforme. Journal of Clinical Oncology 2000;18(7):1481-91.

Yung A, Levin VA, Albright A. Randomized trial of temodal (TEM) vs. procarbazine (PCB) in glioblastoma multiforme (GBM) at first relapse. Proceedings of the American Society of Clinical Oncology 2000;18:139.

\section{References to studies excluded from this review}

\section{Bogdahn 2011 \{published data only\}}

Bogdahn U, Hau P, Stockhammer G, Venkataramana NK, Mahapatra AK, Suri A, et al. The Trabedersen Glioma Study Group. Targeted therapy for high-grade glioma with the TGF-beta2 inhibitor trabedersen: results of a randomized and controlled phase IIb study. Neuro-Oncology 2011;13(1):132-42. 
Bower 1997 \{published data only\}

Bower M, Newlands ES, Bleehen NM, Brada M, Begent $\mathrm{RJ}$, Calvert $\mathrm{H}$, et al.Multicentre CRC Phase II trial of temozolomide in recurrent or progressive high-grade glioma. Cancer, Chemotherapy and Pharmacology 1997;40:484-8.

Gilbert 2010 \{published data only\}

Gilbert MR, Wang M, Aldape K, Sorensen G, Mikkelsen T, Bokstein F, et al.RTOG 0625: a randomized phase II trial of bevacizumab with either irinotecan (CPT) or dose-dense temozolomide (TMZ) in recurrent glioblastoma (GBM). Neuro-Oncology. Montreal, QC, Canada, 2010; Vol. 12: iv39.

Hamilton 2006 \{published data only\}

Hamilton DA. Adding concomitant and adjuvant temozolomide to radiotherapy dose not reduce healthrelated quality of life in people with glioblastoma. Cancer Treatment Reviews 2006;32(6):483-6.

Kim 2010 \{published data only\} Kim IH, Park C-K, Han J-H, Se-Hoon L, Chae YK, Tae MK, et al.Radiotherapy followed by adjuvant temozolomide with or without neoadjuvant ACNU-CDDP chemotherapy in newly diagnosed glioblastomas: a prospective randomized controlled multicenter phase III trial. Neuro-Oncology. Montreal, QC, Canada, 2010:iv51.

Lanzetta 2003 \{published data only\}

Lanzetta G, Campanella C, Rozzi A, Nappa M, Costa A, Fedele $\mathrm{F}$, et al.Temozolamide in radio-chemotherapy combined treatment for newly-diagnosed glioblastoma multiforme: phase II clinical trial. Anticancer Research 2003;23(6D):5159-64.

Lee 2008 \{published data only\}

Lee S-M, Brada M, Stenning S, Thompson L, Gabe R. A randomised trial of procarbazine, $\mathrm{CCNU}$ and vincristine (PCV) vs temozolomide (5-day of 21-day schedule) for recurrent high grade glioma (MRC BR-12, ISRCTN83176944). Annals of Oncology. Stockholm, 2008; Vol. 19 (S8):viii2.

Linz 2009 \{published data only\}

Linz U. Commentary on effects of radiotherapy with concomitant and adjuvant temozolomide versus radiotherapy alone on survival in glioblastoma in a randomised phase III study: 5-year analysis of the EORTCNCIC trial. Lancet Oncology 2009;10:459-66.

Malmstrom 2010 \{published data only\}

Malmstrom A, Poulsen HS, Stragliotto G, Gronberg B, Hansen S, Asklund T, et al.Neoadjuvant temozolomide for grade III and IV astrocytoma: a randomized phase II study. Neuro-Oncology 2010;12(iii):39-40.

Malmstrom 2010b \{published data only\}

Malmstrom A, Gronberg BH, Stupp R, Marosi C, Frappaz HP, Schultz M, et al.Glioblastoma (GBM) in elderly patients: a randomized phase III trial comparing survival in patients treated with 6-week radiotherapy (RT) versus hypofractionated RT over 2 weeks versus temozolomide single-agent chemotherapy. Journal of Clinical Oncology. Chicago, Il, United States, 2010; Vol. 28:18 Suppl 1.
Naboors 2009 \{published data only\}

Naboors LB. NABTT 0306: A randomized phase II trial of EMD 121974 in conjunction with concomitant and adjuvant temozolomide with radiation therapy in patients with newly diagnosed glioblastoma multiforme (GBM). Journal of Clinical Oncology: ASCO annual meeting proceedings 2009;27(15S Part 1):87.

Najak 2010 \{published data only\} Nayak L, Panageas KS, Deangelis LM, Abrey LE, Lassman $\mathrm{AB}$. Radiotherapy (RT) and temozolomide (TMZ) for anaplastic astrocytoma (AA). Neuro-Oncology. Montreal, QC, Canada, 2010:iv77-78.

Newlands 1996 \{published data only\}

Newlands ES, O’Reilly SM, Glaser MG, Bower M, Evans $\mathrm{H}$, Brock C, et al.The Charing Cross Hospital experience with temozolomide in patients with gliomas. European Journal of Cancer 1996;32A:2236-41.

Osoba 2000b \{published data only\}

Osoba D, Brada M, Yung WKA, Prados MD. Health related quality of life in patients with anaplastic astrocytoma during treatment with temozolomide. European Journal of Cancer 2000;36:1788-95.

Qian 2009 \{published data only\} Qian ZZ, Wang HQ, Liu XM, Yang SY, Fu Z, Chang $\mathrm{Y}$, et al.A multicenter randomized controlled study of temozolomide in 97 patients with malignant brain glioma. Chinese Medical Journal 2009;89(29):2059-62.

\section{Renard 2010 \{published data only\}}

Renard L, Clement PM, Hammoch F, Boterberg T, Verschaeve V, Whenham N, et al.Safety analysis of randomized Belgian phase II trial of extended use of adjuvant temozolomide in newly diagnosed glioblastoma patients. Neuro-Oncology. Maastricht, Netherlands, 2010.

\section{Spiegel 2007 \{published data only\}}

Spiegel BMW, Esrailian E, Laine L, Chamberlain MC. Clinical impact of adjuvant chemotherapy in glioblastoma multiforme: a meta-analysis. CNS Drugs 2007;21(9): 775-87.

Stupp 2002 \{published data only\} Stupp R, Dietrich PY, Ostermann Kraljevic S, Pica A, Maillard I, Maeder P, et al.Promising survival for patients with newly diagnosed glioblastoma multiforme treated with concomitant radiation plus temozolamide followed by adjuvant temozolamdide. Journal of Clinical Oncology 2002; 20(5):1375-82.

van den Bent 2009 \{published data only\} van den Bent MJ, Brandes AA, Rampling R, Kouwenhoven $\mathrm{MC}$, Kros JM, Carpentier AF, et al.Randomized phase II trial of erlotinib versus temozolomide or carmustine in recurrent glioblastoma: EORTC brain tumor group study 26034. Journal of Clinical Oncology 2009;27(8):1268-74.

Wang 2010 \{published data only\} Wang X-H, Guo L-Y, Ma B, Yang KH, Zhang QN, Cao N, et al.Radiotherapy combined with temozolomide treatment for glioblastoma multiforme: a meta-analysis. Tumour 2010;30(12):1056-64. 
Weller 2010 \{published data only\}

Weller M, Tabatabai G, Reifenberger G, Herrlinger U, Pichler J, Schnell O, et al.Dose-intensifed rechallenge with temozolomide: one week on/one week off versus 3 weeks on/one week off in patients with progressive or recurrent gliomblastoma. Journal of Clinical Oncology. 2010; Vol. 28:15 Supply 1.

Wick 2009 \{published data only\}

Wick W, Hartmann C, Engel C, Stoffels, Felsberg J, Stockhammer F, et al.NOA-04 randomized phase III trial of sequential radiochemotherapy of anaplastic glioma with procarbazine, lomustine, and vincristine or temozolomide. Journal of Clinical Oncology 2009;27(35):5874-80.

Wick 2010 \{published data only\}

Wick W. NOA-08 randomized phase III trial of 1-week-on/ 1-week-off temozolomide versus involved-field radiotherapy in elderly (older than 65) patients with newly diagnosed anaplastic astrocytoma or glioblastoma (Methusalem). Journal of Clinical Oncology 2010;28(18 Suppl):949.

Yung 1999 \{published data only\}

Yung WK, Prados MD, Yaya-Tur R, Rosenfeld SS, Brada M, Friedman HS, et al.Multicenter phase II trial of temozolomide in patients with anaplastic astrocytoma or anaplastic oligoastrocytoma at first relapse. Journal of Clinical Oncology 1999;17(9):2762-71.

Yung 2000b \{published data only\}

Yung WK, Albright RE, Olson J, Fredericks R, Fink K, Prados MD, et al.A phase II study of temozolomide vs. procarbazine in patients with glioblastoma multiforme at first relapse. British Journal of Cancer 2000;83(5):588-593.

\section{Additional references}

\section{ANOCEF 2007}

Keime-Guibert F, Chinot I, Taillandier L, et al.Radiotherapy for glioblastoma in the elderly. New England Journal of Medicine 2005;356:1527-1535.

\section{Cairncross 2006}

Cairncross G, Berkey B, Shaw E, Jenkins R, Scheithauer B, Brachman D, et al.Phase III trial of chemotherapy plus radiotherapy compared with radiotherapy alone for pure and mixed anaplastic oligodendroglioma: Intergroup Radiation Therapy Oncology Group Trial 9402. Journal of Clinical Oncology 24;18:2707-14.

\section{Castillo 2004}

Castillo MS, Davis FG, Surawica T, Bruner JM, Bigner $\mathrm{S}$, Coons $\mathrm{S}$, et al.Consistency of primary brain tumor diagnoses and codes in cancer surveillance systems. Neuroepidemiology 2004;23:85-93.

\section{Counsell 1996}

Counsell CE, Collie DA, Grant R. Incidence of intracranial tumours in the Lothian region of Scotland, 1989-90. Journal of Neurology, Neurosurgery \& Psychiatry 1996;61(2): 143-50.
Der Simonian 1986

DerSimonian R, Laird N. Meta-analysis in clinical trials. Controlled Clinical Trials 1986;7:177-88.

\section{Fowkes 1991}

Fowkes FGR, Fulton PM. Critical appraisal of published research: introductory guidelines. BMJ 1991;302:1136-40.

Giese 2004

Giese A, Kucinski T, Knopp U, et al.Pattern of recurrence following local chemothereapy with biodegradeable carmustine (BCNU) implant in patients with glioblastoma. Journal of Neuro-oncology 2004;66:351-360.

\section{GMT Group 2002}

Glioma Meta-Analysts Trialists (GMT) Group.

Chemotherapy for high grade glioma. Cochrane Database of Systematic Reviews 2002, Issue 3. [DOI: 10.1002/ 14651858.CD003913]

\section{Grant 2004}

Grant R. Overview: brain tumour diagnosis and management/Royal College of Physicians Guidelines. Journal of Neurology, Neurosurgery and Psychiatry 2004;75 (Suppl 2):18-23.

\section{Hart 2011a}

Hart MG, Grant R, Metcalfe SE. Biopsy versus resection for high grade glioma. Cochrane Database of Systematic Reviews 2011, Issue 2. [DOI: 10.1002/14651858.CD002034]

\section{Hart 2011b}

Hart MG, Grant R, Garside R, Rodgers G, Somerville $\mathrm{M}$, Stein K. Chemotherapy wafers for high grade glioma. Cochrane Database of Systematic Reviews 2011, Issue 3. [DOI: 10.1002/14651858.CD007294]

\section{Higgins 2009}

Higgins JPT, Green S (editors). Cochrane Handbook of Systematic Reviews of Interventions 5.1.0 [updated March 2011]. The Cochrane Collaboration, 2011. Available from www.cochrane-handbook.org.

\section{Juni 2001}

Juni P, Altman DG, Egger M. Systematic reviews in health care: Assessing the quality of controlled clinical trials. BMJ 2001;323(7303):42-6.

Kaal 2004

Kaal ECA, Vecht CJ. The management of brain edema in brain tumours. Current Opinion in Oncology 2004;16: 593-600.

Karnofsky 1948 Karnofksy DA. The use of nitrogen mustards in the palliative treatment of carcinoma. Cancer 1948;1:634-56.

\section{Kleihues 1993}

Kleihues P, Burger PC, Scheithauer BW. The new WHO classification of brain tumours. Brain Pathology 1993;3(3): 255-68.

\section{Louis 2007}

Louis DN, Ohgaki H, Wiestler OD, et al.The 2007 WHO classification of tumours of the central nervous system.. Acta Neuropathologica 2007;114:97-109. 


\section{Mauer 2008}

Mauer ME, Bottomley A, Taphoorn MJB. Evaluating health-related quality of life and symptom burden in brain tumour patients: instruments for use in clinical trials and clinical practice. Current Opinion in Neurology 2008;21: $741-53$.

Parmar 1998

Parmar MKB, Torri V, Stewart L. Extracting summary statistics to perform meta-analyses of the published literature of endpoints. Statistics in Medicine 1998;17:2815-34.

\section{Rampling 2005}

Rampling R, James A, Papanastassoiu V. The present and future management of malignant brain tumours: surgery, radiotherapy, chemotherapy. Journal of Neurology, Neurosurgery and Psychiatry 2005;75(Suppl II):ii24-ii30.

\section{SHS 2006}

Scottish Health Startistics. Brain and central nervous system cancer. http://www.isdscotland.org/Health-Topics/Cancer/ Cancer-Statistics/Brain-and-Central-Nervous-System/. [: http://estras.isdscotland.org/phpprint.php]

\section{van den Bent 2006}

van den Bent MJ, Carpentier AF, Brandes AA, Sanson M, Taphoorn MJ, Bernsen HJ, et al.Adjucant procarbazine, lomustine and vincristine improves progression-free survival but not overall survival in newly diagnosed anaplastic oligodendrogliomas and oligoastrocytomas: a randomized European Organisation for Research and Treatment of Cancer phase II trial. Journal of Clinical Oncology 2006;24 (18):2715-2722.

\section{Velasquez-Perez 2002}

Velasquez-Perez L, Jimenez ME. Clinical-Histopathologic Concordance of Tumors of the Nervous System at the
Manuel Velasco Suarez National Institute of Neurology and Neurosurgery in Mexico City. Archives of pathology and laboratory medicine 2002;127(2):187-192.

\section{Walker 1978}

Walker MD, Alexander E Jr, Hunt WE, MacCarty CS, Mahaley MS Jr, Mealey J Jr, et al.Evaluation of BCNU and/ or radiotherapy in the treatment of anaplastic gliomas. A cooperative clinical trial. Journal of Neurosurgery 1978;49: 333-43.

\section{Walker 2003}

Walker M, Brown J, Brown K, Gregor A, Whittle IR, Grant R. Practical problems with the collection and interpretation of serial quality of life assessments in patients with malignant glioma. Journal of Neuro-Oncology 2003;63(2):179-86.

Wen 2010

Wen PY, Macdonald DR, Reardon DA, Cloughesy TF, Sorensen AG, Galanis E, et al.Updated response assessment criteria for high-grade gliomas: response assessment in neuro-oncology working group [Wen PY, Macdonald DR, Reardon DA, Cloughesy TF, Sorensen AG, Galanis E, Degroot J, Wick W, Gilbert MR, Lassman AB, Tsien C, Mikkelsen T, Wong ET, Chamberlain MC, Stupp R, Lamborn KR, Vogelbaum MA, van den Bent MJ, Chang SM.]. Journal of Clinical Oncology 2010;28(11):1963-72.

\section{References to other published versions of this review}

\section{Hart 2008}

Hart MG, Grant R, Garside R, Rogers G, Somerville M, Stein K. Temozolomide for high grade glioma. Cochrane Database of Systematic Reviews 2008, Issue 4. [DOI: 10.1002/14651858.CD007415]

* Indicates the major publication for the study 


\section{CHARACTERISTICS OF STUDIES}

\section{Characteristics of included studies [ordered by study ID]}

\section{Athanassiou 2005}

\begin{tabular}{|c|c|}
\hline Methods & Single centre randomised phase II study \\
\hline Participants & $\begin{array}{l}\text { Total of } 130 \text { patients, } 110 \text { subsequently used for analysis. Inclusion criteria: age over } 18 \text {, } \\
\text { Grade IV tumour and KPS > 60. Exclusion criteria: "poor medical condition because } \\
\text { of non-malignant systemic disease or acute infection"; any medical condition that could } \\
\text { interfere with oral administration of TMZ }\end{array}$ \\
\hline Interventions & $\begin{array}{l}\text { It used a dose intensification schedule of temozolomide in the adjuvant phase involving } \\
150 \mathrm{mg} / \mathrm{m}^{2} \text { temozolomide on days } 1 \text { to } 5 \text { and days } 15 \text { to } 19 \text { for a maximum of } 6 \text { cycles. } \\
\text { In the concomitant phase temozolomide was administered using a standard } 75 \mathrm{mg} / \mathrm{m}^{2} \\
\text { daily dose throughout. Radiotherapy was administered to both arms in a dose of } 60 \mathrm{~Gy} \\
\text { over } 6 \text { weeks }\end{array}$ \\
\hline Outcomes & Primary: Survival; PFS. Secondary: Safety \\
\hline Notes & $\begin{array}{l}\text { Survival: median TMZ } 13.41 \text { months ( } 95 \% \text { CI } 9.53 \text { to } 17.13 \text { ) versus control } 7.7 \text { months } \\
\text { ( } 95 \% \text { CI } 5.32 \text { versus } 9.2 \text { months), log rank P,0.0001). Survival percentages at } 6,12 \text { and } \\
18 \text { months. } \\
\text { TTP: TMZ } 10.8 \text { months ( } 95 \% \text { CI } 8.08 \text { to } 14.69 \text { ), log rank P < } 0.0001 \text {. TTP survival } \\
\text { percentages at } 6,12 \text { and } 18 \text { months. } \\
\text { Cox proportional hazards model (including age, extent of surgery, KPS and treatment } \\
\text { group) for OS and TTP. Administration of TMZ and KPS were significant prognostic } \\
\text { factors. } \\
\text { Subgroup analysis for poor performance status group: non-significant for OS or TTP. } \\
\text { Toxicity: concomitant TMZ Grade } 3 / 4 \text { leucopenia } 3.5 \% \text { and thrombocytopenia } 5.2 \% \text {, } \\
\text { adjuvant TMZ leucopenia } 2 \% \text { and thrombocytopenia } 5 \% \text {. Non-haematological side } \\
\text { effects: rash } 5 \% \text {, constipation } 3.5 \% \text {, arthralgia } 1.5 \%\end{array}$ \\
\hline
\end{tabular}

Risk of bias

\begin{tabular}{l|l|l}
\hline Bias & Authors' judgement & Support for judgement \\
\hline $\begin{array}{l}\text { Random sequence generation (selection } \\
\text { bias) }\end{array}$ & Unclear risk & Not specified in article \\
\hline $\begin{array}{l}\text { Allocation concealment (selection bias) } \\
\begin{array}{l}\text { Blinding (performance bias and detection } \\
\text { bias) } \\
\text { All outcomes }\end{array}\end{array}$ & High risk & Not specified in article \\
\hline
\end{tabular}

Blinding of participants and personnel High risk

Not blinded $=$ not applicable (performance bias)

All outcomes

Temozolomide for high grade glioma (Review) 
Athanassiou 2005 (Continued)

$\begin{aligned} & \text { Blinding of outcome assessment (detection } \\
& \text { bias) }\end{aligned}$
\begin{tabular}{l} 
All outcomes \\
\hline
\end{tabular}

Incomplete outcome data (attrition bias) Low risk

All outcomes

Selective reporting (reporting bias) Low risk

BR12 2010

Methods

Multicentre RCT based in the UK. Randomisation was via phone to the MRC clinical trials unit. Treatment allocation used minimization with stratification factors of centre, tumour grade ( 3 or 4 or high grade unspecified), and PS ( 0 or 1 v 2 or 3 ) across all three groups. The primary comparison on which the study was powered was TMZ (both schedules combined) versus PCV. With 380 deaths from approximately 500 patients randomly assigned over 3 to 4 years, the study had $80 \%$ power to detect a 2 -month increase in median survival (HR, 0.75) and 90\% power to detect a 3-month increase (HR, 0.67), with a two-sided significance level of P 0.05 . We assumed that at least two thirds of patients had GBM (grade 4), giving $80 \%$ power to detect a similar difference in survival in a planned subgroup analysis of such patients

Participants

447 patients between 2003 and 2007. Inclusion criteria were an interval of over 2 months since completing primary therapy, a life expectancy of over 1 month, adequate baseline laboratory function and general fitness to commence further therapy. Exclusion criteria were pregnancy, oligodendroglial histology, a WHO score of 4 (Table 3), and previous chemotherapy, radiosurgery or brachytherapy.

Interventions

The treatment arm consisted of either TMZ $200 \mathrm{mg} / \mathrm{m}^{2}$ for days 1 to 5 of 28 or TMZ $100 \mathrm{mg} / \mathrm{m}^{2}$ for days 1 to 21 of 28 ('dose dense'). The control arm consisted of PCV (at standard doses) every 6 weeks until progression or 6 cycles in total

Outcomes

Outcomes were OS, PFS, and QoL. Definitions were given for recurrence (multifactorial) and QoL

Notes

OS: HR 0.91 (0.74 to 1.11$)$ P value 0.35

PFS: HR 0.89 (0.73 to 1.08$)$ P value 0.23

QoL: at 24 weeks the mean QoL scores were 51.9 for PCV versus 59.8 for TMZ (P .038) and 64.3 for TMZ-5 versus 54.4 for TMZ-21 (P 0.036), with a significant difference also seen between PCV and TMZ-5 (51.9 v 64.3, respectively;

$P$ 0.006). The percentage of patients with a 10-point improvement from baseline to 24 weeks was more marked in the

TMZ-5 group (TMZ-5 v TMZ-21: 49\% v 19\%, respectively; P 0.005 ; and PCV v TMZ-5: 23\% v 49\%, respectively; P 0.007)

Adverse events (grade 3/4 whole treatment period): PCV 16.4\%, TMZ-5 18.9\%, TMZ$2114 \%$

Risk of bias

Temozolomide for high grade glioma (Review)

Copyright () 2013 The Cochrane Collaboration. Published by John Wiley \& Sons, Ltd. 
BR12 2010

\begin{tabular}{l|ll|l}
\hline Bias & Authors' judgement & Support for judgement \\
\hline $\begin{array}{l}\text { Random sequence generation (selection } \\
\text { bias) }\end{array}$ & Low risk & \\
\hline Allocation concealment (selection bias) & Low risk & Non-blinded study - not applicable \\
\hline $\begin{array}{l}\text { Blinding (performance bias and detection } \\
\text { bias) } \\
\text { All outcomes }\end{array}$ & High risk & \\
\hline $\begin{array}{l}\text { Blinding of participants and personnel } \\
\text { (performance bias) }\end{array}$ & High risk & Non-blinded study - not applicable \\
\hline $\begin{array}{l}\text { All outcomes } \\
\text { Blinding of outcome assessment (detection } \\
\text { bias) } \\
\text { All outcomes }\end{array}$ & High risk & Non-blinded study - not applicable \\
\hline $\begin{array}{l}\text { Incomplete outcome data (attrition bias) } \\
\text { All outcomes }\end{array}$ & Low risk & \\
\hline \begin{tabular}{l} 
Selective reporting (reporting bias) \\
\hline
\end{tabular} & Low risk & \\
\hline
\end{tabular}

\section{Clarke 2009}

Methods

Participants

Interventions
Single centre (MSK NYC USA) randomised controlled non-blinded study. Stratified by random permuted block method using Simon's 2 stage minimax design. Patients stratified at entry. Powered to a historical control. ITT

\begin{tabular}{ll} 
Participants & $\begin{array}{l}\text { A total of } 85 \text { patients between } 2005 \text { to } 2007 . \text { New diagnosis of GBM on pathology. } \\
\text { Inclusion criteria: age } 18 \text { to } 70, \mathrm{KPS}>=60 . \text { Exclusion criteria: other cancer, baseline } \\
\text { labs, pregnant, nursing (presumed to mean under in-patient care) }\end{array}$ \\
\hline Interventions & $\begin{array}{l}\text { Treatment: all patients received radiochemotherapy with } \mathrm{RTx}(60 \mathrm{~Gy})+/-\mathrm{IMRT}+\mathrm{Temo} \\
75 \mathrm{mg} / \mathrm{m}^{2} \text { daily. The 'dose dense' arm received } 150 \mathrm{mg} / \mathrm{m}^{2} \text { on days } 1-7 \& 15 \text { to } 21 \text { of } \\
\text { every } 28 \text { days cycle. The 'metronomic' arm received } 50 \mathrm{mg} / \mathrm{m}^{2} \text { on days } 1 \text { to } 28 \text { of every } \\
28 \text { days cycle. Also } 13 \text {-cis-retinoic acid was given as maintenance therapy to both arms }\end{array}$ \\
\hline Outcomes & $\begin{array}{l}\text { Outcome: OS, progression-free survival (with MacDonald criteria } \& \text { MRI every } 2 \\
\text { months with definitions for pseudo-progression). Adverse events according to NCI CTC } \\
\text { (version } 3.0)\end{array}$ \\
\hline Notes & $\begin{array}{l}\text { Median survival: dose dense } 17.1 \text { (14.0 to } 28.1) \text { months versus metronomic } 15.1 \text { (12.3 } \\
\text { to } 18.9) \text { months } \\
\text { PFS: dose dense } 6.6 \text { months versus metronomic } 5.0 \text { months } \\
\text { Adverse events (total number of grade } 3 / 4): \text { dose dense }=31 \text { versus metronomic } 28\end{array}$
\end{tabular}


Clarke 2009 (Continued)

\section{Risk of bias}

\begin{tabular}{l|ll}
\hline Bias & Authors' judgement & Support for judgement \\
\hline $\begin{array}{l}\text { Random sequence generation (selection } \\
\text { bias) }\end{array}$ & Unclear risk & Not clearly stated in the article \\
\hline $\begin{array}{l}\text { Allocation concealment (selection bias) } \\
\text { Blinding (performance bias and detection } \\
\text { bias) } \\
\text { All outcomes }\end{array}$ & High risk & Not clearly stated in the article \\
\hline $\begin{array}{l}\text { Blinding of participants and personnel } \\
\text { (performance bias) } \\
\text { All outcomes }\end{array}$ & High risk & Not blinded - not applicable \\
\hline $\begin{array}{l}\text { Blinding of outcome assessment (detection } \\
\text { bias) } \\
\text { All outcomes }\end{array}$ & High risk & Not blinded - not applicable \\
\hline $\begin{array}{l}\text { Incomplete outcome data (attrition bias) } \\
\text { All outcomes }\end{array}$ & Low risk & Not blinded - not applicable \\
\hline \begin{tabular}{l} 
Selective reporting (reporting bias) \\
\hline
\end{tabular} & Low risk & \\
\hline
\end{tabular}

EORTC/NCIC 26981-22981

Methods

Participants

Outcomes

Interventions
Central randomisation over the phone or the internet from EORTC headquarters. Stratified by WHO status, type of surgery \& institution. Minimisation technique based on variance method with semi-random assignment. Power: $80 \%$ at 0.05 significance for $33 \%$ increase (HR 0.75) in median survival

Inclusion criteria were: age between 18 to 70 , stable steroid requirements, adequate baseline blood tests, and a WHO performance score of 2 or less (Table 3). Exclusion criteria were not specified. Histology was centrally verified. MGMT status was recorded retrospectively on PCR

Standard radiotherapy schedules of $60 \mathrm{~Gy}$ for 6 weeks was given to both arms. The treatment arm comprised of TMZ $75 \mathrm{mg} / \mathrm{m}^{2}$ daily during radiotherapy then up to 6 adjuvant cycles of 150 to $200 \mathrm{mg} / \mathrm{m}^{2}$ for 1 to 5 out of every 28 days for a total of 6 further cycles. No routine chemotherapy was given to the control arm. Subsequent management was given according to need with no pre-specified protocol mentioned

The primary end point was OS; secondary endpoints included progression-free survival, safety and quality of life (reported separately - see Taphoorn 2005). Definitions were given for progression (radiological or increasing steroids), extent of surgery (surgeons opinion) and adverse events (NCI CTC). Follow-up was at baseline, 28 days after completing 
EORTC/NCIC 26981-22981 (Continued)

radiotherapy, and thereafter at 3 monthly intervals

Taphoorn 2005

EORTC QLQ-C30 and QLQ-BN20. Items were scaled and scored according to standard practice. Raw scores were converted to a linear range of 0 to 100 with higher scores reflecting higher functioning or symptoms. To account for multiple testing and based on prior knowledge seven criteria were pre-specified for analysis. Differences of 10 points were considered clinically significant: smaller differences were disregarded. Assessments were performed prior to treatment, at week 4 of radiotherapy, 4 weeks after completion of radiotherapy, at the end of the 3rd and 6th cycles of adjuvant TMZ, and every 3 months thereafter until disease progression. Prior guidelines were followed with regard to reporting

Notes

Survival: median TMZ 14.6 months (95\% CI 13.2 to 16.8) versus Control 12.1 months (CI 11.2 to 13$)$, HR 0.63 (95\% CI 0.52 to 0.75$) \mathrm{P}<0.001$ log rank test. Also survival at 6 monthly intervals up to 24 months.

Progression-free survival: TMZ 6.9 months (95\% CI 5.8 to 8.2 ) versus Control 5.0 months (4.2 to 5.5), HR 0.54 (95\% CI 0.45 to 0.64$) \mathrm{P}<0.001 \log$ rank test. Also progression-free survival at 6 monthly intervals up to 24 months.

Cox proportional hazards model (including age, corticosteroid use, sex, MMSE score and tumour location): HR 0.62 (95\% CI 0.51 to 0.75 ).

Subgroup analyses: survival advantage maintained in all subgroups analysed except those undergoing biopsy and those with poor performance score

Safety: TMZ Grade 3/4 haematologic toxicity in concomitant phase $7 \%$, adjuvant phase $14 \%$, entire study period $16 \%$, and leading to treatment discontinuation in $5 \%$. No haematologic toxicity in control arm. Results for TMZ versus control were: severe infections $3 \%$ versus $2 \%$; fatigue $33 \%$ versus $26 \%$; and thromboembolic events $3 \%$ versus $2 \%$

Stupp 2009

Survival: HR 0.63 (0.53 to 0.75$) \mathrm{P}<0.0001$

PFS: HR 0.56 (0.47 to 0.66$) \mathrm{P}<0.0001$

Adverse events (late toxicity grade $3 / 4$ ): treatment $=3$ patients, control $=1$ patient

Taphoorn 2005

Follow-on paper describing only the quality of life results from the initial trial run by the EORTC.

No significant difference in HRQoL between TMZ and control arms

490 of 573 patients after baseline analysis

Assessments restricted to first 4 assessments (compliance similar between arms until this point)

Overall baseline HRQoL was substantially impaired compared with controls but not between arms

At first follow-up, groups differed only in social functioning, favouring the radiotherapyonly group

Over subsequent assessments, HRQoL was much the same between treatment groups

Risk of bias

Bias

Authors' judgement

Support for judgement

Temozolomide for high grade glioma (Review) 


\section{EORTC/NCIC 26981-22981 (Continued)}

Random sequence generation (selection Low risk bias)

\begin{tabular}{|c|c|c|}
\hline Allocation concealment (selection bias) & High risk & Not blinded = not applicable \\
\hline $\begin{array}{l}\text { Blinding (performance bias and detection } \\
\text { bias) } \\
\text { All outcomes }\end{array}$ & High risk & Not blinded = not applicable \\
\hline $\begin{array}{l}\text { Blinding of participants and personnel } \\
\text { (performance bias) } \\
\text { All outcomes }\end{array}$ & High risk & Not blinded = not applicable \\
\hline $\begin{array}{l}\text { Blinding of outcome assessment (detection } \\
\text { bias) } \\
\text { All outcomes }\end{array}$ & High risk & Not blinded = not applicable \\
\hline $\begin{array}{l}\text { Incomplete outcome data (attrition bias) } \\
\text { All outcomes }\end{array}$ & Low risk & \\
\hline Selective reporting (reporting bias) & Low risk & \\
\hline
\end{tabular}

Kocher 2008

Methods

Randomised non-blinded non-placebo controlled trial. Power was $80 \%$ at $5 \%$ significance for $10 \%$ improvement in PFS at 9 months (HR 0.75). Randomisation was via telephone

Participants

A total of 65 patients from 11 centres were randomised between 2002 and 2004. Inclusion criteria: age 18 to 70, unifocal GBM, macroscopic tumour resection (based on early CT/ MRI), PS 0-2, stable labs. Exclusion criteria: recurrent disease, prior therapy, other major medical illness or infection, previous malignancy, pregnancy. 5 patients lost to follow-up

Interventions

Both arms received radiotherapy involving 60 Gy in 2.0 Gy daily fractions 5 days per week for 6 weeks. Treatment arm: TMZ $75 \mathrm{mg} / \mathrm{m}^{2}$ on days 1 to 28 concomitant with radiotherapy only. No adjuvant TMZ. Control arm: no further therapy (other than radiotherapy)

Outcomes

Outcomes: OS, PFS and toxicity. Follow-up included clinical assessment, WHO score, QoL questionnaires, and MRI at least 3 monthly

Notes

Adverse events (grade 3/4): treatment arm - nausea 32\% (4\%), lymphopenia 58\% (33\%) , elevated liver enzymes GPT 57\% (7\%) and 40\% (4\%) versus control arm - nausea 3\% (3\%), lymphopenia $21 \%(6 \%)$, elevated liver enzymes GPT 15\% (3\%) and GOT 3\% $(0 \%)$

PFS: treatment 6.3 (5.1-7.5) months versus control 7.6 (6.8 to 8.4) months (P value 0. 801) $\mathrm{HR}=0.94(95 \%$ CI 0.6 to 1.6$)$

OS: treatment 14.6 (11.3 to 18.0$)$ months versus control 17.1 (13.5 to 20.8) months 
( $\mathrm{P}$ value 0.668$) \mathrm{HR}=0.89$ (95\% CI 0.5 to 1.6$)$

QoL: 'for both general and brain-related quality of life, better scores were observed at nearly all points of time in the RT + TMZ group: before therapy, the scores were similar in both groups'

\section{Risk of bias}

\begin{tabular}{l|l|l}
\hline Bias & Authors' judgement & Support for judgement \\
\hline $\begin{array}{l}\text { Random sequence generation (selection } \\
\text { bias) }\end{array}$ & Unclear risk & Not stated in article \\
\hline $\begin{array}{l}\text { Allocation concealment (selection bias) } \\
\text { Blinding (performance bias and detection } \\
\text { bias) } \\
\text { All outcomes }\end{array}$ & High risk & Not clearly stated in article \\
\hline $\begin{array}{l}\text { Blinding of participants and personnel } \\
\text { (performance bias) } \\
\text { All outcomes }\end{array}$ & High risk & Not blinded = not applicable \\
\hline $\begin{array}{l}\text { Blinding of outcome assessment (detection } \\
\text { bias) } \\
\text { All outcomes }\end{array}$ & High risk & Not blinded = not applicable \\
\hline
\end{tabular}

\section{NOA-08 2012}

Methods

Randomised phase III trial. Randomisation was performed centrally by an independent contract research organisation. A list was generated electronically in block of variable length without stratification with allocation 1:1 before the start of the study

Participants

Inclusion criteria were: de-novo anaplastic astrocytoma or glioblastoma that was histologically confirmed locally after biopsy or resection; age older thatn 65 years; and a Karnofsky performance score of 60 or more. Central histological review was performed. Exclusion criteria were: patients having undergone previous systemic chemotherapy or radiotherapy to the brain; inadequate bone marrow reserve, liver function or renal function

Interventions

Temozolomide: 1 week on / 1 week off schedule, $100 \mathrm{mg} / \mathrm{m}^{2}$ on days $1-7$, with increases or decreases of $25 \mathrm{mg} / \mathrm{m}^{2}$ depending on blood counts and tolerability.

Radiotherapy: to gross tumour volume plus a $2 \mathrm{~cm}$ margin over 6-7 weeks in fractions of 1.8-2.0 Gy to a total of 60.0 Gy according to preoperative MRI and dedicated CT or three-dimensional planning systems

Outcomes

Tumour response was defined by the Macdonald criteria. MGMT promotor methylation was assessed by two distinct methylation-specific PCR assays

Primary endpoint: overall survival.

Secondary endpoints: event-free survival, best response, QOL, and safety 
NOA-08 2012 (Continued)

\begin{tabular}{|c|c|c|}
\hline Notes & \multicolumn{2}{|c|}{ Minimum follow-up 12 months. } \\
\hline \multicolumn{3}{|l|}{ Risk of bias } \\
\hline Bias & Authors' judgement & Support for judgement \\
\hline $\begin{array}{l}\text { Random sequence generation (selection } \\
\text { bias) }\end{array}$ & Low risk & $\begin{array}{l}\text { Central electronic randomisation by an in- } \\
\text { dependent organisation }\end{array}$ \\
\hline Allocation concealment (selection bias) & Low risk & $\begin{array}{l}\text { Allocations were revealed by fax transmis- } \\
\text { sion to a project manager }\end{array}$ \\
\hline $\begin{array}{l}\text { Blinding (performance bias and detection } \\
\text { bias) } \\
\text { All outcomes }\end{array}$ & High risk & No blinding or placebo used. \\
\hline $\begin{array}{l}\text { Blinding of participants and personnel } \\
\text { (performance bias) } \\
\text { All outcomes }\end{array}$ & High risk & No blinding or placebo used. \\
\hline $\begin{array}{l}\text { Blinding of outcome assessment (detection } \\
\text { bias) } \\
\text { All outcomes }\end{array}$ & High risk & No blinding or placebo used \\
\hline $\begin{array}{l}\text { Incomplete outcome data (attrition bias) } \\
\text { All outcomes }\end{array}$ & High risk & $\begin{array}{l}\text { Analysis was on an intention-to-treat ba- } \\
\text { sis with all withdrawals and protocol vio- } \\
\text { lations clearly specified. There was a high } \\
\text { rate of drop-outs for quality of life data in } \\
\text { keeping with other studies making it a high } \\
\text { risk of bias }\end{array}$ \\
\hline Selective reporting (reporting bias) & Low risk & All pre-specified outcomes were reported. \\
\hline
\end{tabular}



oncology centres enrolling 342 patients between 2000 and 2009. It focused on patients over 60 years old with a histologically confirmed WHO grade IV astrocytoma. The primary hypopthesis was to test if chemotherapy wth temozolomide was better than hypofractionated radiotherapy (the current standard of care for elderly patients) but with an improved quality of life profile

Power calculation for 480 patients with 160 per treatment group for $10 \%$ survival difference (10-20\% at 1 year). $90 \%$ power at $5 \%$ significance via the log rank

Sponsors had no role in study design, data collection, data analysis, data interpretation, or writing of the report

Randomisation was by computer. Patients were randomised depending on the institution to either: 1:1:1 in blocks of 9 to either temozolomide, hypofractionated radiotherapy, or standard radiotherapy; or in blocks of 8 to either temozolomide or hypofractionated radiotherapy. Blinding was not used

Participants

Interventions
Additionaly inclusion crieria were: WHO performance scores 0-2 (or 3 if a neurological deficit); adequate haematological, renal and liver function; and were expected by the doctor to tolerate all treatment options. After 2004 patients deemend fit to receive combination treatment were exlcuded based on the results of another trial (EORTC/NCIC 26981-22981). Exclusion criteria were: another primary cancer; WHO performance score 3-4; any disorder likely to interfere with study treatment; previous therapy for a brain tumour; and previous radiotherapy to the head that would prevent further irradiation

Temozolomide was administered orally in $200 \mathrm{mg} / \mathrm{m}^{2}$ doses on days $1-5$ of every 28 days for up to six cycles or until radiological progression, clinical progression, or both, unacceptable adverse effects were seen, or until a physcician or patient chose to discontinue treatment. Hypofractionated radiotherapy was administered in 6 fractions of $5.0 \mathrm{~Gy}$ for 3 days a week over 2 weeks or 34.0 Gy delovered in 10 fractions of 3.4 Gy on 5 days a week over 2 weeks. Standard radiotherapy was 60.0 Gy in 30 fractions of 2.0 Gy over 6 weeks

Outcomes

Outcome measures were: QOL EORTC QLQ-30 and BN20. Assessments were at 6 weeks, 3 months, 6 momths. AE via the WHO grading system except nausea and vomiting by the NCIC version 2.0 Further therapy at discretion

Central pathology with IDH1 and MGMT via DNA isolated paraffin embedded tumour quantitative methylation specific PCR normalised to beta-actin (ACTB) with a ratio of $>2.0$ being positive

Notes

Survival: temozolomide versus hypofractionated radiotherapy $(\mathrm{n}=242)$. HR $0.82(0.63-$ 1.06) $\mathrm{p}=0.12$, median survival 8.4 months $(7.3-9.4)$ versus $7.4(6.4-8.4), 25 \%$ at 1 year. Subgroup over 70 benefitted from temozolomide

QOL: $284 / 342(83 \%)$ at baseline, $59 \%$ at 6 weeks, $44 \%$ at 3 months. Generally better with temozolomide althoug no change for global health status

Adverse events: Temozolomide - neutropaenia 12\%, pancytopaenia 2\%, thrombocytopaenia $21 \%$, infection/fever $19 \%$, VTE $7 \%$, ICH 3\%, bleeding $2 \%$, seizures $7 \%$, fatigue $4 \%$, nausea $7 \%$, vomiting $3 \%$. Hypofractinated - infection/fever $7 \%$, VTE $6 \%$, bleeding $2 \%$, seizures $7 \%$, fatigue $6 \%$, vomiting $1 \%$. Standard - infection/fever $14 \%$, VTE $2 \%$, ICH $3 \%$, bleeding $1 \%$. seizures $13 \%$, fatigue $6 \%$, nausea $5 \%$, vomiting $2 \%$ MGMT; available in 258/342 (75\%) but 55 (21\%) not evaluatable. Methylated in 91/

Temozolomide for high grade glioma (Review)

Copyright @ 2013 The Cochrane Collaboration. Published by John Wiley \& Sons, Ltd. 


\section{Nordic 2012 (Continued)}

$203(78 \%)$

\section{Risk of bias}

\begin{tabular}{|c|c|c|}
\hline Bias & Authors' judgement & Support for judgement \\
\hline $\begin{array}{l}\text { Random sequence generation (selection } \\
\text { bias) }\end{array}$ & Low risk & $\begin{array}{l}\text { Computer generated allocation from a cen- } \\
\text { tral location }\end{array}$ \\
\hline Allocation concealment (selection bias) & Low risk & \\
\hline $\begin{array}{l}\text { Blinding (performance bias and detection } \\
\text { bias) } \\
\text { All outcomes }\end{array}$ & High risk & No blinding or placebo used. \\
\hline $\begin{array}{l}\text { Blinding of participants and personnel } \\
\text { (performance bias) } \\
\text { All outcomes }\end{array}$ & High risk & No blinding or placebo used. \\
\hline $\begin{array}{l}\text { Blinding of outcome assessment (detection } \\
\text { bias) } \\
\text { All outcomes }\end{array}$ & High risk & No blinding or placebo used. \\
\hline $\begin{array}{l}\text { Incomplete outcome data (attrition bias) } \\
\text { All outcomes }\end{array}$ & High risk & $\begin{array}{l}\text { Very high risk for quality of life data i.e. } \\
83 \% \text { at baseline, } 59 \% \text { at } 6 \text { weeks, } 44 \% \text { at } \\
3 \text { months. Otherwise low risk }\end{array}$ \\
\hline Selective reporting (reporting bias) & Low risk & All pre-specified outcomes reported \\
\hline
\end{tabular}

Yung 2000a

\begin{tabular}{l|l}
\hline Methods & Randomised multicentre phase II study \\
\hline Participants & 225 patients from multiple international centres. Inclusion criteria: known GBM at \\
first relapse, age of 18 or more, KPS of 70 or more, life expectancy of 12 weeks or \\
more. Exclusion criteria: more than one prior chemotherapy; previous chemotherapy \\
with single agent PRO or dacarbazine; vincristine within 2 weeks prior to study drug; \\
nitrosurea or mitomycin C within 6 weeks prior to study drug; chemotherapy (excluding \\
vincristine, nitrosurea or mitomycin C) within 4 weeks prior to study drug; history \\
of PRO-induced rash; pervious interstitial radiotherapy or stereotactic radiotherapy; \\
pregnancy; breastfeeding; toxicity from prior radiotherapy; HIV positive; previous or \\
concurrent solid tumour at other sites (excluding basal cell carcinoma)
\end{tabular}
to $150 \mathrm{mg} / \mathrm{m}^{2}$ for 28 consecutive days in a 56 day cycle. Treament until unacceptable toxicity, disease progression or 2 years treatment completed 
Yung 2000a (Continued)

\begin{tabular}{|c|c|}
\hline Outcomes & $\begin{array}{l}\text { Objective response, six month PFS, median PFS, survival, adverse events } \\
\text { Osoba 2000a } \\
\text { EORTC QLC-C } 30 \text { and BCM20. Follow-up was prior to each cycle of chemotherapy. } \\
\text { Scoring was according to standard procedures with conversion to a range of } 0 \text { to } 100 \\
\text { and higher scores indicating better functioning or more symptoms. To reduce error } \\
\text { due to repeat statistical testing seven criteria were chosen pre-hoc for testing based on } \\
\text { prior knowledge. Changes were assessed at } 6 \text { months as well as prior to, and at the time } \\
\text { of, disease progression. The significance of changes was determined by statistics, effect } \\
\text { sizes, and the proportions of patients with an improvement of ten points or more (the } \\
\text { minimum considered clinically significant: smaller changes were disregarded) }\end{array}$ \\
\hline Notes & $\begin{array}{l}\text { Objective response: TMZ } 45.6 \% \text { versus PRO } 32.7 \% \text {, P value } 0.049 \\
\text { PFS: median TMZ } 12.4 \text { weeks versus PRO } 8.32 \text { weeks, HR } 1.47 \text { (95\% CI } 1.11 \text { to } 1 \text {. } \\
\text { 95) P value } 0.0063 \text {. PFS percentages at } 6 \text { months. } \\
\text { Survival: HR 1.11, P value } 0.019 \text {. Survival percentages at } 6 \text { months. } \\
\text { Adverse events. Drop outs due to adverse events, TMZ } 3 \text { versus PRO } 11 \text {. No other } \\
\text { adverse events at greater than } 5 \% \text { in either arm } \\
\text { Osoba } 2000 \mathrm{a} \\
\text { At } 6 \text { months of treatment, patients who were free of progression reported either an } \\
\text { improvement of maintenance of all the preselected HRQL domain scores. Patients with } \\
\text { disease progression by } 6 \text { months usually experienced improvement in HRQL prior } \\
\text { to progression, but there was a sharp decline in most of the preselected domains at } \\
\text { progression }\end{array}$ \\
\hline
\end{tabular}

Risk of bias

\begin{tabular}{l|ll}
\hline Bias & Authors judgement & Support for judgement \\
\hline $\begin{array}{l}\text { Random sequence generation (selection } \\
\text { bias) }\end{array}$ & Unclear risk & Not stated \\
\hline $\begin{array}{l}\text { Allocation concealment (selection bias) } \\
\begin{array}{l}\text { Blinding (performance bias and detection } \\
\text { bias) } \\
\text { All outcomes }\end{array}\end{array}$ & High risk & Not blinded - not applicable \\
\hline
\end{tabular}

Blinding of participants and personnel High risk

Not blinded - not applicable (performance bias)

All outcomes

Blinding of outcome assessment (detection High risk bias)

Not blinded - not applicable

All outcomes

Incomplete outcome data (attrition bias) Low risk All outcomes

Not blinded - not applicable

Temozolomide for high grade glioma (Review) 
Yung 2000a (Continued)

Selective reporting (reporting bias)

Low risk

$\mathrm{CT}$ = computed tomography; GBM = glioblastoma multiforme; GOT = glutamic-oxaloacetic transaminase (serum enzyme); GPT = glutamate pyruvate transaminase (serum enzyme); HR = hazard ratio; HRQoL = health-related quality of life; IMRT = intensitymodulated radiation therapy; ITT = intention-to-treat; KPS = Karnofsky Performance Score; MGMT = O6-methylguanine-DNA methyltransferase; MMSE = mini-mental state examination score; $\mathrm{MRI}=$ magnetic resonance imaging; $\mathrm{NCI} C \mathrm{CTC}=\mathrm{National}$ Cancer Institute Cancer Treatment Criteria; OS = overall survival; PCB or PRO = procarbazine; PCV = procarbazine, lomustine and vincristine; $\mathrm{PFS}=$ progression-free survival; $\mathrm{PS}$ = performance status; $\mathrm{QoL}=$ quality of life; $\mathrm{RCT}=$ randomised controlled trial; $\mathrm{RT} x=$ radiotherapy; TMZ = temozolomide; TTP = time to progression;

\section{Characteristics of excluded studies [ordered by study ID]}

\begin{tabular}{|c|c|}
\hline Study & Reason for exclusion \\
\hline Bogdahn 2011 & $\begin{array}{l}\text { This assessed trabedersen (a TGF B2 antisense oligodeoxynucleotide) in one of two doses delivered through } \\
\text { an intra-tumoural convection enhanced delivery system with best medical care (involving either standard dose } \\
\text { temozolomide or PCV) for recurrent/refractory HGG. Temozolomide was used as the control rather than being } \\
\text { directly assessed }\end{array}$ \\
\hline Bower 1997 & Phase II study. Non-randomised participants. \\
\hline Gilbert 2010 & Abstract of conference proceedings: excluded due to a lack of complete presentation of the final results \\
\hline Hamilton 2006 & Review, commentary or presentation of an included RCT. \\
\hline Kim 2010 & Abstract of conference proceedings: excluded due to a lack of complete presentation of the final results \\
\hline Lanzetta 2003 & $\begin{array}{l}\text { A review on the experiences of temozolomide at a single institution between. No prospective data collection or } \\
\text { randomisation of participants }\end{array}$ \\
\hline Lee 2008 & Review, commentary or presentation of an included RCT. \\
\hline Linz 2009 & Review, commentary or presentation of an included RCT. \\
\hline Malmstrom 2010 & Abstract of conference proceedings: excluded due to a lack of complete presentation of the final results \\
\hline Malmstrom 2010b & Abstract of conference proceedings: excluded due to a lack of complete presentation of the final results \\
\hline Naboors 2009 & Abstract of conference proceedings: excluded due to a lack of complete presentation of the final results \\
\hline Najak 2010 & Abstract of conference proceedings: excluded due to a lack of complete presentation of the final results \\
\hline
\end{tabular}

Temozolomide for high grade glioma (Review) 
(Continued)

\begin{tabular}{|c|c|}
\hline Newlands 1996 & $\begin{array}{l}\text { A single centre experience at the Charing Cross Hospital in London on the use of temozolomide. No prospective } \\
\text { data collection or randomisation of participants }\end{array}$ \\
\hline Osoba $2000 \mathrm{~b}$ & Quality of life data on anaplastic astrocytoma from an earlier phase II study - non-RCT \\
\hline Qian 2009 & Incomplete data presentation (i.e. no Kaplan-Meier plots) preventing analysis \\
\hline Renard 2010 & Abstract of conference proceedings: excluded due to a lack of complete presentation of the final results \\
\hline Spiegel 2007 & Meta-analysis rather than RCT. \\
\hline Stupp 2002 & A phase II study. Participants were not randomised. Primary outcomes were safety and toxicity \\
\hline van den Bent 2009 & $\begin{array}{l}\text { This assessed the benefit of erlotinib (a tyrosine kinase inhibitor) with temozolomide or carmustine as the } \\
\text { control in patients with recurrent GBM rather than directly assessing the benefit of temozolomide per se }\end{array}$ \\
\hline Wang 2010 & Meta-analysis rather than RCT. \\
\hline Weller 2010 & Abstract of conference proceedings: excluded due to a lack of complete presentation of the final results \\
\hline Wick 2009 & $\begin{array}{l}\text { This RCT tested if initial upfront chemotherapy alone (with either PCV or TMZ) was as efficacious as initial } \\
\text { radiotherapy alone regarding time to treatment failure with a randomisation schedule of } 1: 1: 2 \text {.compared. } \\
\text { However individual results for the TMZ arm were not reported prohibiting inclusion in the review }\end{array}$ \\
\hline Wick 2010 & Abstract of conference proceedings: excluded due to a lack of complete presentation of the final results \\
\hline Yung 1999 & Phase II study. Participants were not randomised/single arm study \\
\hline Yung 2000b & Phase II study. Participants were not randomised. \\
\hline
\end{tabular}

GBM = glioblastoma multiforme; $\mathrm{HGG}=$ high grade glioma $\mathrm{PCV}=$ procarbazine, lomustine and vincristine; $\mathrm{RCT}=$ randomised controlled trial; $\mathrm{TMZ}=$ temozolomide 
DATA AND ANALYSES

Comparison 1. Primary Concomitant/Adjuvant Therapy

\begin{tabular}{|c|c|c|c|c|}
\hline Outcome or subgroup title & $\begin{array}{l}\text { No. of } \\
\text { studies }\end{array}$ & $\begin{array}{c}\text { No. of } \\
\text { participants }\end{array}$ & Statistical method & Effect size \\
\hline 1 Overall survival & 3 & 745 & Hazard Ratio (Random, 95\% CI) & $0.60[0.46,0.79]$ \\
\hline $\begin{array}{l}1.1 \text { Concomitant and } \\
\text { adjuvant therapy }\end{array}$ & 2 & 683 & Hazard Ratio (Random, 95\% CI) & $0.56[0.42,0.74]$ \\
\hline 1.2 Concomitant therapy only & 1 & 62 & Hazard Ratio (Random, 95\% CI) & $0.89[0.49,1.61]$ \\
\hline 2 Progression-free survival & 3 & 745 & Hazard Ratio (Random, 95\% CI) & $0.63[0.43,0.92]$ \\
\hline $\begin{array}{l}2.1 \text { Concomitant and } \\
\text { adjuvant therapy }\end{array}$ & 2 & 683 & Hazard Ratio (Random, 95\% CI) & $0.54[0.46,0.64]$ \\
\hline 2.2 Concomitant therapy only & 1 & 62 & Hazard Ratio (Random, 95\% CI) & $1.06[0.65,1.75]$ \\
\hline 3 Adverse events & 2 & 2353 & Peto Odds Ratio (Peto, Fixed, 95\% CI) & $2.76[2.02,3.77]$ \\
\hline 3.1 Total adverse events & 0 & 0 & Peto Odds Ratio (Peto, Fixed, 95\% CI) & $0.0[0.0,0.0]$ \\
\hline 3.2 Haematological & 2 & 634 & Peto Odds Ratio (Peto, Fixed, 95\% CI) & $8.09[4.69,13.97]$ \\
\hline 3.3 Fatigue & 1 & 573 & Peto Odds Ratio (Peto, Fixed, 95\% CI) & $1.98[1.15,3.41]$ \\
\hline 3.4 Thromboembolic & 1 & 573 & Peto Odds Ratio (Peto, Fixed, 95\% CI) & $0.74[0.35,1.58]$ \\
\hline 3.5 Infections & 1 & 573 & Peto Odds Ratio (Peto, Fixed, 95\% CI) & $2.45[1.15,5.23]$ \\
\hline
\end{tabular}

Comparison 2. Temozolomide versus radiotherapy in the elderly

\begin{tabular}{|c|c|c|c|c|}
\hline Outcome or subgroup title & $\begin{array}{l}\text { No. of } \\
\text { studies }\end{array}$ & $\begin{array}{c}\text { No. of } \\
\text { participants }\end{array}$ & Statistical method & Effect size \\
\hline $\begin{array}{l}1 \text { Survival (temozolomide alone } \\
\text { versus hypofractionated } \\
\text { radiotherapy) alone }\end{array}$ & 1 & 242 & Hazard Ratio (Random, 95\% CI) & $0.82[0.63,1.07]$ \\
\hline $\begin{array}{l}2 \text { Survival (temozolomide alone } \\
\text { versus standard radiotherapy } \\
\text { alone) }\end{array}$ & 2 & 566 & Hazard Ratio (Random, 95\% CI) & $0.88[0.57,1.36]$ \\
\hline $\begin{array}{l}3 \text { Progression free survival } \\
\text { (temozolomide alone versus } \\
\text { standard radiotherapy alone) }\end{array}$ & 1 & 373 & Hazard Ratio (Random, 95\% CI) & $1.15[0.92,1.44]$ \\
\hline 4 Adverse Events & 2 & 5497 & Odds Ratio (M-H, Random, 95\% CI) & $3.18[1.81,5.58]$ \\
\hline 4.1 Neutropaenia & 2 & 653 & Odds Ratio (M-H, Random, 95\% CI) & $\begin{array}{l}52.21[14.62,186 . \\
51]\end{array}$ \\
\hline 4.2 Pancytopaenia & 1 & 180 & Odds Ratio (M-H, Random, 95\% CI) & $5.11[0.24,108.01]$ \\
\hline 4.3 Thrombocytopaenia & 2 & 653 & Odds Ratio (M-H, Random, 95\% CI) & $19.06[1.14,317.61]$ \\
\hline 4.4 Lymphocytpaenia & 1 & 373 & Odds Ratio (M-H, Random, 95\% CI) & $\begin{array}{l}41.21[16.22,104 . \\
73]\end{array}$ \\
\hline 4.5 Thromboembolic event & 2 & 653 & Odds Ratio (M-H, Random, 95\% CI) & $2.12[1.25,3.58]$ \\
\hline 4.6 Infection & 2 & 653 & Odds Ratio (M-H, Random, 95\% CI) & $1.64[1.14,2.34]$ \\
\hline 4.7 Fatigue & 2 & 653 & Odds Ratio (M-H, Random, 95\% CI) & $1.22[0.67,2.20]$ \\
\hline 4.8 Nausea/vomiting & 2 & 653 & Odds Ratio (M-H, Random, 95\% CI) & $4.03[1.74,9.32]$ \\
\hline
\end{tabular}

Copyright $\odot 2013$ The Cochrane Collaboration. Published by John Wiley \& Sons, Ltd. 
Comparison 3. Different temozolomide dosing schedules

\begin{tabular}{lccll} 
Outcome or subgroup title & $\begin{array}{c}\text { No. of } \\
\text { studies }\end{array}$ & $\begin{array}{c}\text { No. of } \\
\text { participants }\end{array}$ & Statistical method & Effect size \\
\hline 1 Survival & 1 & 85 & Hazard Ratio (Random, 95\% CI) & $0.84[0.51,1.40]$ \\
2 Adverse events & 1 & 387 & Peto Odds Ratio (Peto, Fixed, 95\% CI) & $2.12[1.15,3.91]$ \\
$\quad \begin{array}{l}2.1 \text { Leucopaenia } \\
\text { 2.2 Neutropaenia }\end{array}$ & 1 & 59 & Peto Odds Ratio (Peto, Fixed, 95\% CI) & $2.59[0.34,19.40]$ \\
$\quad \begin{array}{l}\text { 2.3 Lymphopaenia } \\
\text { 2.4 Thrombocytopaenia }\end{array}$ & 1 & 59 & Peto Odds Ratio (Peto, Fixed, 95\% CI) & $1.38[0.22,8.50]$ \\
$\quad 1$ & 92 & Peto Odds Ratio (Peto, Fixed, 95\% CI) & $5.09[2.12,12.18]$ \\
$\quad \begin{array}{l}2.5 \text { Elevation of } \\
\text { aminotransferases }\end{array}$ & 1 & 59 & Peto Odds Ratio (Peto, Fixed, 95\% CI) & $0.45[0.04,4.52]$ \\
$\quad$ 2.6 Fatigue & 1 & 59 & Peto Odds Ratio (Peto, Fixed, 95\% CI) & $0.21[0.04,1.11]$ \\
\hline
\end{tabular}

Comparison 4. Therapy for recurrent disease

\begin{tabular}{ccclc} 
Outcome or subgroup title & $\begin{array}{c}\text { No. of } \\
\text { studies }\end{array}$ & $\begin{array}{c}\text { No. of } \\
\text { participants }\end{array}$ & \multicolumn{1}{c}{ Statistical method } & Effect size \\
\hline 1 Survival & 2 & 672 & Hazard Ratio (Random, 95\% CI) & $0.90[0.76,1.06]$ \\
1.1 Grade 3 \& 4 tumours & 1 & 447 & Hazard Ratio (Random, 95\% CI) & $0.91[0.74,1.12]$ \\
1.2 Grade 4 tumours only & 1 & 225 & Hazard Ratio (Random, 95\% CI) & $0.87[0.65,1.16]$ \\
2 Progression-Free Survival & 2 & 672 & Hazard Ratio (Random, 95\% CI) & $0.79[0.61,1.03]$ \\
2.1 Grade 3 \& 4 tumours & 1 & 447 & Hazard Ratio (Random, 95\% CI) & $0.89[0.73,1.09]$ \\
2.2 Grade 4 tumours only & 1 & 225 & Hazard Ratio (Random, 95\% CI) & $0.68[0.51,0.90]$ \\
3 Adverse events & 2 & 887 & Peto Odds Ratio (Peto, Fixed, 95\% CI) & $1.19[0.81,1.75]$ \\
3.1 All adverse events & 1 & 220 & Peto Odds Ratio (Peto, Fixed, 95\% CI) & $1.53[0.81,2.89]$ \\
3.2 Haematological & 1 & 447 & Peto Odds Ratio (Peto, Fixed, 95\% CI) & $1.01[0.61,1.65]$ \\
3.3 Fatigue & 1 & 220 & Peto Odds Ratio (Peto, Fixed, 95\% CI) & $1.50[0.26,8.82]$ \\
\hline
\end{tabular}




\section{Analysis I.I. Comparison I Primary Concomitant/Adjuvant Therapy, Outcome I Overall survival.}

Review: Temozolomide for high grade glioma

Comparison: I Primary Concomitant/Adjuvant Therapy

Outcome: I Overall survival

Study or subgroup

$\mathrm{TMZ}+\mathrm{RT}$

RT only

$\log$ [Hazard Ratio]

Hazard Ratio

Weight

Hazard Ratio

N

(SE)

IV,Random,95\% Cl IV,Random,95\% Cl

I Concomitant and adjuvant therapy

EORTC/NCIC 2698I-2298|

$287 \quad 286$

$-0.462(0.0882)$

Athanassiou 2005

$57 \quad 53$

$-0.757 \mid(0.1565)$

Subtotal (95\% CI)

Heterogeneity: $\mathrm{Tau}^{2}=0.03 ; \mathrm{Chi}^{2}=2.70, \mathrm{df}=1(P=0.10) ; \mathrm{I}^{2}=63 \%$

Test for overall effect: $Z=4.01(P=0.000060)$

2 Concomitant therapy only

Kocher 2008

$29 \quad 33$

$-0.1165(0.3028)$

(1)

Subtotal (95\% CI)

Heterogeneity: not applicable

Test for overall effect: $Z=0.38(P=0.70)$

Total (95\% CI)

Heterogeneity: $\operatorname{Tau}^{2}=0.03 ; \mathrm{Chi}^{2}=4.48, \mathrm{df}=2(\mathrm{P}=0.1 \mathrm{I}) ; \mathrm{I}^{2}=55 \%$

Test for overall effect: $Z=3.66(P=0.00025)$

Test for subgroup differences: $\mathrm{Chi}^{2}=1.92, \mathrm{df}=\mathrm{I}(\mathrm{P}=0.17), \mathrm{I}^{2}=48 \%$

\begin{tabular}{rrr}
$49.5 \%$ & $0.63[0.53,0.75]$ \\
$34.7 \%$ & $0.47[0.35,0.64]$ \\
$\mathbf{8 4 . 2} \%$ & $\mathbf{0 . 5 6}[\mathbf{0 . 4 2 , 0 . 7 4 ]}$ \\
& & \\
$15.8 \%$ & $0.89[0.49,1.61]$ \\
$\mathbf{1 5 . 8} \%$ & $\mathbf{0 . 8 9}[\mathbf{0 . 4 9 , 1 . 6 1}]$ \\
& & \\
\hline & &
\end{tabular}

$\begin{array}{lllll}0.01 & 0.1 & 1 & 10 & 100\end{array}$

Favours TMZ+RT Favours RT only 


\section{Analysis I.2. Comparison I Primary Concomitant/Adjuvant Therapy, Outcome 2 Progression-free survival.}

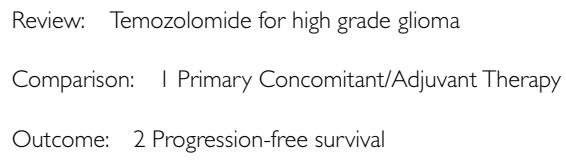

Subtotal (95\% CI)

Heterogeneity: $\mathrm{Tau}^{2}=0.0 ; \mathrm{Chi}^{2}=0.5 \mathrm{I}, \mathrm{df}=\mathrm{I}(\mathrm{P}=0.47) ; \mathrm{I}^{2}=0.0 \%$

Test for overall effect: $Z=7.46(P<0.0000 I)$

2 Concomitant therapy only

$\begin{array}{llll}\text { Kocher } 2008 & 29 & 33 & 0.0619(0.2553)\end{array}$

Subtotal (95\% CI)

Heterogeneity: not applicable

Test for overall effect: $Z=0.24(P=0.8 I)$

Total (95\% CI)

Heterogeneity: $\mathrm{Tau}^{2}=0.08 ; \mathrm{Ch}^{2}=6.82, \mathrm{df}=2(\mathrm{P}=0.03) ; \mathrm{I}^{2}=71 \%$

Test for overall effect: $Z=2.38(P=0.017)$

Test for subgroup differences: $\mathrm{Chi}^{2}=6.3 \mathrm{I}, \mathrm{df}=\mathrm{I}(\mathrm{P}=0.0 \mathrm{I}), \mathrm{I}^{2}=84 \%$

\begin{tabular}{rrr}
\hline & $29.9 \%$ & $0.47[0.30,0.72]$ \\
$43.7 \%$ & $0.56[0.47,0.66]$ \\
$\mathbf{7 3 . 6} \%$ & $\mathbf{0 . 5 4}[\mathbf{0 . 4 6 , 0 . 6 4}]$ \\
& & \\
\hline & $26.4 \%$ & $1.06[0.65,1.75]$ \\
& $\mathbf{2 6 . 4 \%}$ & $\mathbf{1 . 0 6}[\mathbf{0 . 6 5}, \mathbf{1 . 7 5}]$ \\
& $\mathbf{1 0 0 . 0} \%$ & $\mathbf{0 . 6 3}[\mathbf{0 . 4 3}, \mathbf{0 . 9 2}]$ \\
& & \\
\hline
\end{tabular}




\section{Analysis I.3. Comparison I Primary Concomitant/Adjuvant Therapy, Outcome 3 Adverse events.}

Review: Temozolomide for high grade glioma

Comparison: I Primary Concomitant/Adjuvant Therapy

Outcome: 3 Adverse events

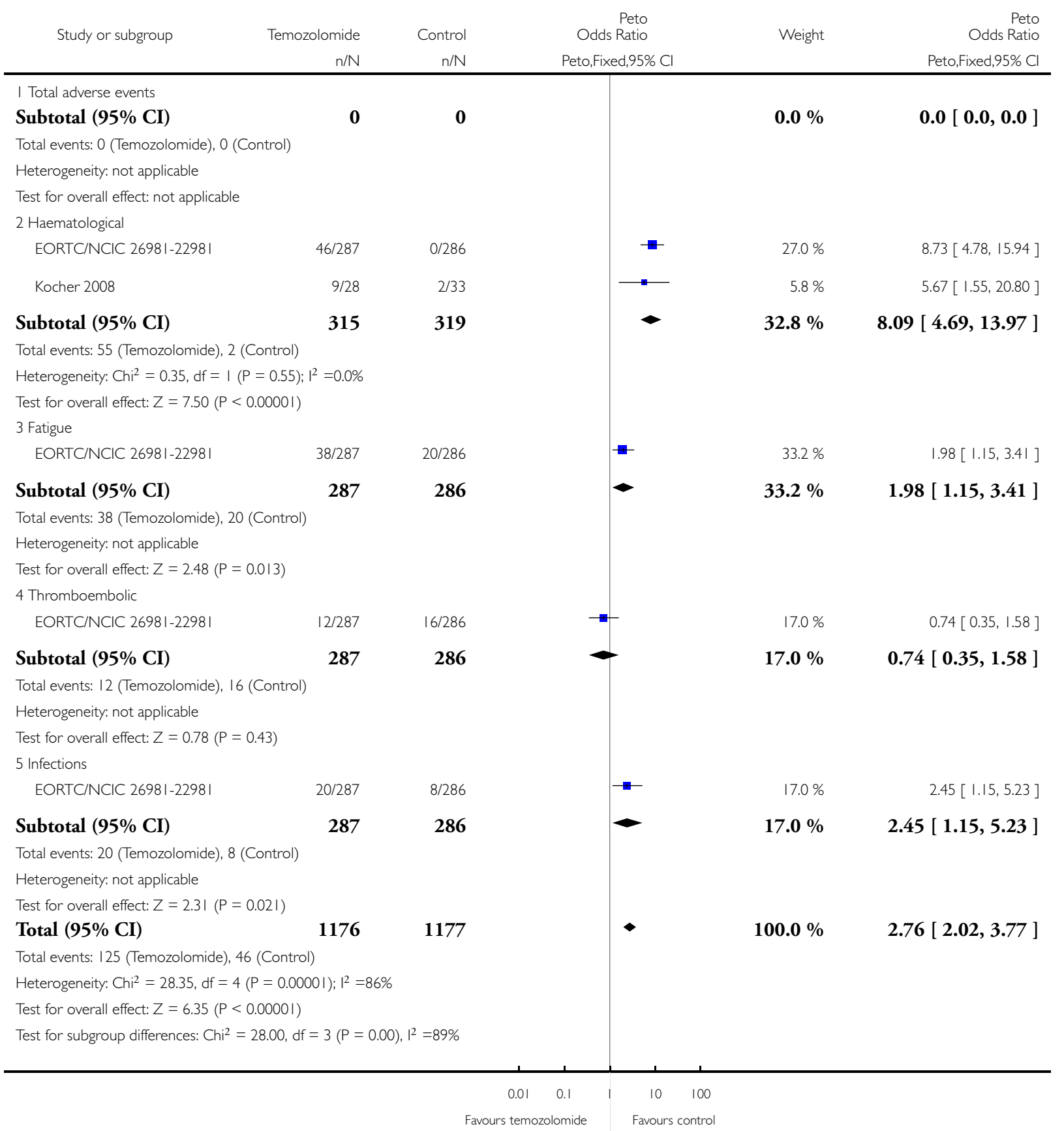

Temozolomide for high grade glioma (Review)

Copyright @ 2013 The Cochrane Collaboration. Published by John Wiley \& Sons, Ltd. 
Analysis 2.I. Comparison 2 Temozolomide versus radiotherapy in the elderly, Outcome I Survival (temozolomide alone versus hypofractionated radiotherapy) alone.

Review: Temozolomide for high grade glioma

Comparison: 2 Temozolomide versus radiotherapy in the elderly

Outcome: I Survival (temozolomide alone versus hypofractionated radiotherapy) alone

\begin{tabular}{|c|c|c|c|c|c|c|}
\hline Study or subgroup & Temozolomide & Radiotherapy & log [Hazard Ratio] & Hazard Ratio & Weight & Hazard Ratio \\
\hline & $N$ & $N$ & (SE) & IV,Random,95\% Cl & & IV,Random,95\% Cl \\
\hline Nordic 2012 & 119 & 123 & $-0.1985(0.1345)$ & & $100.0 \%$ & $0.82[0.63,1.07]$ \\
\hline
\end{tabular}

Total (95\% CI)

$100.0 \% \quad 0.82[0.63,1.07]$

Heterogeneity: not applicable

Test for overall effect: $Z=1.48(P=0.14)$

Test for subgroup differences: Not applicable

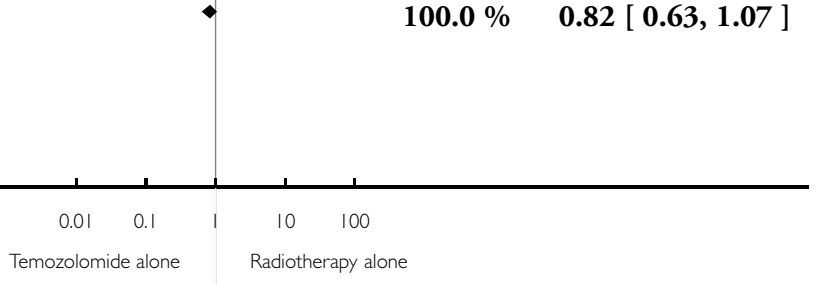


Analysis 2.2. Comparison 2 Temozolomide versus radiotherapy in the elderly, Outcome 2 Survival (temozolomide alone versus standard radiotherapy alone).

Review: Temozolomide for high grade glioma

Comparison: 2 Temozolomide versus radiotherapy in the elderly

Outcome: 2 Survival (temozolomide alone versus standard radiotherapy alone)

\begin{tabular}{|c|c|c|c|c|c|c|}
\hline \multirow[t]{2}{*}{ Study or subgroup } & Temozolomide & Radiotherapy & log [Hazard Ratio] & Hazard Ratio & Weight & Hazard Ratio \\
\hline & $\mathrm{N}$ & $\mathrm{N}$ & (SE) & IV,Random,95\% Cl & & IV,Random,95\% Cl \\
\hline NOA-08 2012 & 195 & 178 & $0.0862(0.134)$ & 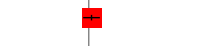 & $51.3 \%$ & $1.09[0.84,1.42]$ \\
\hline Nordic 2012 & 93 & 100 & $-0.3567(0.1517)$ & + & $48.7 \%$ & $0.70[0.52,0.94]$ \\
\hline
\end{tabular}

Total (95\% CI)

Heterogeneity: $\mathrm{Tau}^{2}=0.08 ; \mathrm{Chi}^{2}=4.79, \mathrm{df}=\mathrm{I}(\mathrm{P}=0.03) ; \mathrm{I}^{2}=79 \%$

Test for overall effect: $Z=0.59(P=0.56)$

Test for subgroup differences: Not applicable

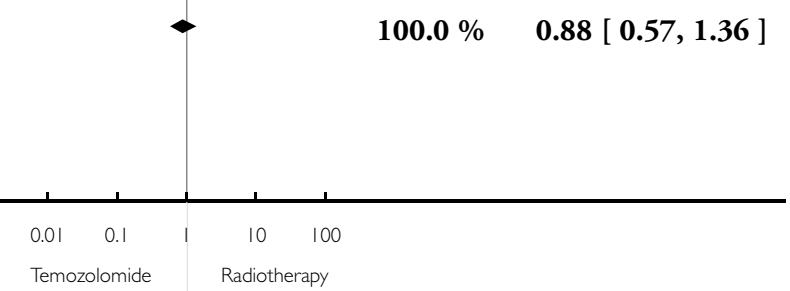

Analysis 2.3. Comparison 2 Temozolomide versus radiotherapy in the elderly, Outcome 3 Progression free survival (temozolomide alone versus standard radiotherapy alone).

Review: Temozolomide for high grade glioma

Comparison: 2 Temozolomide versus radiotherapy in the elderly

Outcome: 3 Progression free survival (temozolomide alone versus standard radiotherapy alone)

\begin{tabular}{|c|c|c|c|c|c|c|}
\hline \multirow[t]{2}{*}{ Study or subgroup } & Temozolomide & Radiotherapy & log [Hazard Ratio] & Hazard Ratio & Weight & Hazard Ratio \\
\hline & $\mathrm{N}$ & $N$ & (SE) & IV,Random,95\% Cl & & IV,Random,95\% Cl \\
\hline NOA-08 2012 & 195 & 178 & $0.1398(0.1138)$ & & $100.0 \%$ & $1.15[0.92,1.44]$ \\
\hline
\end{tabular}

Total (95\% CI)

Heterogeneity: not applicable

Test for overall effect: $Z=1.23(P=0.22)$

Test for subgroup differences: Not applicable

$100.0 \% \quad 1.15[0.92,1.44]$

Temozolomide for high grade glioma (Review)

Copyright @ 2013 The Cochrane Collaboration. Published by John Wiley \& Sons, Ltd. 
Analysis 2.4. Comparison 2 Temozolomide versus radiotherapy in the elderly, Outcome 4 Adverse Events.

Review: Temozolomide for high grade glioma

Comparison: 2 Temozolomide versus radiotherapy in the elderly

Outcome: 4 Adverse Events

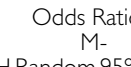

H,Random, $95 \%$

Odds Ratio

H,Random $95 \%$

1 Neutropaenia

NOA-08 2012

$72 / 195$

$\mathrm{n} / \mathrm{N}$

C

2/178

11/90

$0 / 190$

Nordic 2012

285

368

Subtotal (95\% CI)

Total events: 83 (Temozolomide alone), 2 (Radiotherapy alone)
Heterogeneity: $\mathrm{Tau}^{2}=0.0 ; \mathrm{Chi}^{2}=0.00, \mathrm{df}=$ । $(\mathrm{P}=0.97) ;\left.\right|^{2}=0.0 \%$

Heterogeneity: $\mathrm{Tau}^{2}=0.0 ; \mathrm{Chi}^{2}=0.00, \mathrm{df}=$
Test for overall effect: $Z=6.09(\mathrm{P}<0.0000 \mathrm{I})$

2 Pancytopaenia

Nordic 2012

Subtotal (95\% CI)

diotherapy alone)

Total events: 2 (Temozolomide
Heterogeneity: not applicable

Test for overall effect: $Z=1.05(P=0.29)$

3 Thrombocytopaenia

$50 / 195$

Nordic 2012

$19 / 90$

Subtotal (95\% CI)

285$$
\text { (1) }
$$

0

$2.4 \%$

$5.11[0.24,108.01]$

Total events: 69 (Temozolomide alone), 9 (Radiotherapy alone)

Heterogeneity: $\mathrm{Tau}^{2}=3.23 ; \mathrm{Ch}^{2}=3.92, \mathrm{df}=\mathrm{I}(\mathrm{P}=0.05) ; \mathrm{I}^{2}=74 \%$

Test for overall effect: $Z=2.05(P=0.040)$

4 Lymphocytpaenia

NOA-08 2012

$106 / 195$

195

$5 / 178$

Subtotal $(95 \% \mathrm{CI})$

Total events: 106 (Temozolomide alone), 5 (Radiotherapy alone)

Heterogeneity: not applicable

Test for overall effect: $Z=7.8 \mathrm{I}(\mathrm{P}<0.0000 \mathrm{I})$

5 Thromboembolic event

$\begin{array}{lrr}\text { NOA-08 } 2012 & 40 / 195 & 18 / 178 \\ \text { Nordic } 2012 & 6 / 90 & 8 / 190\end{array}$

Subtotal (95\% CI)

285

178

$9 / 178$

$\rightarrow$

$6.8 \%$

$6.48[3.08,13.62]$

$2.6 \%$

$103.9 \mid[6.19,1743.70]$

368

$-9.5 \%$

$19.06[1.14,317.61]$

Total events: 46 (Temozolomide alone), 26 (Radiotherapy alone)

Heterogeneity: $\mathrm{Tau}^{2}=0.0 ; \mathrm{Chi}^{2}=0.30, \mathrm{df}=\mathrm{I}(\mathrm{P}=0.59) ; \mathrm{I}^{2}=0.0 \%$

368

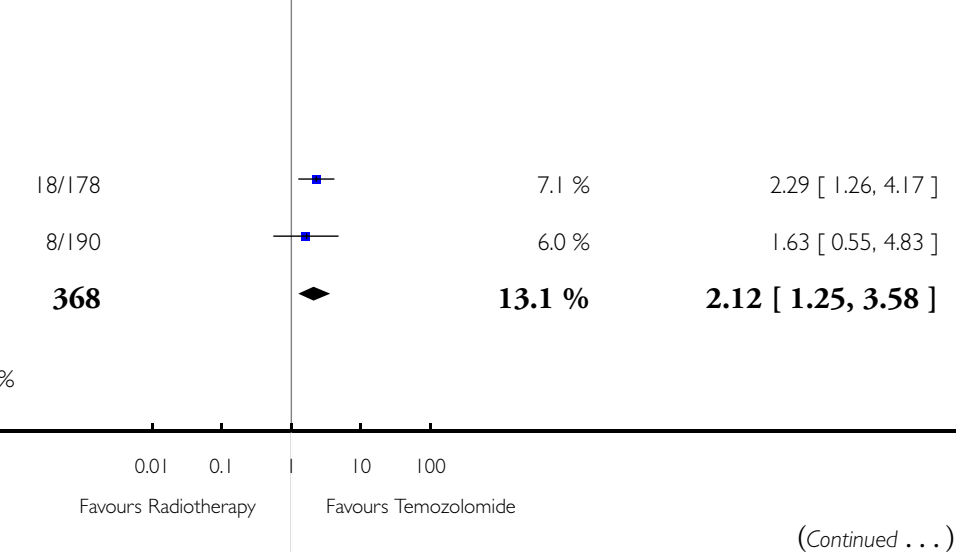

(Continued....) 
Test for overall effect: $Z=2.80(P=0.0051)$

6 Infection $\mathrm{Cl}$

NOA-08 2012

Subtotal (95\% CI)

$89 / 195$

$17 / 90$

285

$20 / 190$

Total events: 106 (Temozolomide alone), 83 (Radiotherapy alone) Heterogeneity: Tau $^{2}=0.0 ; \mathrm{Chi}^{2}=0.38, \mathrm{df}=\mathrm{I}(\mathrm{P}=0.54) ; \mathrm{I}^{2}=0.0 \%$ Test for overall effect: $Z=2.70(P=0.0070)$

7 Fatigue

NOA-08 2012

$61 / 195$

Nordic 2012

\section{5}

\section{8}

368
$43 / 178$
368

Subtotal (95\% CI)

368

Total events: 65 (Temozolomide alone), 55 (Radiotherapy alone)

Heterogeneity: $\mathrm{Tau}^{2}=0.06 ; \mathrm{Chi}^{2}=1.31, \mathrm{df}=\mathrm{I}(\mathrm{P}=0.25) ; \mathrm{I}^{2}=24 \%$

Test for overall effect: $Z=0.65(P=0.52)$

8 Nausea/vomiting

NOA-08 2012

$38 / 195$

Nordic 2012$$
9 / 90
$$

$7 / 178$

$8 / 190$

Subtotal (95\% CI)

285

368

Total events: 47 (Temozolomide alone), 15 (Radiotherapy alone)

Heterogeneity: $\mathrm{Tau}^{2}=0.15 ; \mathrm{Chi}^{2}=1.70, \mathrm{df}=\mathrm{I}(\mathrm{P}=0.19) ; \mathrm{I}^{2}=41 \%$

Test for overall effect: $Z=3.26(P=0.001 \mathrm{I})$

9 Seizures

$\begin{array}{lrr}\text { NOA-08 } 2012 & 31 / 195 & 22 / 178 \\ \text { Nordic } 2012 & 6 / 90 & 19 / 190\end{array}$

Subtotal $(95 \%$ CI)

285

368

Total events: 37 (Temozolomide alone), 4 I (Radiotherapy alone) Heterogeneity: $\mathrm{Tau}^{2}=0.1 \mathrm{I} ; \mathrm{Ch}^{2}=1.65, \mathrm{df}=\mathrm{I}(\mathrm{P}=0.20) ; \mathrm{I}^{2}=39 \%$ Test for overall effect: $Z=0.07(P=0.94)$

10 Cutaneous

NOA-08 2012

$16 / 195$

195

$19 / 178$

Subtotal (95\% CI)

Total events: 16 (Temozolomide alone), 19 (Radiotherapy alone)

Heterogeneity: not applicable

Test for overall effect: $Z=0.81(P=0.42)$

Total (95\% CI)

2475

3022

178

Total events: 577 (Temozolomide alone), 255 (Radiotherapy alone)

Heterogeneity: $\operatorname{Tau}^{2}=1.07 ; \mathrm{Chi}^{2}=123.10, \mathrm{df}=16(\mathrm{P}<0.0000 \mathrm{I}) ; \mathrm{I}^{2}=87 \%$

Test for overall effect: $Z=4.02(P=0.000058)$

Test for subgroup differences: $\mathrm{Chi}^{2}=86.19, \mathrm{df}=9(\mathrm{P}=0.00), \mathrm{I}^{2}=90 \%$
$6.9 \%$

$0.75[0.37,1.50]$

$6.9 \%$

$0.75[0.37,1.50]$

$14.4 \%$

1.64 [ 1.14, 2.34 ]

$1.43[0.90,2.26]$

$0.69[0.22,2.20]$

$1.22[0.67,2.20]$

$5.91[2.57,13.62]$

$2.53[0.94,6.79]$

$4.03[1.74,9.32]$

$1.34[0.74,2.41]$

$0.64[0.25,1.67]$

$1.03[0.51,2.05]$

$13.5 \%$

$100.0 \%$

\section{$\begin{array}{lllll}0.01 & 0.1 & 1 & 10 & 100\end{array}$}

Favours Radiotherapy Favours Temozolomide

Temozolomide for high grade glioma (Review)

Copyright @ 2013 The Cochrane Collaboration. Published by John Wiley \& Sons, Ltd. 


\section{Analysis 3.I. Comparison 3 Different temozolomide dosing schedules, Outcome I Survival.}

Review: Temozolomide for high grade glioma

Comparison: 3 Different temozolomide dosing schedules

Outcome: I Survival

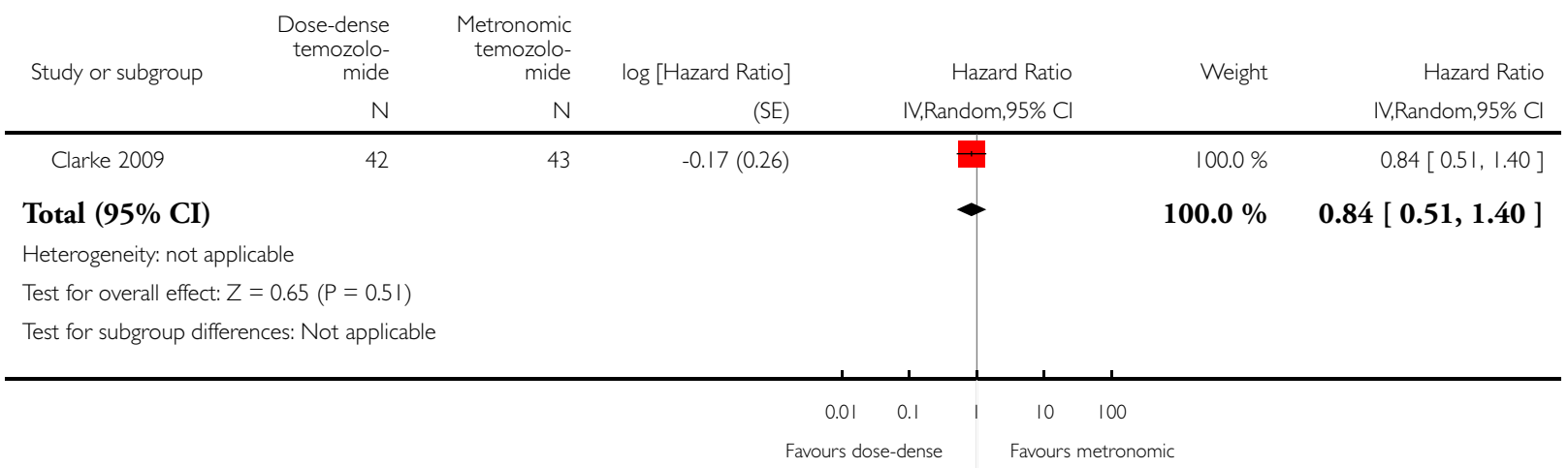




\section{Analysis 3.2. Comparison 3 Different temozolomide dosing schedules, Outcome 2 Adverse events.}

Review: Temozolomide for high grade glioma

Comparison: 3 Different temozolomide dosing schedules

Outcome: 2 Adverse events

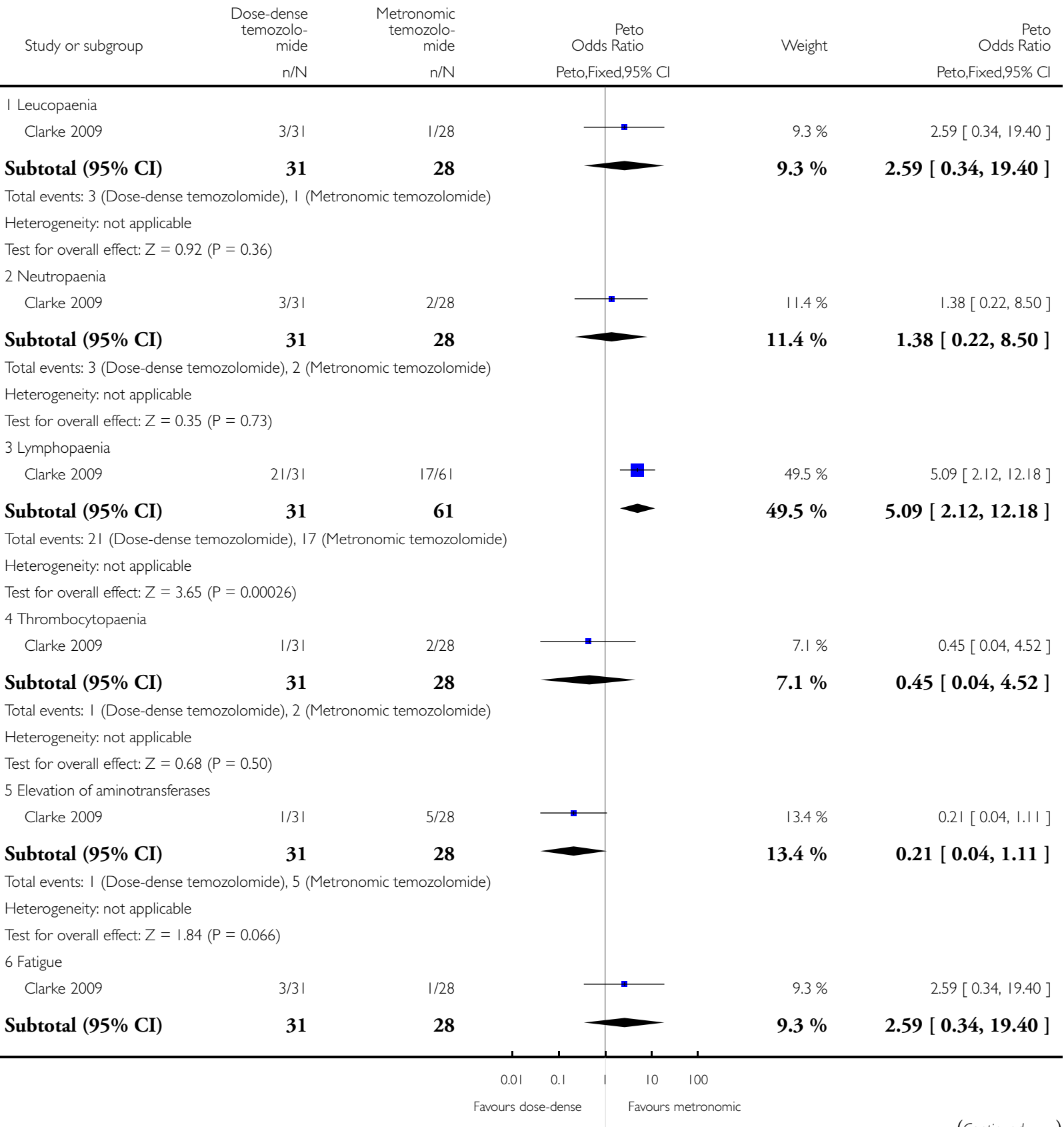

(Continued....)

Temozolomide for high grade glioma (Review)

Copyright @ 2013 The Cochrane Collaboration. Published by John Wiley \& Sons, Ltd. 


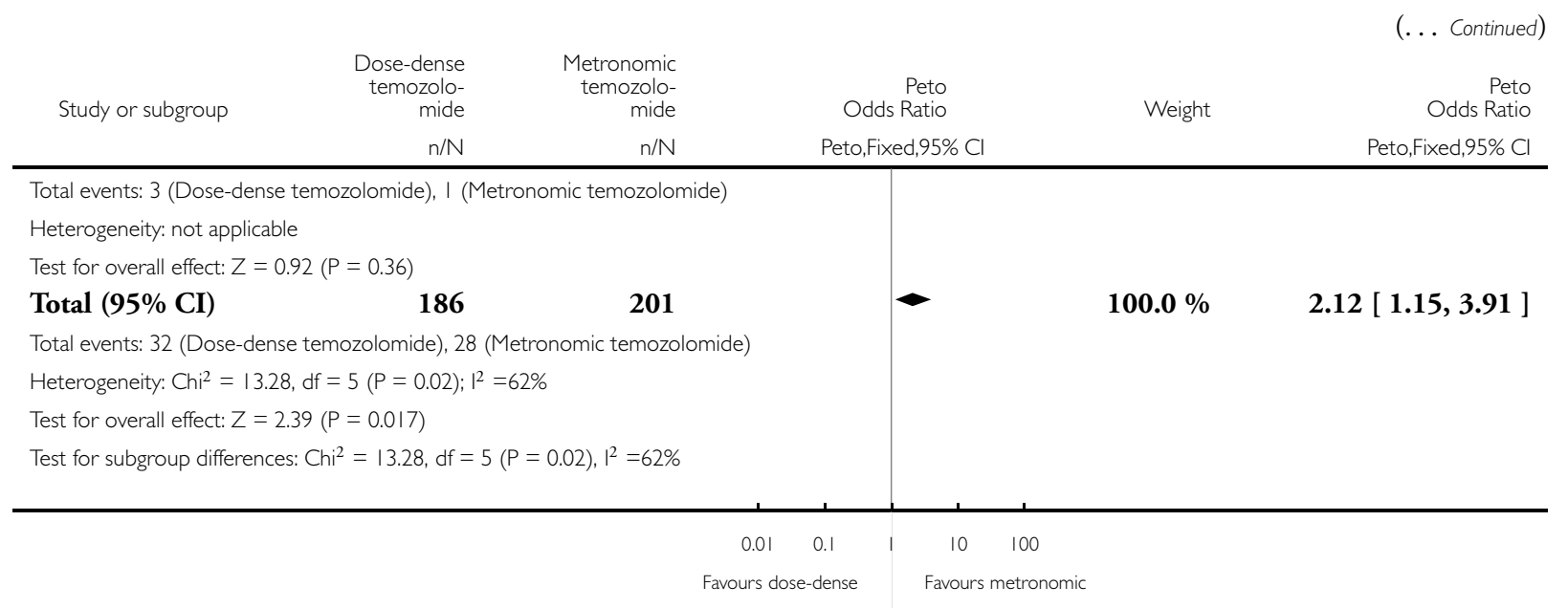

\section{Analysis 4.I. Comparison 4 Therapy for recurrent disease, Outcome I Survival.}

Review: Temozolomide for high grade glioma

Comparison: 4 Therapy for recurrent disease

Outcome: I Survival

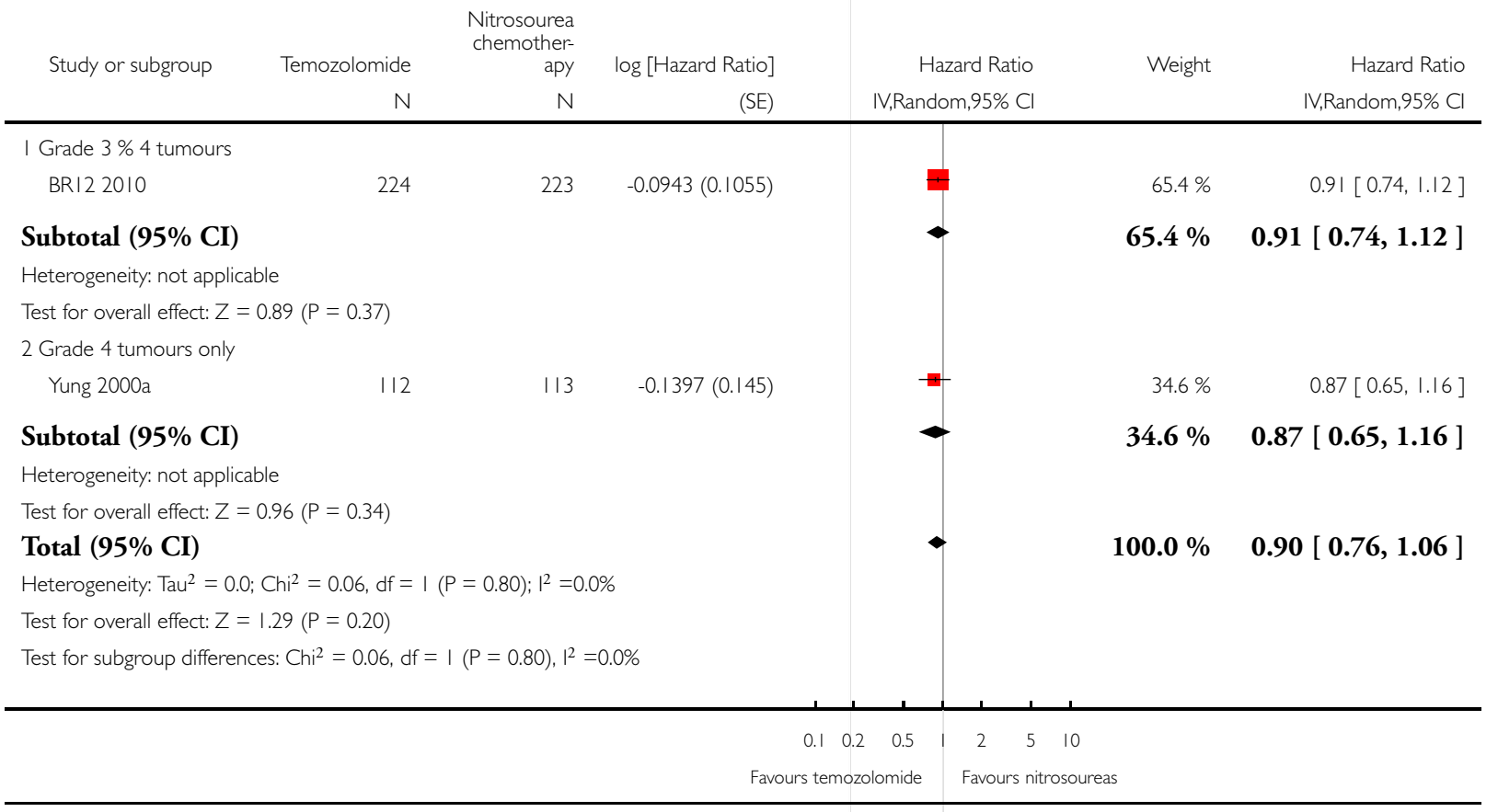

Temozolomide for high grade glioma (Review)

Copyright @ 2013 The Cochrane Collaboration. Published by John Wiley \& Sons, Ltd. 


\section{Analysis 4.2. Comparison 4 Therapy for recurrent disease, Outcome 2 Progression-Free Survival.}

Review: Temozolomide for high grade glioma

Comparison: 4 Therapy for recurrent disease

Outcome: 2 Progression-Free Survival

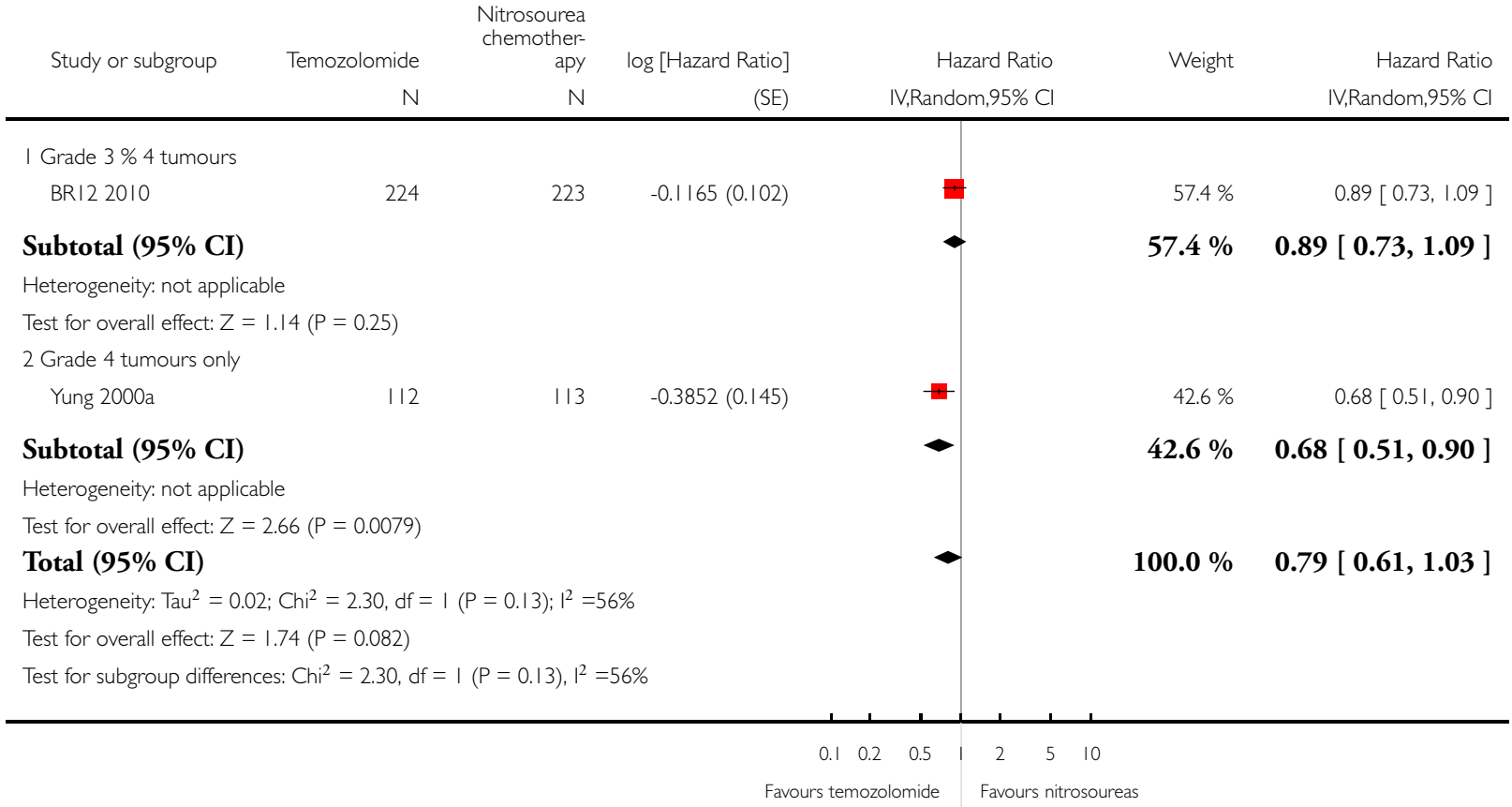




\section{Analysis 4.3. Comparison 4 Therapy for recurrent disease, Outcome 3 Adverse events.}

Review: Temozolomide for high grade glioma

Comparison: 4 Therapy for recurrent disease

Outcome: 3 Adverse events

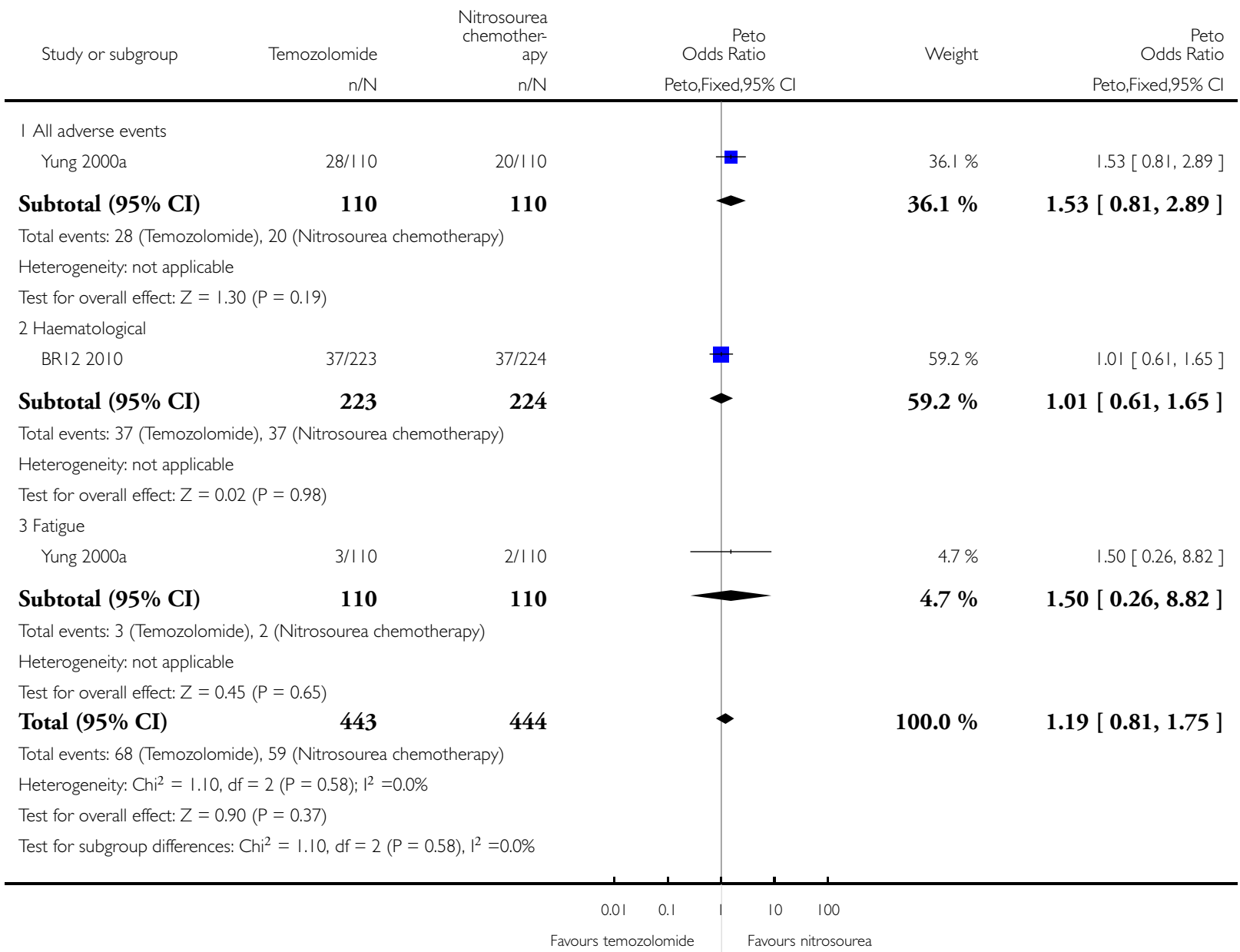


ADDITIONAL TABLES

Table 1. Internal Validity

\begin{tabular}{|c|c|c|c|c|c|c|c|c|}
\hline Measure & Clarke 2009 & $\begin{array}{l}\text { EORTC/ } \\
\text { NCIC } \\
26981- \\
22981\end{array}$ & $\begin{array}{l}\text { Kocher } \\
2008\end{array}$ & $\begin{array}{l}\text { Athanas- } \\
\text { siou } \\
2005\end{array}$ & Yung 2000a & BR12 2010 & $\begin{array}{l}\text { Nordic } \\
2012\end{array}$ & $\begin{array}{l}\text { NOA-08 } \\
2012\end{array}$ \\
\hline $\begin{array}{l}\text { Power calcu- } \\
\text { lation? }\end{array}$ & $\begin{array}{l}\text { Yes } \\
\text { (adequate } \\
\text { power) }\end{array}$ & Yes & Yes & $\begin{array}{l}\text { No. Proba- } \\
\text { bly under } \\
\text { powered. }\end{array}$ & $\begin{array}{l}\text { Yes. Ade- } \\
\text { quate power } \\
\text { (for PFS). }\end{array}$ & Yes & Yes & Yes \\
\hline $\begin{array}{l}\text { Proper ran- } \\
\text { domisation? }\end{array}$ & Not clear & Yes & Not stated & $\begin{array}{l}\text { Methods } \\
\text { not reported }\end{array}$ & Not clear & Yes & Yes & Yes \\
\hline $\begin{array}{l}\text { Groups sim- } \\
\text { ilar at base- } \\
\text { line? }\end{array}$ & $\begin{array}{l}\text { Probably } \\
\text { (no statisti- } \\
\text { cal test used) }\end{array}$ & $\begin{array}{l}\text { Probably } \\
\text { (no statisti- } \\
\text { cal test used) }\end{array}$ & $\begin{array}{l}\text { Proba- } \\
\text { bly not (but } \\
\text { no statistical } \\
\text { test used) }\end{array}$ & Yes & $\begin{array}{l}\text { No (greater } \\
\text { time to re- } \\
\text { lapse } \\
\text { and after ra- } \\
\text { diotherapy } \\
\text { in PCB) }\end{array}$ & $\begin{array}{l}\text { Probably } \\
\text { (no statisti- } \\
\text { cal test used) }\end{array}$ & Yes & $\begin{array}{l}\text { Probably } \\
\text { (no statisti- } \\
\text { cal test used) }\end{array}$ \\
\hline $\begin{array}{l}\text { Investiga- } \\
\text { tors } \\
\text { blinded? }\end{array}$ & No & No & No & No & No & No & No & No \\
\hline $\begin{array}{l}\text { Outcome } \\
\text { assessors } \\
\text { blinded? }\end{array}$ & No & No & No & No & No & No & No & No \\
\hline $\begin{array}{l}\text { Patients } \\
\text { blinded? }\end{array}$ & No & No & No & No & No & No & No & No \\
\hline $\begin{array}{l}\text { Eligi- } \\
\text { bility criteria } \\
\text { stated? }\end{array}$ & Yes & Yes & Yes & Yes & Yes & Yes & Yes & Yes \\
\hline $\begin{array}{l}\text { Ob- } \\
\text { jective out- } \\
\text { come mea- } \\
\text { sures? }\end{array}$ & Yes & $\begin{array}{l}\text { Yes (except } \\
\text { progression) }\end{array}$ & $\begin{array}{l}\text { Yes (except } \\
\text { progression) }\end{array}$ & Yes & $\begin{array}{l}\text { Yes (except } \\
\text { progression) }\end{array}$ & Yes & Yes & Yes \\
\hline $\begin{array}{l}\text { Analysis on } \\
\text { ITT basis? }\end{array}$ & Yes & $\begin{array}{l}\text { Yes (not } \\
\text { QoL) }\end{array}$ & Yes & No & $\begin{array}{l}\text { Yes (not } \\
\text { QoL) }\end{array}$ & Yes & $\begin{array}{l}\text { No (only } \\
291 \text { or } 342 \\
\text { enrolled pa- } \\
\text { tients anal- } \\
\text { ysed) }\end{array}$ & $\begin{array}{l}\text { No (only } \\
373 \text { of } 412 \\
\text { enrolled pa- } \\
\text { tients anal- } \\
\text { ysed) }\end{array}$ \\
\hline $\begin{array}{l}\text { All } \\
\text { patients ac- } \\
\text { counted for? }\end{array}$ & Yes & $\begin{array}{l}\text { Yes (not } \\
\text { QoL) }\end{array}$ & Yes & Yes & $\begin{array}{l}\text { Yes (not } \\
\text { QoL) }\end{array}$ & Yes & $\begin{array}{l}\text { Yes (not } \\
\text { QOL) }\end{array}$ & $\begin{array}{l}\text { Yes (not } \\
\text { QOL) }\end{array}$ \\
\hline
\end{tabular}


Table 1. Internal Validity (Continued)

\begin{tabular}{|c|c|c|c|c|c|c|c|c|}
\hline $\begin{array}{l}\text { With- } \\
\text { drawals } \\
\text { specified? }\end{array}$ & Yes & $\begin{array}{l}\text { Yes (not } \\
\text { QoL) }\end{array}$ & Yes & Yes & $\begin{array}{l}\text { Yes (not } \\
\text { QoL) }\end{array}$ & Yes & $\begin{array}{l}\text { Yes (not } \\
\text { QOL) }\end{array}$ & $\begin{array}{l}\text { Yes (not } \\
\text { QOL) }\end{array}$ \\
\hline $\begin{array}{l}\text { With- } \\
\text { drawal rea- } \\
\text { sons given? }\end{array}$ & Yes & $\begin{array}{l}\text { Yes } \quad \text { (not } \\
\text { QoL) }\end{array}$ & Yes & Yes & $\begin{array}{l}\text { Yes (not } \\
\text { QoL) }\end{array}$ & Yes & No & $\begin{array}{l}\text { Yes (not } \\
\text { QOL) }\end{array}$ \\
\hline $\begin{array}{l}\text { Inter-centre } \\
\text { consistency? }\end{array}$ & Single centre & $\begin{array}{l}\text { Not } \\
\text { reported }\end{array}$ & $\begin{array}{l}\text { Not } \\
\text { reported }\end{array}$ & $\begin{array}{l}\text { Not applica- } \\
\text { ble }\end{array}$ & $\begin{array}{l}\text { Not } \\
\text { reported }\end{array}$ & $\begin{array}{l}\text { Not } \\
\text { reported }\end{array}$ & $\begin{array}{l}\text { Not } \\
\text { reported }\end{array}$ & $\begin{array}{l}\text { Not } \\
\text { reported }\end{array}$ \\
\hline $\begin{array}{l}\text { Conflicts of } \\
\text { interest? }\end{array}$ & $\begin{array}{l}\text { cCertain au- } \\
\text { thors had } \\
\text { a consultant } \\
\text { or } \\
\text { advisory role } \\
\text { with Scher- } \\
\text { ing-Plough }\end{array}$ & $\begin{array}{l}\text { sSponsored } \\
\text { by Schering- } \\
\text { Plough }\end{array}$ & $\begin{array}{l}\text { Ssponsored } \\
\text { by ESSEX } \\
\text { pharma }{ }^{\circledR}\end{array}$ & $\begin{array}{l}\text { None } \\
\text { declared }\end{array}$ & $\begin{array}{l}\text { Certain } \\
\text { authors had } \\
\text { a consultant } \\
\text { or } \\
\text { advisory role } \\
\text { with Scher- } \\
\text { ing-Plough }\end{array}$ & $\begin{array}{l}\text { Certain } \\
\text { authors had } \\
\text { a consultant } \\
\text { or } \\
\text { advisory role } \\
\text { with Scher- } \\
\text { ing-Plough }\end{array}$ & $\begin{array}{l}\text { The trial was } \\
\text { sponsored } \\
\text { by Merck } \\
\text { but they had } \\
\text { no other role } \\
\text { in the study }\end{array}$ & $\begin{array}{l}\text { The trial was } \\
\text { funded by } \\
\text { Merck } \\
\text { Sharp } \\
\text { and Dohme } \\
\text { but they had } \\
\text { no other role } \\
\text { in the study }\end{array}$ \\
\hline
\end{tabular}

$\mathrm{PCB}=$ procarbazine; PFS = progression-free survival; $\mathrm{QoL}=$ quality of life

Table 2. External Validity

\begin{tabular}{|c|c|c|c|c|c|c|c|c|}
\hline Measure & Clarke 2009 & $\begin{array}{l}\text { EORTC/ } \\
\text { NCIC } \\
26981- \\
22981\end{array}$ & $\begin{array}{l}\text { Kocher } \\
2008\end{array}$ & $\begin{array}{l}\text { Athanas- } \\
\text { siou } \\
2005\end{array}$ & Yung 2000a & BR12 2010 & $\begin{array}{l}\text { Nordic } \\
2012\end{array}$ & $\begin{array}{l}\text { NOA-08 } \\
2012\end{array}$ \\
\hline $\begin{array}{l}\text { Age (mean } \\
\text { and range) }\end{array}$ & $\begin{array}{l}\text { Dose dense: } \\
59.1 \quad(30- \\
70) \\
\text { Metro- } \\
\text { nomic: } \\
54.1 \quad(21- \\
71)\end{array}$ & $\begin{array}{l}\text { TMZ: } 33 \% \\
<50 \\
\text { RTx: } 31 \%< \\
50\end{array}$ & $\begin{array}{ll}\text { TMZ: } & 59 \\
(34-67) & \\
\text { RTx: } & 58 \\
(37-69) & \end{array}$ & $\begin{array}{l}\text { TMZ: } \\
\text { 42/53 > } 50 \\
\text { RTx: 48/57 } \\
>50\end{array}$ & $\begin{array}{l}\text { TMZ: } \\
52 \quad(21-76) \\
\text {. PRO: } 51 \\
(21-74)\end{array}$ & $\begin{array}{l}\text { Median } \\
\text { age } 53 \text { both } \\
\text { arms }\end{array}$ & $\begin{array}{l}\text { TMZ: } \\
70 \quad(60-88) \\
\text {; HypoRTx: } \\
70(60-83) ; \\
\text { RTx: } \quad 70 \\
(60-80)\end{array}$ & $\begin{array}{ll}\text { TMZ: } & 72 \\
(68-44) & \\
\text { RTx: } & 71 \\
(686-82) & \end{array}$ \\
\hline Sex (M:F) & $\begin{array}{l}\text { Dose dense } \\
29: 13 \\
\text { Metro- } \\
\text { nomic } \\
27: 16\end{array}$ & $\begin{array}{l}\text { TMZ 64:36 } \\
\text { RTx 61:39 }\end{array}$ & $\begin{array}{l}\text { TMZ 15:14 } \\
\text { RTx 26:7 }\end{array}$ & $\begin{array}{l}\text { TMZ 64:36 } \\
\text { RTx 61:39 }\end{array}$ & $\begin{array}{l}\text { TMZ 69:31 } \\
\text { PCB 63:36 }\end{array}$ & $\begin{array}{l}\text { TMZ } \\
63.7: 36.3 \\
\text { PCV } \\
65.2: 34.8\end{array}$ & $\begin{array}{l}\text { TMZ: 59: } \\
41 \\
\text { HypoRTx: } \\
\text { 51:49 } \\
\text { RTx: 68:32 }\end{array}$ & $\begin{array}{l}\text { TMZ: } 45: \\
55 \\
\text { RTx: 49:51 }\end{array}$ \\
\hline Histology & $\begin{array}{l}\text { Local: GBM } \\
100 \% \\
\text { (no central } \\
\text { review) }\end{array}$ & $\begin{array}{l}\text { Local: GBM } \\
100 \% \\
\text { Central } \\
(85 \%):\end{array}$ & $\begin{array}{l}\text { Local: GBM } \\
100 \% \\
\text { (no central }\end{array}$ & $\begin{array}{l}\text { Local: GBM } \\
100 \% \\
\text { (no central }\end{array}$ & $\begin{array}{l}\text { Confirmed } \\
\text { GBM: } \\
\text { TMZ } 91 \%\end{array}$ & $\begin{array}{l}\text { TMZ: } \\
\text { Grade } 323 . \\
\text { 3\% Grade } 4\end{array}$ & $\begin{array}{l}\text { Cen- } \\
\text { tral review in } \\
87 \% \text { : }\end{array}$ & $\begin{array}{l}\text { TMZ: } \\
\text { GBM 91\%, } \\
\text { AA 9\% }\end{array}$ \\
\hline
\end{tabular}

Temozolomide for high grade glioma (Review)

Copyright @ 2013 The Cochrane Collaboration. Published by John Wiley \& Sons, Ltd. 
Table 2. External Validity

(Continued)

\begin{tabular}{|c|c|c|c|c|c|c|c|c|}
\hline & & GBM 93\% & review) & review) & PCB 96\% & $\begin{array}{l}74.4 \% \\
\text { PCV: } \\
\text { Grade } 322 . \\
8 \% \\
\text { Grade } 474 . \\
1 \% \\
\text { (All } \\
\text { confirmed } \\
\text { after central } \\
\text { review) }\end{array}$ & $\begin{array}{l}\text { glioblas- } \\
\text { toma in } \\
97 \% \text { (no di- } \\
\text { agnosis - 3; } \\
\text { WHO II - 1; } \\
\text { WHO III - } \\
4)\end{array}$ & $\begin{array}{l}\text { RTx: } \\
\text { GBM 86\%, } \\
\text { AA 13\% } \\
\text { (All } \\
\text { confirmed } \\
\text { after central } \\
\text { review) }\end{array}$ \\
\hline $\begin{array}{l}\text { Perfor- } \\
\text { mance Sta- } \\
\text { tus (mean } \\
\text { and range) }\end{array}$ & $\begin{array}{l}\text { Median KPS } \\
90 \text { all arms }\end{array}$ & $\begin{array}{l}\text { TMZ: } 39 \% \\
=0,47 \%= \\
1,13 \%=2 \\
\text { RTx: } 38 \%= \\
0,49 \%=1, \\
12 \%=0\end{array}$ & $\begin{array}{l}\text { TMZ: } \\
\text { WHO } 2=0 \\
\text { RTx: WHO } \\
2=2\end{array}$ & $\begin{array}{l}\text { TMZ: } 47 \% \\
\text { KPS } \\
>80 \text { RTx: } \\
32 \% \text { KPS > } \\
80 .\end{array}$ & $\begin{array}{l}\text { KPS } 70 \text { or } \\
\text { more: } \mathrm{TMZ} \\
100 \% \text { PCB } \\
99 \%\end{array}$ & $\begin{array}{l}\text { TMZ: } 0= \\
20.2 \%, 1= \\
43.5 \%, 2= \\
24.7 \% \\
\text { PCV: } \\
0=15.2 \\
1=48.2 \% \\
2=28.1 \%\end{array}$ & $\begin{array}{l}\text { TMZ: } \\
\text { WHO 0-1 = } \\
78 \% \text {, WHO } \\
2-3=22 \% \\
\text { HypoRTx: } \\
\text { WHO 0-1 = } \\
80 \%, \text { WHO } \\
2-3=20 \% \\
\text { RTx: WHO } \\
0-1=72 \% \text {, } \\
\text { WHO 2-3 = } \\
28 \%\end{array}$ & $\begin{array}{l}\text { TMZ: KPS } \\
80(60-100) \\
\text { RTx: } 80 \\
(60-100)\end{array}$ \\
\hline $\begin{array}{l}\text { Extent of } \\
\text { Surgery }\end{array}$ & $\begin{array}{l}\text { Dose dense: } \\
\text { biopsy } 24 \% \\
\text { total } 43 \% \\
\text { Metro- } \\
\text { nomic: } \\
\text { biopsy } 21 \% \\
\text { total } 35 \%\end{array}$ & $\begin{array}{l}\text { TMZ: } 17 \% \\
\text { biopsy, } 39 \% \\
\text { complete } \\
\text { RTx: } 16 \% \\
\text { biopsy, } 40 \% \\
\text { complete }\end{array}$ & $\begin{array}{l}\text { Macro- } \\
\text { scopic } \\
\text { complete tu- } \\
\text { mour resec- } \\
\text { tion: } 100 \%\end{array}$ & $\begin{array}{l}\text { TMZ: total } \\
= \\
18 \% \text {, biopsy } \\
=\quad 42 \% . \\
\text { RTxl: total = } \\
15 \% \text {, biopsy } \\
=42 \%\end{array}$ & $\begin{array}{l}\text { Previous re- } \\
\text { section: } \\
\text { TMZ 87\% } \\
\text { PCB } \\
91 \% \text { Previ- } \\
\text { ous Chemo- } \\
\text { therapy: } \\
\text { TMZ 65\% } \\
\text { PCB 68\% }\end{array}$ & $\begin{array}{l}\text { TMZ: } \\
\text { biopsy 26\% } \\
\text { total 13.9\% } \\
\text { PCV: } \\
\text { biopsy 26\% } \\
\text { total 13.5\% }\end{array}$ & $\begin{array}{l}\text { TMZ: } \\
\text { biopsy 26\%, } \\
\text { resection } \\
74 \% \\
\text { HypoRTx: } \\
\text { biopsy } 27 \% \text {, } \\
\text { resection } \\
73 \% \\
\text { RT: biopsy } \\
27 \% \text {, resec- } \\
\text { tion } 73 \%\end{array}$ & $\begin{array}{l}\text { TMZ: com- } \\
\text { plete } \\
27 \% \text {, partial } \\
31 \% \text {, biopsy } \\
41 \% \text {, miss- } \\
\text { ing < } 1 \% \\
\text { RTx: com- } \\
\text { plete } 20 \% \text {, } \\
\text { partial } 35 \% \text {, } \\
\text { biopsy } 37 \% \text {, } \\
\text { missing } 0 \%\end{array}$ \\
\hline Follow-up & $\begin{array}{l}\text { Median } 18 . \\
8 \\
\text { months (un- } \\
\text { til 15 Dec } \\
2008 \text { ) }\end{array}$ & $\begin{array}{ll}\begin{array}{l}\text { Median } \\
\text { months }\end{array} & \\
\text { (range } & 11 \\
\text { days to } & 79 \\
\text { months) } & \end{array}$ & Not stated & $\begin{array}{l}\text { Median } \\
11.2 \text { months } \\
\text { (range } 3.4 \text { to } \\
27 \text { months) }\end{array}$ & Not stated & $\begin{array}{l}\text { TMZ: } \\
\text { months } \\
\text { PCV: } 14.5 \\
\text { months }\end{array}$ & $\begin{array}{l}\text { Not stated } \\
\text { (but at study } \\
\text { close on } 4 \\
\text { patients still } \\
\text { alive and } 3 \\
\text { lost to fol- } \\
\text { low-up) }\end{array}$ & $\begin{array}{l}\text { Minimum } \\
\text { follow- } \\
\text { up was } 12 \\
\text { months }\end{array}$ \\
\hline
\end{tabular}

$\mathrm{GBM}$ = glioblastoma multiforme; $\mathrm{PCB}=$ procarbazine; $\mathrm{PCV}=$ procarbazine, lomustine and vincristine; $\mathrm{RT} x=$ radiotherapy; $\mathrm{TMZ}=$ temozolomide 
Table 3. WHO Performance Status

\begin{tabular}{ll}
\hline Grade & Definition \\
\hline 0 & Fully active, able to carry on all pre-disease performance without restriction \\
\hline 1 & $\begin{array}{l}\text { Restricted in physically strenuous activity but ambulatory and ale to carry out work of a light or sedentary nature e.g. light } \\
\text { house work, office work }\end{array}$ \\
\hline 2 & $\begin{array}{l}\text { Ambulatory and capable of all self care, but unable to carry out ay work activities. Up and about more than } 50 \% \text { of waking } \\
\text { hours }\end{array}$ \\
\hline 3 & Capable of only limited self care, confined to bed or chair more than $50 \%$ of waking hours \\
\hline 4 & Completely disabled. Cannot carry out any self-care. Totally confined to bed or chair \\
\hline 5 & Dead \\
\hline
\end{tabular}

Table 4. Karnofsky Performance Scale

\begin{tabular}{|c|c|}
\hline Score & Definition \\
\hline 100 & Normal, no complaints, no evidence of disease \\
\hline 90 & Able to carry on normal activity: minor symptoms of disease \\
\hline 80 & Normal activity with effort: some symptoms of disease \\
\hline 70 & Cares for self: unable to carry on normal activity or active work \\
\hline 60 & Requires occasional assistance but is able to care for needs \\
\hline 50 & Requires considerable assistance and frequent medical care \\
\hline 40 & Disabled: requires special care and assistance \\
\hline 30 & Severely disabled: hospitalisation is indicated, death not imminent \\
\hline 20 & Very sick, hospitalisation necessary: active treatment necessary \\
\hline 10 & Moribund, fatal processes progressing rapidly \\
\hline 0 & Dead \\
\hline
\end{tabular}




\section{A P P E N D I C E S}

\section{Appendix I. MEDLINE}

The original search strategy has been adapted from the Ovid version to the Silver Platter version. Terms 1 to 37, used to identify all randomized and clinical controlled trials were taken from the first two parts of the Highly Sensitive Search Strategy (HSSS) devised by Carol Lefebvre.

1. randomized controlled trial.pt.

2. controlled clinical trial.pt.

3. randomized controlled trials/

4. random allocation/

5. double-blind method/

6. single-blind method/

7. 1 or 2 or 3 or 4 or 5 or 6

8. limit 7 to animal

9. limit 7 to human

10. 8 and 9

11. 8 not 10

12. 7 not 11

13. clinical trial.pt.

14. exp clinical trials/

15. clin\$ with trial\$.tw.

16. placebos/

17. placebo\$.tw.

18. random $\$$.tw.

19. exp research design/

20. 13 or 14 or 15 or 16 or 17 or 18 or 19

21. limit 20 to animal

22. limit 20 to human

23. 21 and 22

24. 21 not 23

25. 20 not 24

26. comparitive study/

27. exp evaluation studies/

28. follow-up studies/

29. prospective studies/

30. (control $\$$ or prospectiv\$ or volunteer $\$$ ).tw.

31.26 or 27 or 28 or 29 or 30

32. limit 31 to animal

33. limit 31 to human

34.32 and 33

35.32 not 34

36. 31 not 35

37.12 or 25 or 36

38. explode "Brain-Neoplasms"/ all subheadings

39. explode "Central-Nervous-System-Neoplasms"/ all subheadings

40. explode "Cerebral-Cortex"/ all subheadings

41. explode "Glioma"/ all subheadings

42. malignant near glioma*

43. glioblastoma* or "glioblastoma multiforme"

44. astrocytoma* or "anaplastic astrocytoma"

45. brain tumo? $\mathrm{r}^{*}$

46. neuroectodermal tumo? $r^{*}$

Temozolomide for high grade glioma (Review)

Copyright $\odot 2013$ The Cochrane Collaboration. Published by John Wiley \& Sons, Ltd. 
47. ependymoma*

48. oligodendroglioma*

49. or $/ 38-48$

50. temozolomide

51. temodar

52. temodal

53. or $/ 50-52$

54.37 and 49 and 53

\section{Appendix 2. EMBASE}

The original search strategy has been adapted from Ovid version to SilverPlatter version, all "MESH" headings were checked in Thesaurus (as the vocabulary was updated in January 2003) and minor changes were made in "MESH" terms.

1. explode "clinical-trial"/ all subheadings

2. explode "controlled-study"/ all subheadings

3. explode "meta-analysis"/ all subheadings

4. explode "crossover-procedure"/ all subheadings

5. explode "double-blind-procedure"/ all subheadings

6. explode "single-blind-procedure"/ all subheadings

7. explode "randomization"/ all subheadings

8. explode "prospective-study"/ all subheadings

9. clin* near trial*

10. singl*

11. double*

12. (singl* or double* or trebl* or tripl*) near (blind* ${ }^{*}$ or mask ${ }^{*}$ )

13. random*

14. control*

15 . \#1 or $\# 2$ or $\# 3$ or $\# 4$ or $\# 5$ or $\# 6$ or $\# 7$ or $\# 8$ or $\# 9$ or $\# 10$ or $\# 11$ or $\# 12$ or \#13 or \#14

16. $\mathrm{EC}=$ "HUMAN"

17. \#15 and (EC = "HUMAN")

18. explode "brain-tumor"/ all subheadings

19. explode "central-nervous-system"/ all subheadings

20. explode "brain-cortex"/ all subheadings

21. malignant near glioma*

22. glioblastoma multiforme*

23. astrocytoma* or anaplastic astrocytoma*

24. brain tumo? $\mathrm{r}^{*}$

25. neuroectodermal tumo? $\mathrm{r}^{*}$

26. ependymoma*

27. oligodendroglioma*

28. \#18 or \#19 or \#20 or \#21 or \#22 or \#23 or \#24 or \#25 or \#26 or \#27

29. temozolamide

30. temodar

31. temodal

32. \#29 or \#30 or \#31

33.15 and 28 and 32

Temozolomide for high grade glioma (Review)

Copyright $\odot 2013$ The Cochrane Collaboration. Published by John Wiley \& Sons, Ltd. 


\section{Appendix 3. SCIENCE CITATION INDEX (198I to 2007)}

A similar search strategy to the one for Biosis was used. Searches were made in the Title, Keyword or Abstract.

Unlike Biosis, there was no "major concepts" search facility.

The differences were as follows:

1. "tumo*" was used in place of "tumo* $\mathrm{r}$ "

2. “central \& nervous \& system \& tumo*” and “central \& nervous \& system \& neoplasm” were two additional searches.

\section{Appendix 4. CENTRAL}

Capital letters are MESH terms, the rest are free text terms. The original search strategy was used.

1. CENTRAL NERVOUS SYSTEM NEOPLASMS

2. BRAIN NEOPLASMS

3. GLIOMA

4. (malignant and glioma)

5. (glioblastoma and multiforme)

6. astrocytoma*

7. (anaplastic and astrocytoma*)

8. (brain and tumor*)

9. (neuroectodermal and tumor*)

10. (\#1 or \#2 or \#3 or \#4 or \#5 or \#6 or \#7 or \#8 or \#9)

11. Temozolamide

12. Temodar

13. Temodal

14. (\#11 or \#12 or \#13)

15. \#10 and \#14

\section{Appendix 5. Physician Data Query (PDQ)}

http://www.nci.nih.gov/cancertopics/pdq

The search followed the prescribed searching forms specific for the database, using terms from the above searches.

Search form - all types of brain tumours - adults, children

Treatment

Active and closed

Phase III and IV

Temozolamide

\section{Appendix 6. meta-Register of Controlled Trials (mRCT)}

Keywords: brain, glioma, temozolamide

\section{Appendix 7. CENTRAL search strategy update}

\#1 MeSH descriptor Glioma explode all trees

\#2 glioma*

\#3 astrocytoma*

\#4 oligodendroglioma*

\#5 oligoastrocytoma*

\#6 glioblastoma*

\#7 GBM

\#8 ependymoma* 


\section{Appendix 8. MEDLINE search strategy update}

1 exp Glioma/

2 glioma*.mp.

3 astrocytoma*.mp.

4 oligodendroglioma*.mp.

5 oligoastrocytoma*.mp.

6 glioblastoma*.mp.

7 GBM.mp.

8 ependymoma*.mp.

91 or 2 or 3 or 4 or 5 or 6 or 7 or 8

10 randomized controlled trial.pt.

11 controlled clinical trial.pt.

12 randomized.ab.

13 placebo.ab.

14 clinical trials as topic.sh.

15 randomly.ab.

16 trial.ti.

1710 or 11 or 12 or 13 or 14 or 15 or 16

189 and 17

\section{Appendix 9. EMBASE search strategy update}

1 exp glioma/

2 glioma*.mp.

3 astrocytoma*.mp.

4 oligodendroglioma*.mp.

5 oligoastrocytoma*.mp.

6 glioblastoma*.mp.

7 GBM.mp.

8 ependymoma*.mp.

91 or 2 or 3 or 4 or 5 or 6 or 7 or 8

10 crossover procedure/

11 double blind procedure/

12 randomized controlled trial/

13 single blind procedure/

14 random*.mp.

15 factorial $^{*} . \mathrm{mp}$.

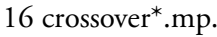

17 cross over*.mp.

18 cross-over*.mp.

19 placebo*.mp.

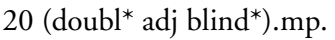

21 (singl* adj blind*).mp.

22 assign $^{*} \cdot \mathrm{mp}$.

23 allocat*.mp.

24 volunteer*.mp.

2510 or 11 or 12 or 13 or 14 or 15 or 16 or 17 or 18 or 19 or 20 or 21 or 22 or 23 or 24

269 and 25

Temozolomide for high grade glioma (Review)

Copyright @ 2013 The Cochrane Collaboration. Published by John Wiley \& Sons, Ltd. 


\section{WHAT'S NEW}

Last assessed as up-to-date: 6 March 2013.

\begin{tabular}{ll|l}
\hline Date & Event & Description \\
\hline 6 March 2013 & $\begin{array}{l}\text { New citation required but conclusions have not } \\
\text { changed }\end{array}$ & $\begin{array}{l}\text { Review updated; text substantially re-written and new } \\
\text { studies added but conclusions not changed }\end{array}$ \\
\hline 12 December 2012 & New search has been performed & Search strategy dates amended \\
\hline
\end{tabular}

\section{H I S T O R Y}

Review first published: Issue 4, 2008

\begin{tabular}{|c|c|c|}
\hline Date & Event & Description \\
\hline 3 November 2009 & Amended & $\begin{array}{l}\text { Minor amendment made in results section due to an error in transcribing the data from the figures } \\
\text { Temozolomide resulted in an increase in survival (HR } \mathbf{0 . 8 4}, 95 \% \text { CI } 0.50 \text { to } 0.68, \mathrm{P}<0.001 \text { ) } \\
\text { compared with the control arm now reads Temozolomide resulted in an increase in survival }(\mathrm{HR} \\
\mathbf{0 . 5 8}, 95 \% \text { CI } 0.50 \text { to } 0.68, \mathrm{P}<0.001 \text { ) compared with the control arm }\end{array}$ \\
\hline
\end{tabular}

\section{CONTRIBUTIONSOFAUTHORS}

Michael Hart led and wrote the original review. Ruth Garside assisted with the screening, data checking and ran the paired study and was aided by Gabriel Rogers, Margaret Somerville and Ken Stein in the original review. Robin Grant supervised the review and was involved with the final editing process. Michael Hart updated the review in 2013.

\section{DECLARATIONSOF INTEREST}

All authors report no conflict of interest. 


\section{SOURCES OF SUPPORT}

\section{Internal sources}

- Dr Michael Hart was a recipient of a Cochrane Review Grant, UK.

\section{External sources}

- No sources of support supplied

\section{NDEX TERMS}

\section{Medical Subject Headings (MeSH)}

Antineoplastic Agents, Alkylating [* ${ }^{*}$ therapeutic use]; Brain Neoplasms [ ${ }^{*}$ drug therapy]; Dacarbazine [ ${ }^{*}$ analogs $\&$ derivatives; therapeutic use]; Glioblastoma [*drug therapy]; Neoplasm Recurrence, Local [drug therapy]

\section{MeSH check words}

Humans 